Linköping Studies in Science and Technology.

Dissertations, No. 1782

\title{
Developing a Framework for Supply Chain Planning in Construction
}

Micael Thunberg

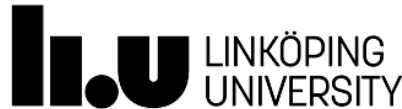


Developing a Framework for Supply Chain Planning in Construction

Micael Thunberg

Linköping Studies in Science and Technology. Dissertations, No. 1782

Copyright $\odot$, Micael Thunberg, 2016, unless otherwise noted.

ISBN 978-91-7685-703-8

ISSN $0345-7524$

Linköping University

Department of Science and Technology

SE-601 74 Norrköping, Sweden

Printed by LiU-Tryck, Linköping, Sweden, 2016 


\section{Abstract}

Supply chain management ( $\mathrm{SCM}$ ) has been stressed as a remedy to many of the underlying issues in the construction industry. However, the positive examples where SCM has been successfully utilised and diminished the lingering issues in construction is scarce. The question is why. Previous studies have stressed the importance of planning both the construction project as such but also the supply chain and the logistics. As an important part of SCM, supply chain planning (SCP) focuses on planning different aspects of the supply chain through involving different members of the supply chain in the planning process. SCP in construction is scarce as the planning of the logistics in general. Failing to plan the supply chain, involving supply chain members in the planning, and integrating the processes of planning the supply chains and the construction project can be one reason for the low numbers of successful SCM adoption in construction. In improving the SCP in construction, this thesis develops a SCP framework for construction that involves the main contractor, subcontractors, and suppliers. The aim is to improve SCP, collaboration, and eliminate many of the common problems in construction through a SCM and SCP perspective.

The developed framework is based on an existing planning framework for sales and operations planning. This framework is generic and synthesises planning in general. It consists of identifying/developing: outcomes, input, organisation, process, key performance measurements, and IT-tools. It is thus necessary to investigate what these aspects means in a construction context. Four research objects will be fulfilled:

Objective 1. Identify common logistical problems and linkages between them

\section{Objective 2. Develop a SCP process}

Objective 3. Develop a SCP organisation

Objective 4. Identify performance measurements

The first objective will aid in focusing the work with developing the framework as one aim of the framework is to aid in eliminating common logistical problems. In doing so it is needed to identify what problems exist and how the SCP framework can aid in overcoming them. The second and third objective focus on developing the framework in terms of developing a planning process (procedure) and an organisation for developing the plans. These two also includes identifying outcomes of SCP and important inputs. The final objective focus on suggesting important performance measurements for aiding in the planning process.

Several different studies have aid in fulfilling the objectives and the purpose. A case study, literature review, and a series of interviews aided in fulfilling objective 1. The interview series and focus groups were used for fulfilling objectives 2 and 3. Objective 4 used the results from the case study. Through logical reasoning and compiling the previous works made it possible to finalise and develop the framework. 
Findings indicate that common logistical problems can be categorised as: material flow issues, internal company communication, project communication, and complexity. The first one contains problems with e.g. delivery reliability, material flows, and inventories. Company communication regards problems with e.g. sharing information internally, not updating plans, and not understanding the construction process. Project communication is similar but concerns the issues with e.g. sharing and updating plans with subcontractors and suppliers. The final one regards different type of problems that all concerns the complex nature of projects like: late changes, site layout, and lack of standard processes. These problems are often inter-linked and locate in different planning levels. This means that different managers should work with different problems and the site manager should not be responsible for all of them.

The framework consists of the two processes, one pre-construction process and one on-site process. The first one focuses on developing a material delivery schedule (an important outcome) through involving the main contractor, subcontractors, and suppliers early in the project. The latter one focuses on updating the plan both in short-terms but also on a longer horizon on-site. Four meetings are identified as necessary, two in the pre-construction phase (Pre-construction subcontractor meeting and Purchase meetings) and two in the on-site phase (Weekly update meetings and Supplier start-up meetings).

The main contribution of the thesis is the framework as such with a process and organisation for developing a material delivery schedule. Due to the fact that in involves members of the supply chain and activities early in the project improves the integration of the supply and construction process. The thesis also aids in providing information on how SCP can address common logistical problems in construction and how trust can be improved. The thesis also gives rise formulating propositions to be tested in future studies. 


\section{Populärvetenskaplig sammanfattning}

Tänk om det såg ut så här i byggbranschen... ”När byggnationen väl ska sätta igång så är all planering av materialet redan klart och alla leverantörer och underentreprenörer sedan länge är redan involverade i projektet. Vi vet när materialet ska komma och hur mycket och tack vare underentreprenörens tidiga deltagande i planeringen så vet vi även mer exakt när deras material kommer och hur mycket som kommer. Leverantörerna är nöjda eftersom deras tidiga involvering och det informationssystem som används för att sprida viktiga information gör så att de kan planera sin produktion mer exakt. De vet ju mer exakt i förväg nu när byggentreprenören behöver sitt material. Tack vare mätning av logistiken samt att tilliten förbättrats när aktörerna tidigt samarbetar om planeringen av materialet kan lärdomar från tidigare projekt dras. Man vet även att leverantören av fönster klarade av att leverera $67 \%$ i rätt tid, till rätt plats, $i$ rätt kvantitet och med rätt dokumentation. Är detta bra nog eller behöver vi starta ett utvecklingsprogram med leverantören? Tack vare den tidiga planeringen och involveringen av berörda parter lyckades vi hålla nere lagernivåerna och felaktiga leveranser på ett minimum. Med alla mätningar från byggarens logistikverktyg har vi för första gången data, svart på vitt, om hur leverantörer sköter sina åtaganden, hur lång tid vi tar på oss för att lossa gods och vad det är vi egentligen gör när det kommer material till vår byggarbetsplats."

Beskrivningen ovan berättar om en situation där ett planeringsverktyg används för att planera leveransen av material till en byggarbetsplats tillsammans med underentreprenörerna och leverantörerna redan i projekteringsfasen. Forskningen som presenteras i denna avhandling har haft som mål att utveckla ett sådan planeringsverktyg med tydliga processbeskrivningar för hur planeringen ska gå till, en organisation som ska genomföra planeringen samt mätetal som kan användas för se hur väl logistiken fungerar och ev. styra planeringen av den. Länge har man inom byggbranschen tampats med försenade leveranser av material, brist på tillit mellan entreprenörer och leverantörer och projekt som har dragit ut på tiden och kostnaden. En förbättrad planering av materielleveranserna löser inte alla problem men kan lösa många av dem. Detta kan i sin tur leda till effektivare byggarbetsplatser, projekt som levereras i tid och håller kostnaderna, men framförallt större säkerhet $\mathrm{i}$ att material kommer på utsatt tid. Eftersom byggbranschen är en stor och viktig del i samhällsekonomin är detta av stor vikt ur ett samhällsperspektiv.

Resultatet är unikt på så sätt att den påvisar hur leverantörer, underentreprenörer och huvudentreprenörer kan samarbeta för att förbättra både materialflödet och byggprojektet so sådant. Tidigare forskning har oftast fokuserat på en av dem, antingen materialflödet utan insikt $\mathrm{i}$ hur projektet kan påverkas eller hur byggprojektet kan förbättras utan insikt i hur materialflödet kan påverka eller påverkas av förändringarna. Helhetsperspektiv är ledord som drivit denna forskning. 
För att få en viktig förankring till byggbranschen har planeringsverktyget tagits fram tillsammans med viktiga aktörer som PEAB, NCC, JM, Arcona, Skanska, Paroc, Vedum, and Knauf-Danogips, Bygg-Ole och Marbodal. Detta har gett en bred förståelse för hur planeringen bör fungera. Metoder som har använts är platsbesök, intervjuer, litteratursökning samt fokusgrupper. 


\section{Foreword}

Before I started my PhD-studies I was not sure if I wanted to become a $\mathrm{PhD}$ student at all. Questions like "Will I make it?" "Do I want to be a PhD student?" emerged in my head. However, at the same time as I questioned a presumptive future career as a PhD-student and a $\mathrm{PhD}$ degree, I also knew that I really wanted to do this. I love to learn new things and question why things are as they are. So I knew I would enjoy being a PhD-student, and I have not regretted it (for most of the times).

There are so many people that I wish to thank for supporting me while writing this thesis and while working with my project. First of all, I wish to thank my supervisors Martin Rudberg, Anna Fredriksson, Fredrik Persson, and Tina Karrbom-Gustavsson for always encouraging, inspiring, and pushing me to do my best. Without you all, I would not be where I am today. Thanks! I also want to thank my colleagues at the Department of Science and Technology especially Henric Jonsson, Andreas Ekeskär, and Mats Janné. With the help I received from you guys, by reading and commenting on the papers, the quality of my thesis has improved considerably. Furthermore, your senses of humour and open-mindedness have stimulated me to complete this thesis. Other people I wish to thank are Maria Johansson, Glenn Gyllin, Lars Gutwasser, Jonas Thörnqvist, Magnus Lindskog, Martin Heljedal, Anne-Mari Korpela, Johan Danielsson, and Jesper Strandberg.

Finally, the ones that I cannot forget are my dearest friends and family, especially you F! You have all supported me when I have felt anxious about my thesis but also shared the joy of my progress. 



\section{Acknowledgement}

The author is grateful to Robert Javalds, Henrik Lokander, Robin Johansson, Glenn Gyllin, and Maria Johansson for their invaluable contribution towards developing the BSCOR framework. The funding for this work comes from Brains \& Bricks - a research-centre including both universities, companies, and municipalities, see also www.liu.se/forskning/b2. Funding also comes from the Development Fund of the Swedish Construction Industry (SBUF). Companies that have participated in this work are PEAB, NCC, JM, Arcona, Skanska, Paroc, Vedum, Knauf-Danogips, Bygg-Ole, and Marbodal. 



\section{Thesis outline}

This thesis is a compilation thesis (thesis by publication) comprising six articles; one is published in an ISI-classified journal, two are published as parts of conference proceedings, and three are working papers submitted to academic journals. The thesis is titled Developing a framework for supply chain planning in construction as it ought to develop a framework that could be used for planning and measuring construction supply chains. The introductory chapters in this thesis describe the background as to why the work is deemed necessary, and states the purpose and research objectives. It also guides the reader in the current literature and explains what each paper in the thesis concerns. Finally, the introductory chapters also describe the work on compiling and present the final framework. It also pinpoints the contributions and current ideas on future work. Listed below are the six articles that, together with the introductory chapters, constitute this thesis.

\section{Paper 1}

Thunberg, M., and Persson, F. (2014), "Using the Scor Model's Performance Measurements to Improve Construction Logistics", Production Planning and Control, 25, 13, 1065-1078.

\section{Paper 2}

Persson, F. and Thunberg, M. (2012). "Adapting the SCOR Model to the Construction Industry Settings”. In: Töyli, J., Johansson, L., Lorentz, H., Ojala, L. \& Laari, S. (Eds.), 24th NOFOMA 2012, 7-8th of June 2012 Turku, Finland.

\section{Paper 3}

Thunberg, M., Rudberg, M., and Karrbom-Gustavsson, T. (2015). "Categorising On-Site Problems: A Supply Chain Management Perspective on Construction Projects". Working Paper, submitted to Construction Innovation, in the second revision round.

\section{Paper 4}

Thunberg, M. and Fredriksson, A. (2016). "Taking a Supply Chain Planning Perspective on Common Construction Problems". Working Paper, submitted to Construction Management \& Economics, in the first revision round.

\section{Paper 5}

Thunberg, M. and Rudberg, M. (2016). “Coordinating Construction Supply Chains through Integrated Planning". Working Paper.

\section{Paper 6}

Thunberg, M. Fredriksson, A., and Rudberg, M., (2016). "Developing an Organisation and Process for Supply Chain Planning in Construction". In: 23 ${ }^{\text {rd }}$ EurOMA conference, 19-21st of June 2016, Trondheim, Norway. 



\section{Table of contents}

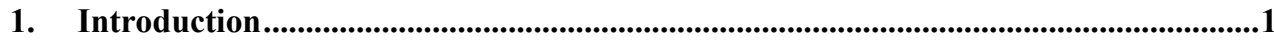

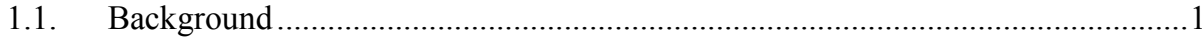

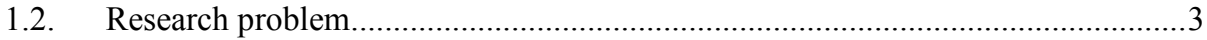

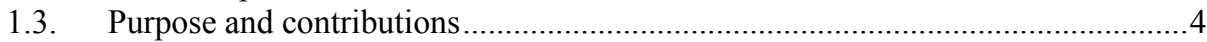

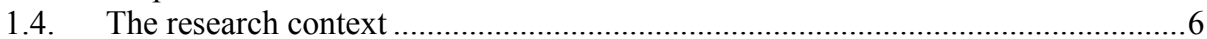

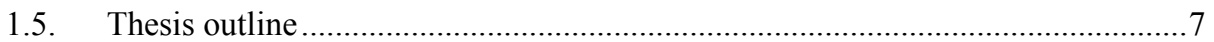

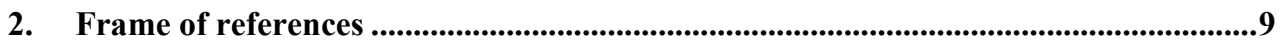

2.1. Construction project management …...........................................................

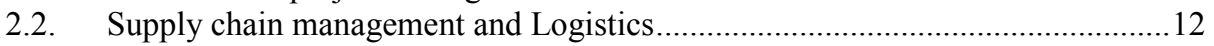

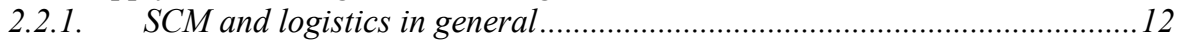

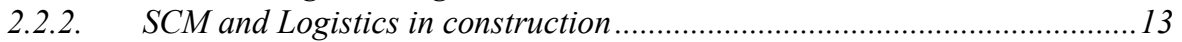

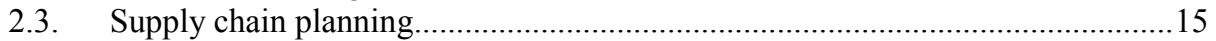

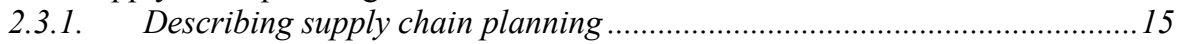

2.3.2. Setting the base for a planning framework ................................................... 18

2.4. Performance measurement............................................................................... 19

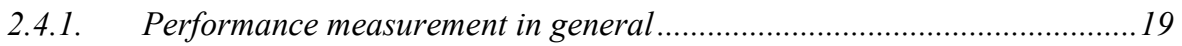

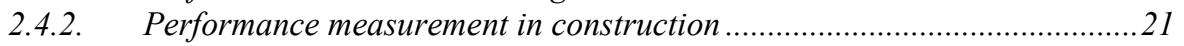

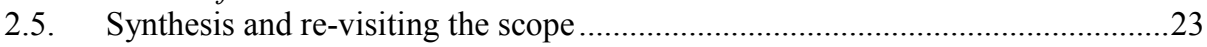

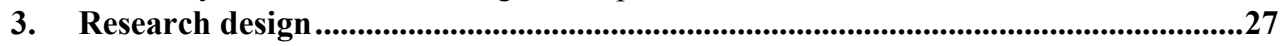

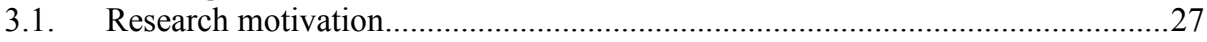

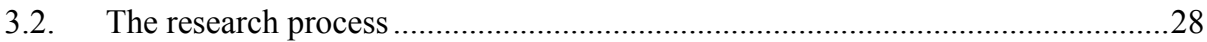

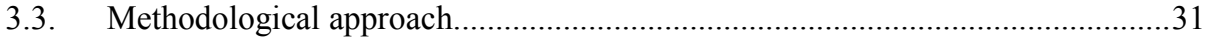

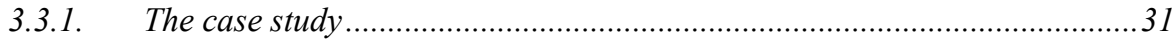

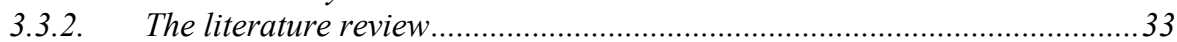

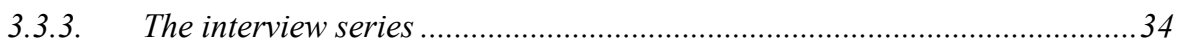

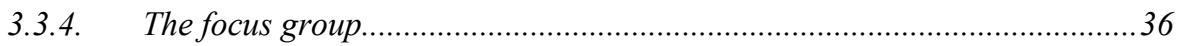

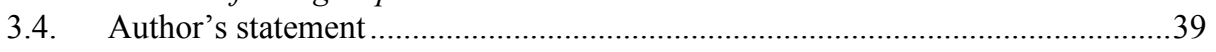

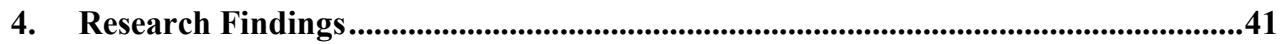

4.1. Identify common logistical problems and how they are linked ..........................41

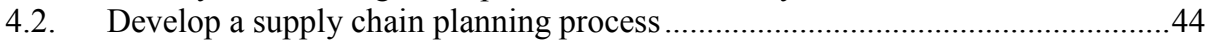

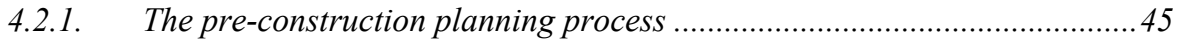

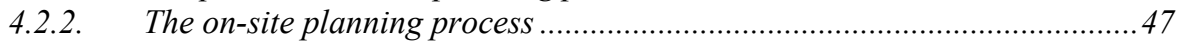

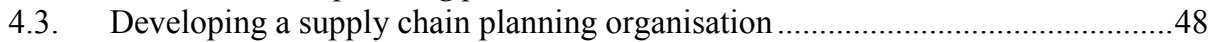

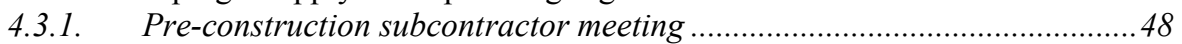

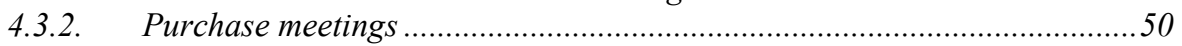

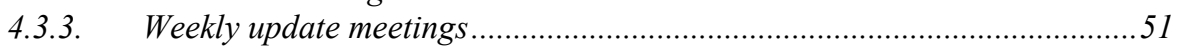

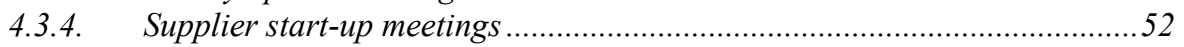

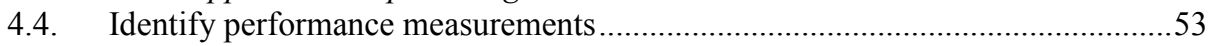

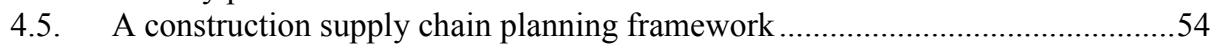

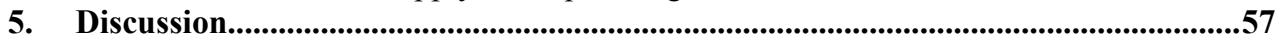

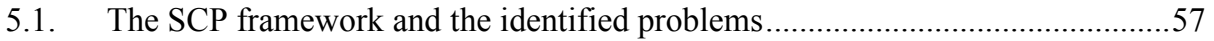

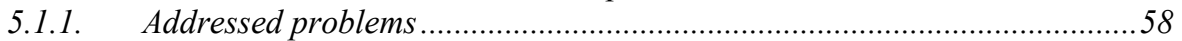

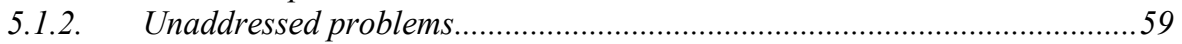

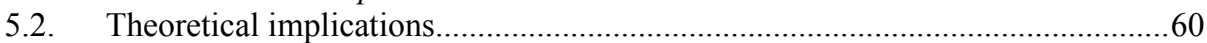




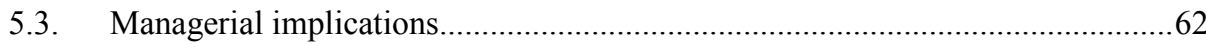

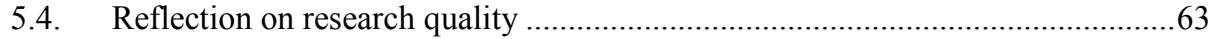

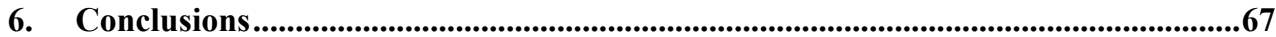

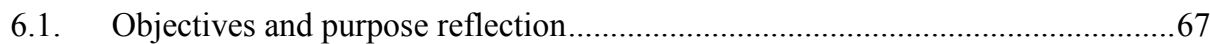

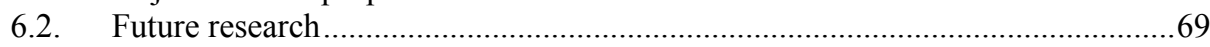

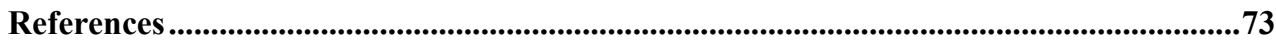

Paper 1 - Using the SCOR model's performance measurements to improve construction logistics

Paper 2 - Adapting the SCOR model to the construction industry settings

Paper 3 - Categorising on-site problems: A supply chain management perspective on construction projects

Paper 4 - Taking a supply chain planning perspective on common construction problems

Paper 5 - Coordinating construction supply chains through integrated planning

Paper 6 - Developing an organisation and process for supply chain planning in construction 


\section{List of figures and tables}

Figure 1. The relation between a construction project, the construction process and the supply

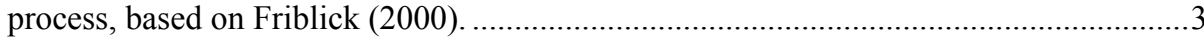

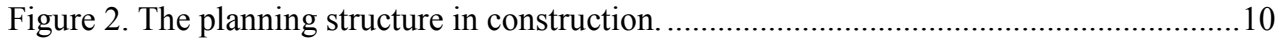

Figure 3. Construction supply chains, based on (Cox and Ireland 2002).............................14

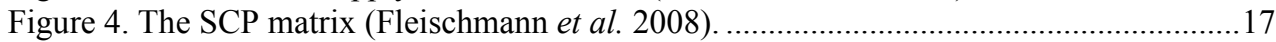

Figure 5. The supply chain perspective used in the SCOR model (SCOR 2010). ..................17

Figure 6. The sourcing plan as defined in the SCOR model (SCOR 2010)..........................18

Figure 7. The synthesis of S\&OP by Tavares Thomé et al. (2012)......................................19

Figure 8. Illustrating the connection between SCP, construction planning, and projects. ......24

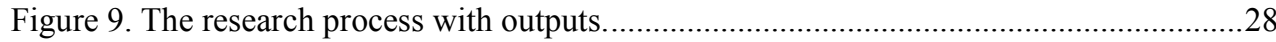

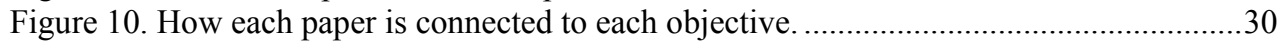

Figure 11. Grouping identified problems into problem categories......................................42

Figure 12. Positioning the identified problem categories in the construction project. ...........43

Figure 13. A model for linking the identified problems. .......................................................44

Figure 14. The SCP process for construction for the sourcing part.....................................45

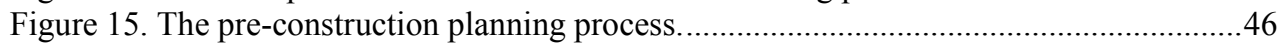

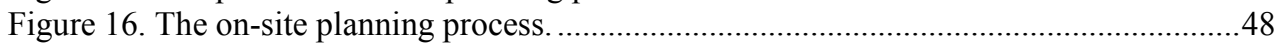

Figure 17. Pre-construction SCP planning process activities treated during the meetings. ....50

Figure 18. On-site SCP process activities treated during the meetings. ................................52

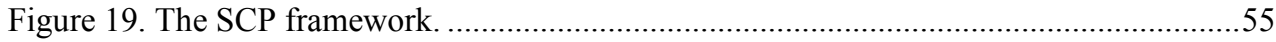

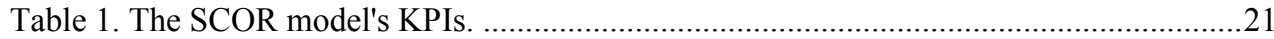

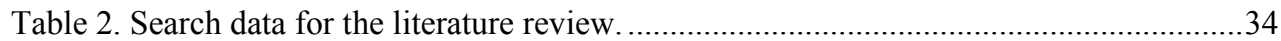

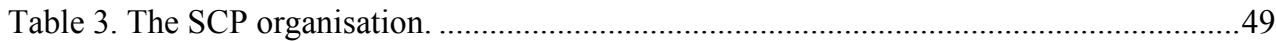

Table 4. The identified performance measurements............................................................54

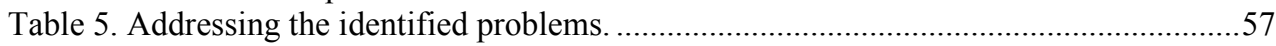

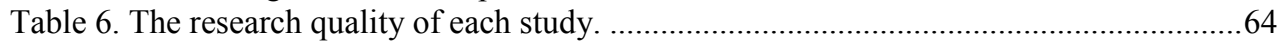

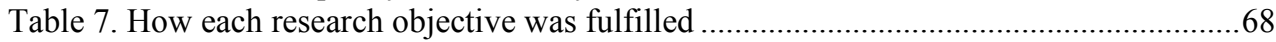





\section{Introduction}

It is a common belief in the construction industry that putting greater emphasis on managing the whole supply chain, from raw materials to the end-product, can positively affect cost, productivity, time, and quality. However, this requires an integrative planning process that involves suppliers and subcontractors early in the construction project. This thesis investigates how supply chain planning can integrate the supply process and the construction process in order to facilitate improvements of logistics in construction.

\subsection{Background}

The construction industry is often accused of being unproductive (Josephson and Hammarlund 1999) and having difficulties communicating with members in the project (Dainty et al. 2006). Looking at the productivity, data from SCB (2013) indicates that the construction price index has increased more than the consumer price index in Sweden and was as of 2011 about twice as high (SCB 2013). Josephson and Saukkoriipi (2005) could also show that on average craftsmen in Sweden spent more than $80 \%$ of their working day on waiting, material handling, and indirect work. This indicates that means to improve the productivity need to be identified. Dubois and Gadde (2002) argue that the loosely coupled nature of the construction industry can be a reason for the communication difficulties. Communication difficulties can in the long run hamper the productivity as the there is an increase in the number of reworks due to faulty information (Love and Li 2000). Several governmental reports such as Byggkommissionen (2002), Egan (1998), Latham (1994), and Statskontoret (2009) have described the low productivity in the construction industry. Cox and Ireland (2002) describe from a UK context that improving this industry will have an important impact on the whole society as it stands for about $7 \%$ of the total GDP.

It has for a long time been discussed how supply chain management (SCM) can aid in overcoming the difficulties with communication and low productivity (Latham 1994). About 15 years ago, Vrijhoef and Koskela (2000) have already shown that common on-site logistical problems such as late deliveries and faulty materials were a result of how the supply chains are managed. Inadequate management of supply chains affects costs, productivity, time, and quality of the end-product in the construction industry (Fearne and Fowler 2006). This is also supported by more recent reports such as those of Bankvall et al. (2010) and BIS (2013) and both conclude that the current situation stems from an inadequate way of managing suppliers and subcontractors. Dainty et al. (2001b) argue that subcontractors are involved too late in the planning of construction and supply chains. It is suggested that logistics and SCM are of importance for the construction industry in order to 
meet the demands of the construction clients, improve the communication, and increase the productivity.

An important part of SCM is planning and having a planning process in place, where supply chain members are continuously involved and integrated. This integrative planning of supply chains is called supply chain planning (SCP). SCP is further discussed in section 2, but briefly it is described as the process for developing demand plans and supply plans that involve suppliers and subcontractors. Supply plans include material delivery schedules indicating when ordered materials will arrive. It can be argued that this integrative process for developing e.g. material delivery schedules is missing in construction today. Subcontractors and suppliers are not involved in developing material delivery schedules. Gidado (2004) and Laufer and Tucker (1987) stress that poor planning in general causes time and cost overruns in construction. To address costs, productivity, communication, and time overruns with SCM, it is also necessary to look at the planning part of SCM. Integrating the suppliers and subcontractors in the development of material delivery schedules is crucial for the success of the construction project. Attention should therefore be given to seeing how SCP can be a facilitator for improving the industry, which is missing today (Tserng et al. 2006).

SCP is concerned with the coordination and integration of key business activities undertaken by an enterprise, from the procurement of raw materials to the distribution of the final products to the customer (Gupta and Maranas 2003: 1219). Procurement in construction is often planned and performed prior to production on-site, as illustrated in Figure 1. This means that suppliers and subcontractors should be integrated in developing material delivery schedules in the pre-construction phase itself. Integration of the supply process and the construction process in Figure 1 can be achieved by involving suppliers and subcontractors early in the planning process, which is missing (Friblick 2000). SCP in construction thus encompasses and affects activities both in the supply process and the construction process, as illustrated in Figure 1. Common logistics problems could be addressed by integrating the construction process and the supply process through SCP. The arrows connecting the supply and construction processes in Figure 1 illustrates the integration and how decisions in one process affect the other one. Decisions in e.g. the design phase about material selection will affect the supply process. 


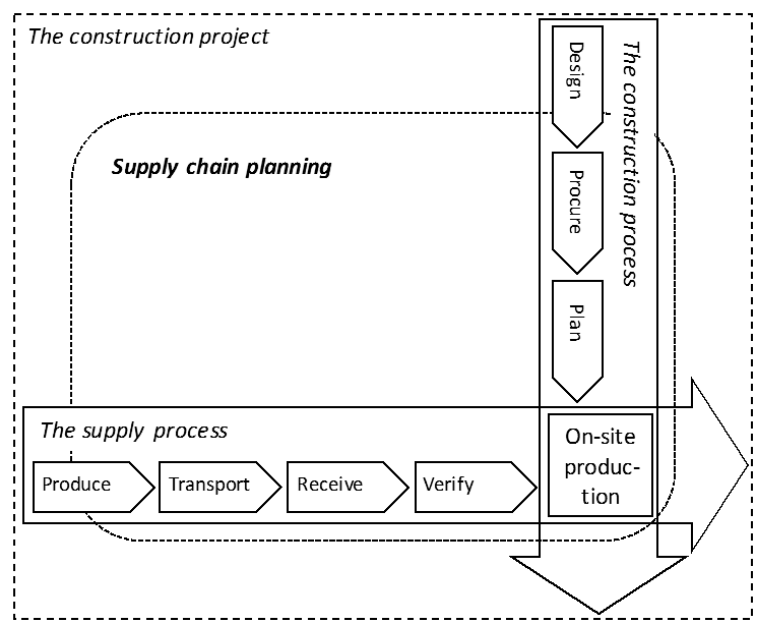

Figure 1. The relation between a construction project, the construction process and the supply process, based on Friblick (2000).

\subsection{Research problem}

Winch and Kelsey (2005) describe how project planning in construction has traditionally been quite narrow and focusing mostly on time scheduling. The commonly used guide to the project management body of knowledge (PMBOK) developed by PMI (2004) emphasises that project planning should result in a budget and time schedule. This can be the reason as to why focus in construction planning has so far been on developing time schedules. Project managers and site managers are good at developing a project plan and a production time schedule but what is missing today is how the time schedule and the material delivery schedule are connected and how they are updated on-site. Updating the plans is necessary as the project changes over time and things that were uncertain in the beginning will be less uncertain as we get closer to production. Nordstrand (2008) describes that a material delivery schedule should be developed based on the time schedule. Planning should also involve suppliers and subcontractors (Dainty et al. 2001b). As members of the project and the supply chains, suppliers and subcontractors have important information that need to be considered in the planning process. The subcontractors and suppliers should therefore be integrated in the process of developing material delivery schedules.

Ballard (2000) introduced a system for planning construction activities to be carried out by involving suppliers and subcontractors. His work focuses on the later parts of the construction process, i.e. the on-site part of planning. He does not describe how the subcontractors and suppliers should be involved in the planning process prior to production on-site. Johansen and Wilson (2006) argue that more attention should be paid to preconstruction planning when it comes to selecting suppliers etc. However, even though their article focuses on the early parts of the construction process it lacks in integrating the supply process and the construction process. 
A predominant focus in construction has been the contractor-client perspective. The supplier-contractor perspective has received little attention (Bygballe et al. 2010, Dainty et al. 2001a, Vidalakis et al. 2011). Not considering the suppliers' importance in the project will make it more difficult to see how suppliers affect project performance (Pan et al. 2010). This can be an explanation as to why planning so far has been focusing on the scheduling of activities to meet the client deadlines rather than on planning the supply process with the suppliers. It is therefore important to also involve suppliers in the planning process. This can also describe why a predominant perspective on performance measurement has so far focused on client satisfaction rather than on supplier and supply chain performance (see e.g. Wegelius-Lehtonen 2001). Supply chain performance is also of importance for the client as late material deliveries can negatively affect the construction time and delay the whole project.

To summarise, the problems with the research about planning supply chain aspects within construction are:

- Missing connections between the production time schedule and the material delivery schedule

- Suppliers and subcontractors are not involved in the planning of the supply chain

- Focus is either on the pre-construction planning or the on-site planning

- Planning is done to meet client requirements and not to improve the supply chain

These problems could be overcome by introducing a framework for supply chain planning that involves subcontractors and suppliers, focuses on planning both in the pre-construction phase and in the on-site phase, and connects the time schedule and the material delivery schedule. The scope is thus on planning in terms of developing material delivery schedules in the pre-construction phase and updating it on-site, depending on the progress of the construction process. This is done through a SCP framework that integrates the supply and construction processes by involving the subcontractors and suppliers in the development of material delivery schedules. An effect of the integration of the two processes and involving subcontractors and suppliers in the process has the potential to improve communication, reduce construction time and costs, and improve productivity.

\subsection{Purpose and contributions}

Based on the discussion above, the purpose can be formulated as: to develop a SCP framework for construction that involves the main contractor, subcontractors, and suppliers. It has been discussed how important it is to integrate the supply and construction processes to improve planning and project performance (Dainty et al. 2001b, Friblick 2000). The main contractor and the subcontractors are representatives of the construction process, while the suppliers represent the supply process. Involving these actors in the planning process will result in an integration of the construction process and the supply process.

A first step for developing the SCP framework is to map the current state in construction with regard to logistics. This means to identify common logistical problems and also to map the 
current state of logistic performance in construction. It is argued that many of the problems arise due to the lack of SCP in construction. It is therefore important to analyse if there are any inter-linkages between logistical problems and how SCP can aid in solving the problems. Plans are developed to achieve goals but also to address uncertainties (Gidado 1996). If no plans are developed, most activities will be uncertain. Knowing what problems to address, can aid in identifying how the SCP framework should be designed and what the framework should aim at overcoming. This can be summarised into:

\section{Objective 1. Identify common logistical problems and linkages between them}

The next step is to find means to overcoming these problems. This is done by developing a SCP framework that can address these problems. Planning frameworks often include a process design or procedure (Fleischmann et al. 2008), an organisation, and performance measurements (Tavares Thomé et al. 2012). This means that the design of the SCP framework should focus on developing a process describing the planning procedure, an organisation to perform the procedure, and identifying performance measurements for measuring supply chain performance and directing the decision making in the process. This can be summarised into the three final objectives of this thesis:

\section{Objective 2. Develop a SCP process}

\section{Objective 3. Develop a SCP organisation}

\section{Objective 4. Identify performance measurements}

The anticipated contribution with the developed SCP framework is an integration of supply chain members for developing a material delivery schedule. The effect of this integration is a shift in focus: from seeing SCM and planning of materials as an on-site activity to seeing them as part of the pre-construction process as well. The suggested shift in focus can be a facilitator for overcoming many of the logistical problems commonly encountered on-site today. This shift also means that some of the questions should be handled by people other than the site managers. Better SCP and logistics are an anticipated practical implication of this research. It will also help the practitioners understand why logistical problems occur and how SCP can aid in addressing these problems.

This thesis's target group includes researchers in the construction management field. Construction management research is vaguely defined, but Voordijk and Adriaanse (2016) describe it as a scientific discipline that seeks to explain phenomena that are related to the design, production and operation of the built environment with the use of theories from other scientific disciplines. This thesis contributes with theories from the SCM scientific discipline/research field in terms of suggesting SCP as a means to address problems in logistics. Logistical problems are in Voordijk and Adriaanse's definition associated with the fields of production and operations.

The thesis aims to contribute towards extending the body of knowledge within construction management research by suggesting SCP as a means for addressing logistical problems and improve construction projects. SCM is a research field that has attracted attention from many authors within construction management research. However, few within the construction 
management research field have studied how SCP as part of SCM can facilitate in overcoming the logistics problems in construction. Introducing SCP to construction management research extends the available theoretical background for addressing logistical problems in construction.

\subsection{The research context}

The term construction can be used both for civil engineering and house building projects. The focus in this thesis is on house building. Construction is thus used synonymously with house building. The characteristics of the construction industry can be summarised as project-driven with temporary organisations, decentralised decision making, and fragmented with many small companies.

Regarding the project-driven and temporary nature, a project is defined by a clear start and end time (PMI 2013). The life of the organisation is therefore as long as the construction project in itself, making it temporary. This means, that the organisational structure for the project is born and dies with the project. The project team is taken from the line organisation and works with a clear task in the project (Lundin and Söderholm 1995). Even if a project is often seen as temporary, it is influenced by its surrounding environment and history (Engwall 2003). This means that people and organisations and other members of the project have a history that can affect the project. Temporary organisations often have problems with sharing knowledge among projects (Meng 2012). This makes it important to find systems and organisational structures that could aid in sharing knowledge between projects (Love et al. 2004, Modig 2007). Another problem with temporary organisations is that trust among members has to be developed for each project (Bygballe et al. 2010).

The nature of projects in construction has resulted in a decentralised industry with an inherent loosely coupled system (Dubois and Gadde 2000). It is argued that a decentralised decision making is of advantage as coordination of local resources can be done better locally on-site rather than in a centralised organisation (Dubois and Gadde 2000). However, this decentralisation can also result in autonomous projects. Each project acts as an independent firm decoupled from the parent company. A consequence is that the coordination and information sharing are hampered (Bygballe et al. 2010). The decentralised nature of the construction industry also affects the procurement of materials. Much of the procurement is done locally on-site and often by the site manager (Frödell 2014). This often yields in shortterm contracts and a focus on price rather on total cost.

The temporary nature and the decentralisation of decision making have resulted in fragmentation of the construction industry with several small contracting companies and subcontractors. In Sweden (year 2007) the majority of construction companies had few employees. A total of seven companies employed more than 500 employees and 18,210 companies employed less than 500 employees, while a total of 10,759 companies had no employees at all (SCB 2013). Fearne and Fowler (2006) report that this fragmentation creates uncertainty in projects as there is no continuity in terms of the subcontractors used. This extensive subcontractor base is what makes coordination more difficult (Dubois and Gadde 
2000, Gidado 2004). If plans and work activities are not coordinated, it can have a negative impact on the performance, cost, time, and quality (Love and Edwards 2004).

The construction industry is also characterised by a system of different type of contracts. Common type of contracts are design-build and design-bid-build. One form of a design-build contract is in-house construction when the building is done in-house and the contractor also acts as the client. These contract types result in differences in when the main contractor enters the project, when subcontractors and suppliers can be sourced, and how the communication channels are designed. The main contractor has larger opportunities to develop a supplier base with long-term relationship in in-house and design-build contracts than in design-bid-build contracts, where suppliers and subcontractors have to be sourced by the client in an open bidding contest. This means that the supply chain and the supply process in Figure 1 are formed in different periods of the construction project depending on type of contract.

In this thesis, sources of data are gathered mainly from projects and companies working with in-house and design-build contracts. This means that the supply chain is formed early in a project with a possibility of forming long-term relationships in the supply chain. Data is also gathered from a house building context. Projects studied are based in Sweden and focus on new constructions. All of the projects are traditional on-site production. This limits the applicability of the results and the generalisation, but also helps the reader to understand in which context the result is applicable and what needs to be investigated further.

\subsection{Thesis outline}

This introductory chapter (section 1) describes the background of the study that has motivated the purpose and the research. Section 2 (Frame of references) provides a thorough description of the important concepts covered in this thesis. Section 2 starts with describing project management and planning for understanding how material delivery schedules are developed in construction. Secondly, a short introduction to SCM and logistics is given to show the standpoint taken by the author. Thirdly, SCP is presented and described. A description of performance measurement is then given to describe how supply chain performance can be measured and how performance measurement is done in construction. Finally, section 2 ends with a synthesis summarising how each subsection will be treated in the rest of the thesis.

The research design section (section 3) outlines how each study in the thesis was conducted, but also presents the whole research strategy and process. The thesis findings are presented in section 4. Research findings is structured by describing how each research objective was fulfilled and ends with a subsection fulfilling the research purpose. It is in this subsection where the SCP framework is introduced. The discussion section (section 5) presents how the SCP framework can address the identified problems and what the theoretical and managerial implications are. Section 5 also gives a reflection on research quality. The conclusion (section 6) summarises the study and identifies possibilities for future research. 


\section{Frame of references}

This section aims at describing the theoretical concepts utilised in this thesis. These concepts are: construction project management, SCM and logistics, planning and SCP, and performance measurement. The latter three will be described both in general and from a construction perspective. The section is structured by first describing construction project management ending up with describing how plans in general are developed and how the material delivery schedule is developed. The other concepts are individually described thereafter. A synthesis is presented in the end that combines the different sub-sections to describe SCP in construction and clarify the scope of the thesis.

\subsection{Construction project management}

Project management is defined by the project management body of knowledge (PMBOK) as:

\footnotetext{
"The application of knowledge, skills, tools, and techniques to project activities to meet project requirements (...) through the application and integration of the project management processes of initiating, planning, executing, monitoring and controlling, and closing." (PMI 2004: 8)
}

An essential part of project management is to establish clear and achievable objectives and to deliver these objectives within the scope, on time, and within the budget. In order to deliver within the scope, on time, and within the budget, projects require extensive planning. In a construction context this means to identify the client's requirements and identify what project activities should be performed when and by whom (Winch 2010). However, there is more to project management and its planning than just developing a realistic production time schedule, this will be described below.

As mentioned earlier, the construction industry is a project oriented industry. This means that theory about planning in construction borrows its content from general project management theory (Laufer and Tucker 1987, Winch 2010, Zwikael 2009). Common components of project management are portfolio management, programme management, project planning, and scheduling (Wysocki 2012). A programme is a group of related projects managed and coordinated in similar ways (PMI 2004). In a construction context a programme is often translated to a multi-project environment where several sub-projects should be managed and coordinated (Walker 2015). Walker (2015) also argues that the differences between a programme and a portfolio are not clear. Wysocki (2012) gives a business perspective on portfolio management by defining it as all projects managed by the company, i.e. all projects accepted and won in the bidding phase. Important input to the portfolio and the bidding phase should be the strategic plan of the company and demand forecasts in order to identify projects 
that the company finds suitable to run. The project portfolio yields a long-term resource plan and input in planning of a certain project.

Project planning in construction can be separated into two planning processes, often entitled pre-construction planning and on-site planning (Johansen and Wilson 2006). The preconstruction planning process comprises selection of project team, creation of the project documentation system, initiating the purchasing of materials, development of the time schedules and milestones, and other pre-project-execution activities (Menches et al. 2008). The on-site planning is, on the other hand, more operationally focused and comprises ensuring that planned activities can be fulfilled, schedule adherence, material procurement, weekly meetings, etc. (Johansen and Wilson 2006). Faniran et al. (1998) use the term construction planning for identifying what activities to perform and developing the production time schedule. This means that construction planning is a sub-set of project planning and focuses more on the construction part.

Figure 2 synthesises the different planning components that exist in the literature and presents a planning hierarchy in construction (hereinafter called the construction planning structure). Programme management/planning is omitted in Figure 2 because programmes are treated as larger projects and are thus included in project planning. It should also be noted that Figure 2 depicts the main contractor's perspective in a design-build contract context.

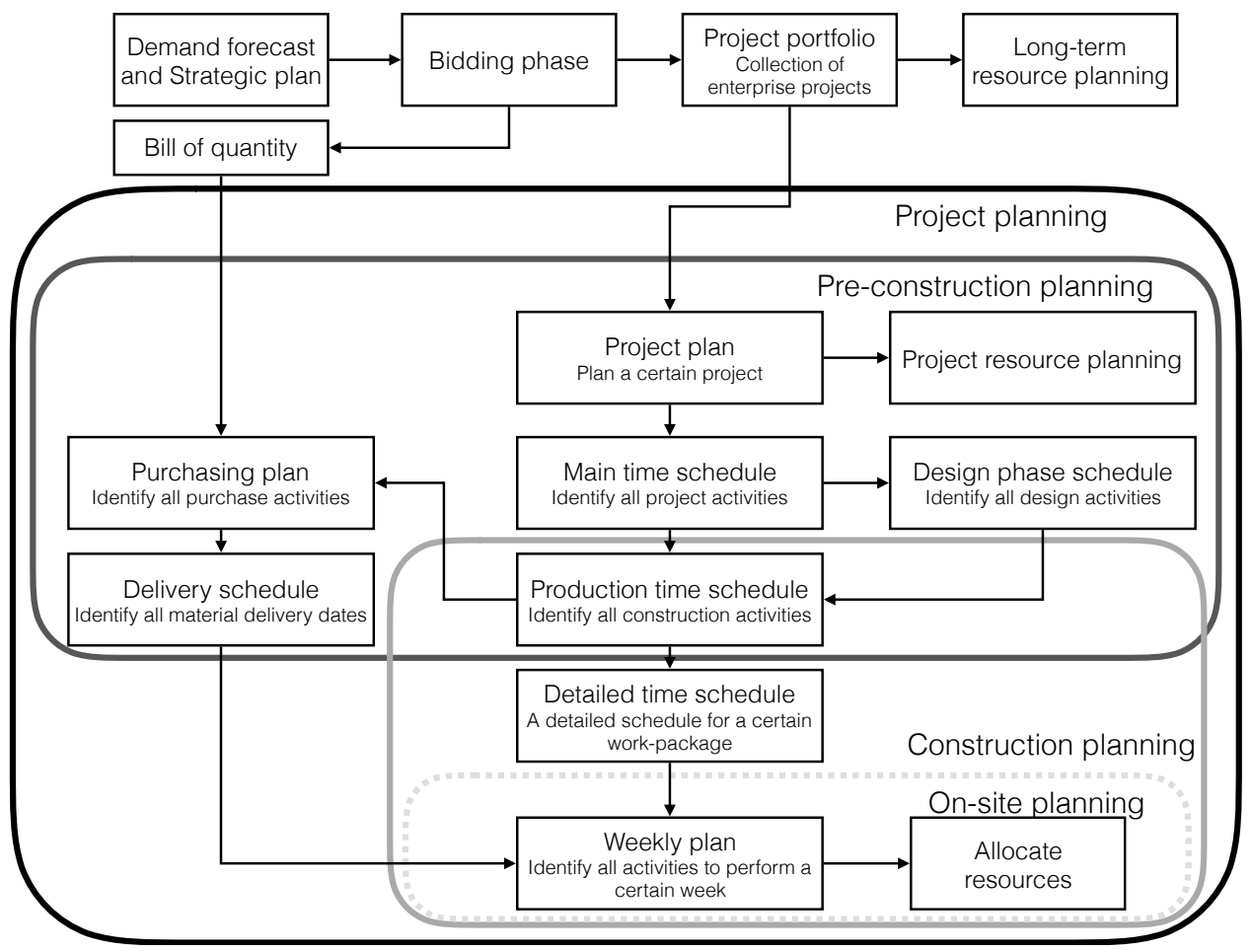

Figure 2. The planning structure in construction. 
Starting with pre-construction planning, the first process is about developing the project plan. This includes identifying the goal of the project, allocating resources, identifying risks, and developing a time schedule (Wysocki 2012). The project plan is divided into sub-plans like budget, quality, action plan, and time plan (Yates and Eskander 2002). As the planning procedure comes from project planning, important outputs are an overall project schedule called main time schedule (Nordstrand 2008) and resource plans (PMI 2004). The main time schedule includes activities for managing documentation, production start and end, and production in general. The production process is here considered as one activity and will be further detailed in the production time schedule. The main time schedule is an important input to the design phase schedule and the production time schedule. The design schedule includes all the activities in the design phase of the project, whereas the production time schedule includes all activities in the construction process on-site. The production time schedule is also dependent on the output from the design phase schedule for knowing when activities should start.

The production time schedule is part of both the pre-construction planning and the construction planning and is an important input for the purchase process and scheduling deliveries of materials. The bill of quantity developed during the bidding phase is also an important input to the purchasing plan. The production time schedule is at this point tentative and many actors work on developing it at different stages. This makes the purchase plan and the delivery schedule uncertain at this point. As the time schedule is updated during the course of the construction project it also means that the purchase plan and the delivery schedule should be updated. Finally, the production time schedule is separated into detailed work-package time schedules like installations, ground work, and other on-site workpackages.

The on-site planning covers the part where the construction plan is updated on a rolling horizon, typically in weekly buckets. The plan should be updated as the certainty about what will be done gets clearer. This also means that specific resources can be allocated to perform a certain activity. It should also be noted that the construction planning structure is set up in parallel by all contractors involved in a project.

In construction, the emphasis is often on developing the production time schedule (Laufer and Tucker 1987). Faniran et al. (1998) and others also argue that construction planning is too focused on technical issues rather than developing comprehensive processes for planning. Effective planning should ensure that all involved actors know what to do, when to do it, and whether the required resources are available. As Zwikael (2009) pointed out, a project plan also includes procurement plans and material plans. Forgetting these aspects in planning the project does not facilitate a well-functioning supply chain and logistics. Agapiou et al. (1998) argue that the productivity of construction projects would increase if logistic issues (like scheduling of materials, etc.) were given greater attention in the planning process.

Another important part of planning is to coordinate the work with other project participants, like confirming that all participants share the same view of what the project goals are (Fellows 2009). This should be done early in the project and as such, the pre-construction and 
on-site planning processes should not be seen as two isolated processes (Johansen and Wilson 2006, Laufer and Tucker 1987). Rather, the on-site planning process is to a large extent affected by the decisions made in the pre-construction planning phase. Fellows (2009) describes that coordination is most often absent in construction projects, which leads to unshared goals between participants and unsuccessful projects.

\subsection{Supply chain management and Logistics}

\subsubsection{SCM and logistics in general}

This sub-section aims at describing SCM and logistics in general terms.

\section{Supply chain management}

An important concept to describe is what a supply chain is. Christopher (2011) defines a supply chain as:

\footnotetext{
“(...) the network of organisations that are involved through upstream and downstream linkages, in the different processes and activities that produce value in the form of products and services in the hands of the ultimate consumer." (Christopher 2011: 13)
}

This indicates that supply chains concern both the flow of material and the flow of information, as also highlighted by the Council of Supply Chain Management Professionals (CSCMP 2013). La Londe and Masters (1994) mean that any company that sources materials and/or sells products has one or more supply chains linked to the organisation. This can visually be described as a supply network rather than a chain (Christopher 2011, Lambert and Cooper 2000). The management of these chains is often called SCM. However, supply chains do exist even if they are not managed (Mentzer et al. 2001). CSCMP defines SCM as:

\footnotetext{
"Supply Chain Management encompasses the planning and management of all activities involved in sourcing and procurement, conversion, and all logistics management activities. Importantly, it also includes coordination and collaboration with channel partners, which can be suppliers, intermediaries, third-party service providers, and customers. In essence, supply chain management integrates supply and demand management within and across companies. Supply Chain Management is an integrating function with primary responsibility for linking major business functions and business processes within and across companies into a cohesive and high-performing business model. It includes all of the logistics management activities noted above, as well as manufacturing operations, and it drives coordination of processes and activities with and across marketing, sales, product design, finance, and information technology." (CSCMP 2013) [Emphasis added]
}

The definition of SCM by CSCMP (2013) highlights four important aspects. First of all, the planning and the execution of the plan (entitled 'management' in the quotation) are both subsets of SCM. Secondly, logistics is also a subset to SCM, which Larson and Halldorsson (2004) would call a unionistic perspective. Thirdly, coordination and collaboration are important aspects. In order to develop coordination and collaboration, the concept of relationship management is also important. Finally, SCM acts as an integrating function both within the organisation and between organisations. Integration is important for sharing information and gaining a holistic view that allows working as a supply chain and minimises the risk of sub-optimisation (Christopher 2011). 
The results of adopting the SCM philosophy include lowered costs, improved customer value and satisfaction, and cooperative advantages (Christopher 2011, Mentzer et al. 2001). However, Mentzer et al. (2001) describe that most companies must first become supply chain oriented before adopting SCM. While SCM includes information sharing, risk sharing, cooperation, customer service focus, integration, long-term relationships, and coordination, supply chain orientation focuses on developing trust, commitment, vision, interdependence, identifying the leader of the supply chain, and top management support (Mentzer et al. 2001).

The standpoint taken in this thesis is that SCM is considered to be the management of all activities in the physical flow and information flow in the supply chain including the relationship with suppliers and customers, i.e. adhering to CSCMP's definition.

\section{Logistics management}

One common question is what distinguishes logistics from SCM. CSCMP defines logistics as:

"The process of planning, implementing, and controlling procedures for the efficient and effective transportation and storage of goods including services, and related information from the point of origin to the point of consumption in conformance with customers' requirements. This definition includes inbound, outbound, internal, and external movements" (CSCMP 2013).

CSCMP also defines logistics management as:

“(...) that part of supply chain management that plans, implements, and controls the efficient, effective forward and reverse flow and storage of goods, services, and related information between the point of origin and the point of consumption in order to meet customers' requirements.(...)” (CSCMP 2013)

This implicitly means that logistics and logistics management are parts of SCM. Mentzer et al. (2008) scrutinised the contemporary literature (up to year 2007) to see how different authors distinguished logistics management, SCM, and operations management. They concluded that the topic is coloured by personal perceptions and no view is more correct than that of the others. However, their perspective on the matter is that logistics is a sub-set of SCM and that logistics activities cross both the SCM and the operations management sphere (Mentzer et al. 2008).

\subsubsection{SCM and Logistics in construction}

\section{SCM in construction}

The term SCM is a relatively new concept to the construction industry. The two seminal works produced by Egan (1998) and Latham (1994) suggest that planning issues, reworks, defects, etc. lead to reduced productivity and increased costs. Egan (1998), Latham (1994), and Vrijhoef and Koskela (2000) suggest that the problems facing the industry could be overcome through better coordination of members in the supply chain.

Akintoye et al. (2000) concluded that the main objective among practitioners in construction implementing SCM was to bring benefits to the client and improve customer service. That can explain why most contractors engage in collaboration with clients rather than with suppliers (Akintoye et al. 2000). However, a greater focus on collaboration with suppliers is 
important. As Vrijhoef and Koskela (2000) describe, many of the logistics problems on-site like material delivery delays have their origin earlier in the supply chain like not communicating with suppliers. They portrayed the focus on SCM in construction as four roles: focus on the interface of the supply chain and on-site activities, improving the supply chain, transferring on-site activities to the supply chain, or integrating the supply chain and the on-site work. However, Saad et al. (2002) conclude that even if the industry see SCM as a means for overcoming common problems it is not prepared for it and do not understand the concept. Both CSCMP (2013) and Mentzer et al. (2001) discuss soft parameters such as trust, commitment, relationship, and integration as important in SCM. This makes SCM more of a philosophy rather than an implementable tool.

One important aspect of SCM is trust. Akintoye et al. (2000) conclude that trust among members is an important factor for efficient SCM implementation and that a lack of commitment on part of the top management is the main reason for poor adoption success. Yet, a climate of trust is not present in the industry (Dainty et al. 2001a). Tennant and Fernie (2013) report that top management commitment could be lacking due to a poor understanding of what SCM is. The belief today is that SCM can be used to integrate members to better coordinate the work in the supply chain. For example, Karim et al. (2006) discuss the need of main contractors to better manage subcontractors' supply chains as subcontractors stand for a great portion of the work on site and hence even the number of defects.

\section{Construction supply chains}

The construction industry was described earlier as being characterised by being decentralised, fragmented, and having a temporary nature. These have an impact on how the logistics and supply chains are managed. The use of temporary organisations to perform a construction project also yields in temporary supply chains. A typical construction supply chain is complex as several different trades including consultants, suppliers, and sub-contractors are involved (Cox and Ireland 2002, O'Brien et al. 2002). Figure 3 below depicts the complexity of a construction supply chain. It consists of three major flows: material, equipment, and labour.

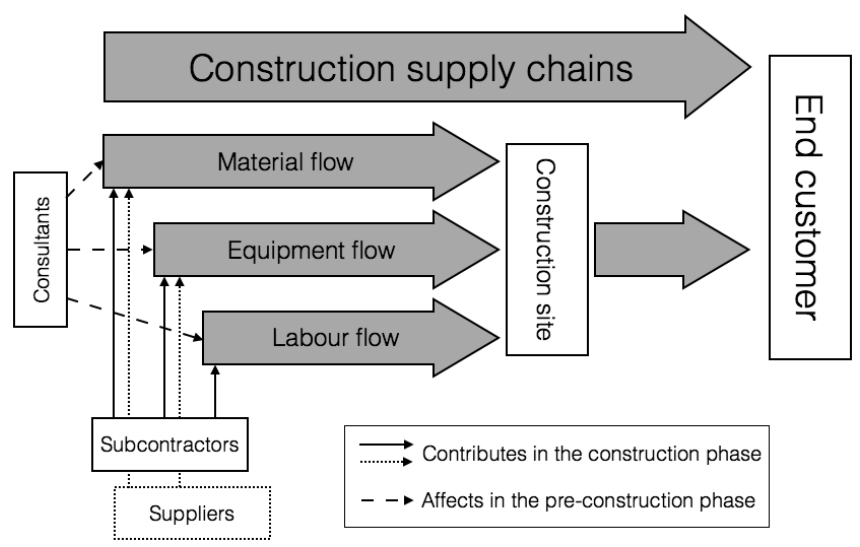

Figure 3. Construction supply chains, based on (Cox and Ireland 2002). 
There a several characteristics of a construction supply chain that need to be addressed. A construction project does not have the convenience of a factory to build the end-product. Instead the end-product is built at the same time as the factory. This requires a continuous source of equipment and labour flowing to and from the construction site. Added to this is the complexity of how information and input from consultants, architects, and designers affects the different supply chains. The consultants' decision and work will affect the project and the supply chains. If it is planned to use specialised products from suppliers abroad, it will affect the reliability of the material flow which in turn can affect the labour flow because the craftsmen do not have the material in time for production. Vrijhoef (1998) describes how design flaws and other early problems can negatively affect the supply chain and the project. It is therefore important to involve the construction team early in the project for avoiding decisions that can affect time and cost negatively (Akintoye et al. 2000).

Another construction supply chain characteristic is how chains are managed. It is often up to the site managers to manage the supply chain. There are many chains and suppliers to manage in a construction site (Vrijhoef and Ridder 2007). However, the culture of decentralised decision affects the supply chains and the logistics. It is up to the site manager to decide which suppliers and subcontractors to select and how to work with the logistics in the project. If the site manager does not have the ability or the interest in SCM and logistics, the project will probably suffer in those two areas. As described earlier, this can be the reason for coordination issues and the many uncertainties in the construction supply chains (Bankvall et al. 2010, Dubois and Gadde 2002, Fearne and Fowler 2006).

Many researchers believe that paying more attention to logistics and adopting SCM will have a positive effect on the time and cost overruns, productivity, quality, and even safety (Agapiou et al. 1998, Akintoye et al. 2000, Meng 2012). Vrijhoef and Koskela (2000) reported on how communication difficulties between contractors, suppliers, and architects can lead to time overruns on-site. Faulty materials for instance, can result in re-work and therefore increased costs (Hwang et al. 2009, Vrijhoef and Koskela 2000) and decreased productivity (Josephson and Saukkoriipi 2005). If the flow of materials is perfect, then the craftsmen do not have to wait for the materials or handle problems such as late deliveries and can focus on value-addition activities such as assembling.

\subsection{Supply chain planning}

\subsubsection{Describing supply chain planning}

Planning is, in general, about balancing needs with resources to achieve a shared goal. Planning is often separated hierarchically into strategic, tactical, and operational planning. Both Bryson (2011) and Montana and Charnov (2008) describe strategic planning as the process of identifying where you are now, where you want to be, and the means to getting there. This includes identifying goals for the company and sharing them within all functions. The outcome of the strategic planning gives input to the tactical planning. Tactical planning is the process of outlining activities that have to be done in order to fulfil the goals of the strategic plan (Fleischmann et al. 2008). The operational planning finally breaks down the 
activities and objectives for identifying daily activities that have to be done and assigns individuals to complete them (Montana and Charnov 2008).

Fleischmann et al. (2008), and Vollmann et al. (2005) suggest the use of long-term, midterm, and short-term rather than the terms strategic, tactical, and operational. Regardless of terminology used, planning is done with different planning horizons. This also applies for SCP. As described earlier, a supply chain consists of processes and activities where several organisations produce value to the end-customer (Christopher 2011). This means that these organisations in the supply chain must work in a coordinated manner and develop plans considering the whole supply chain. As Christopher (2011) puts it, more focus is put on the competitiveness of the supply chain rather than of single companies. This requires information sharing about demand, supply, and production aspects among the members in the supply chain (Olhager 2013). It also means that it is important to integrate other supply chain members in the planning process as the complexity of the supply chain with several planners might result in sub-optimisation and lack of a holistic perspective (Pibernik and Sucky 2007).

There are many perspectives on what SCP is. Jonsson and Holmström (2016) argue that academic texts about SCP today lack in mutual understanding of what SCP is and what the outcome of SCP should be. Jonsson and Holmström (2016) defines SCP:

\footnotetext{
"as an implemented operations planning and control framework, system, process, or method with a supply chain scope.” (Jonsson and Holmström 2016: 63)
}

This definition is quite vague, where SCP can be seen as a framework, system, process, or method as long as it has a supply chain scope. However, Jonsson and Holmström (2016) also point out that SCP consists of four parts: sales and operations planning for coordinating supply and demand in the supply chain, network production planning for several plants, planning and control of inventory and replenishment in the supply chain, and information sharing and collaboration. A similar perspective of SCP is the one described by Fleischmann et al. (2008), reproduced in Figure 4. They include both the production aspects of SCP but also procurement, distribution, and sales. The problem with the SCP declaration of Fleischmann et al. (2008) is that it is quite focused on the focal manufacturing company and lacks in an integrative supply chain perspective.

Another definition of SCP is the one declared by Gupta and Maranas (2003):

"(...) is concerned with the coordination and integration of key business activities undertaken by an enterprise, from the procurement of raw materials to the distribution of the final products to the customer." (Gupta and Maranas 2003: 1219)

This contains the integrative supply chain perspective but lacks in defining what the key business activities are. They do however stress customer focus, which is in line with Lummus and Vokurka (1998), that SCP should focus on creating value for the end-customer. As being part of SCM (CSCMP 2013), SCP should focus on customer value but also integration. The SCP should thus include means for achieving this integration of supply chain members. In order to integrate the members of the supply chain it is important to share supply and demand information such as forecasts and production programs. Rudberg et al. (2002) include 
demand planning, supply planning, promotion planning, transportation planning, and product development as parts of SCP.

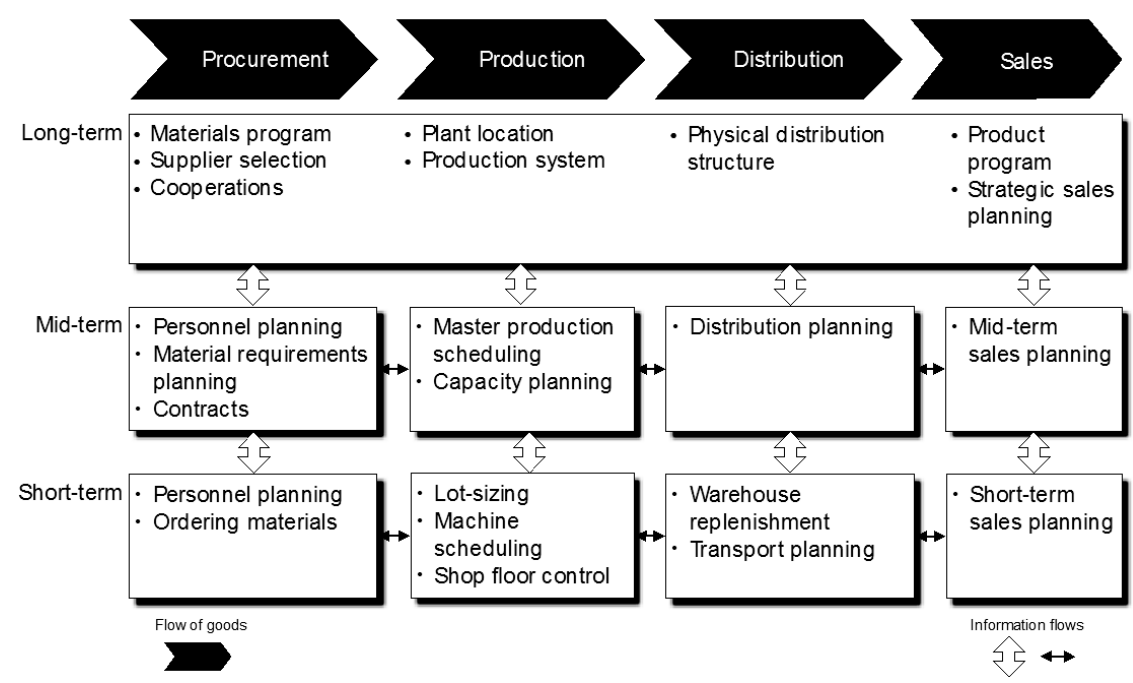

Figure 4. The SCP matrix (Fleischmann et al. 2008).

As mentioned earlier, defining SCP is not easy. But trying to grasp the essence of the above definitions and declarations indicates that SCP can be seen as the process for balancing needs and demands with available resources throughout the entire supply chain for integrating supply chain members and creating value for the end-customer. SCP can be visualised by connecting each supply chain actors' SCP matrixes in Figure 4 throughout the supply chain, as illustrated in Figure 5, which originates from the SCOR model's (supply chain operations reference model) perspective of integrating the supply chain. The overall planning process illustrates the necessary holistic perspective in SCP for eliminating sub-optimisation. Figure 5 also connects each company in the supply chain which illustrate the necessary integration and collaboration in SCP.

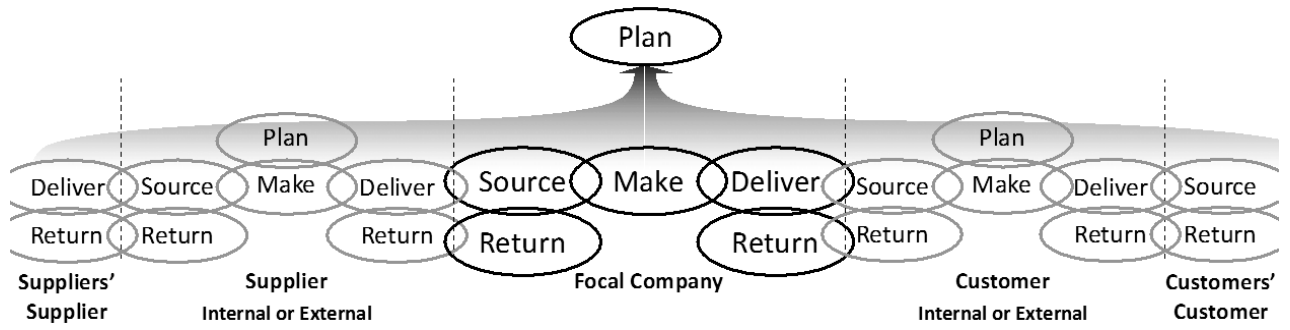

Figure 5. The supply chain perspective used in the SCOR model (SCOR 2010).

The three levels presented by Gupta and Maranas (2003) and others (cf. Fleischmann et al. 2008, Lummus and Vokurka 1998, Sodhi 2003) is also recognised in this definition. The strategic part incorporates the process of long-term planning about where to localise production (Jonsson and Holmström 2016) and to identify which markets to focus on and 
which suppliers to collaborate with (Lambert and Cooper 2000). These are questions that have to be planned on a long-term basis often with a planning horizon of several years.

The output of the strategic level is an important input to the tactical planning part (Sodhi 2003). Sodhi (2003) and Van Landeghem and Vanmaele (2002) argue that tactical planning encompasses determining how much should be produced in which production plant and when, with planning horizon about months or weeks. This calls for an extensive information sharing with suppliers and integrating them in the planning process.

Finally, the operational part of planning covers controlling the daily inventory levels and material replenish (Fahimnia et al. 2015, Jonsson and Holmström 2016). Usually the operational planning has a planning horizon about days or weeks. Looking at the shortterm/mid-term part of SCP. Integrating supply chain members is achieved through e.g. sharing supply plans in terms of purchase orders with suppliers. It starts with identifying what materials are needed and when, this is illustrated in Figure 6. This should be balanced with available materials and resources for developing a sourcing plan. The integration is then achieved by forwarding the sourcing plan to the suppliers in the supply chain. As being a long-term/short-term plan, the sourcing plan needs regular updating (cf. Gupta and Maranas 2003). The key point here is to effectively develop purchase orders (a sourcing plan) and distribute it to the suppliers and update the plan.

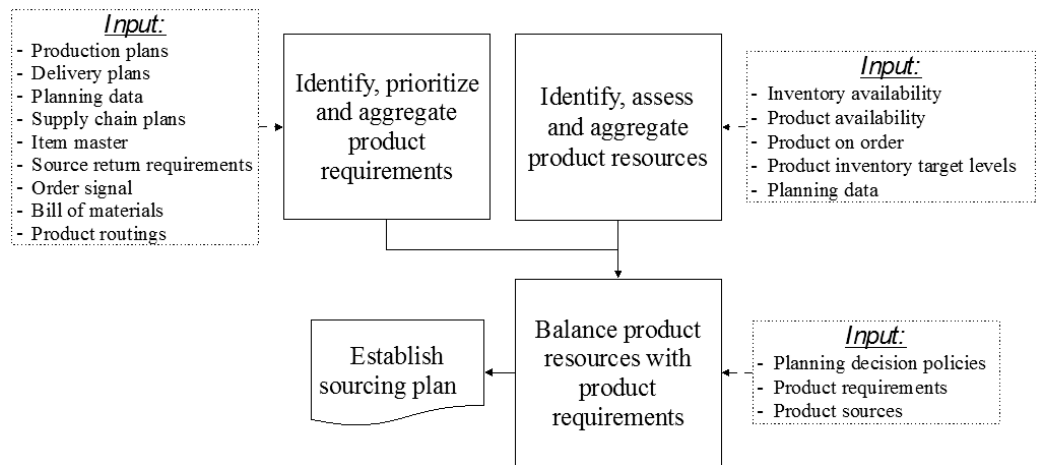

Figure 6. The sourcing plan as defined in the SCOR model (SCOR 2010).

\subsubsection{Setting the base for a planning framework}

As Soni and Kodali (2013) elaborate on, there is no coherence in the literature on what a framework is and what separates it from a model. In this thesis, the term framework is used for identifying actions for reaching a certain goal (Soni and Kodali 2013). A framework can be seen as a toolbox containing 'tools' for seeking solutions to existing problems. Planning is seen as the process for identifying goals and activities and means for achieving the goals. A planning framework is thus a toolbox containing tools for identifying activities and means for achieving certain goals. Jonsson et al. (2013) includes three concepts in SCP: a process, an organisation, and a planning system. The process includes steps of activities to perform in planning, the organisation details who should participate in decision making, and planning systems with regard to the IT systems needed to facilitate planning. These concepts can be seen as the tools needed in SCP. 
Tavares Thomé et al. (2012) synthesised the literature for identifying important concepts (tools) in sales and operations planning (S\&OP). They summarised it as identifying the context of planning, the input, structure and processes (with meetings, organisation, IT systems, key performance indicators), and outcomes, shown in Figure 7. They also illustrate how S\&OP is affected by and affects the business plan, strategic plan, and operations. This is in line with the concepts of SCP identified by Jonsson et al. (2013) with the addition of context, input, outcome, and key performance indicators (KPI). These are also relevant for SCP. As Jonsson and Holmström (2016) elaborate on, SCP literature often lacks in identifying outcomes. If the outcome is unclear it also means that the input is unclear, as the outcome controls what input is needed. The KPI is important for controlling the performance and steering the decision making. Figure 7 can thus be seen as a planning framework and suits as a point of departure for developing the SCP framework in this thesis.

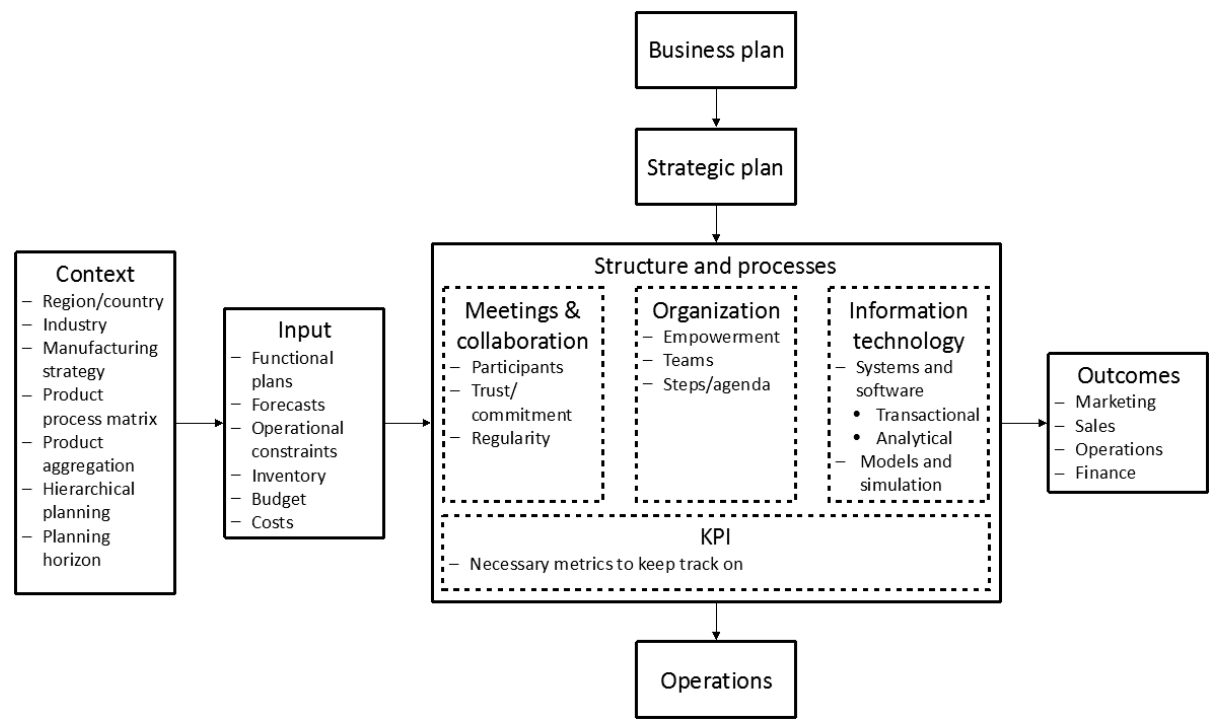

Figure 7. The synthesis of S\&OP by Tavares Thomé et al. (2012).

\subsection{Performance measurement}

\subsubsection{Performance measurement in general}

Larson and Halldorsson (2004) discussed that the difference between SCM and logistics are strategic vs. operational aspects. SCM concerns setting up the strategic relationships, while logistics concerns the actual operational transaction of goods. Most metrics suggested for measuring the performance of the supply chain concern aspects that would be ascribed to logistics (cf. Brewer and Speh 2000, Gunasekaran et al. 2001). These metrics concern factors like lead times, order fulfilment, and costs. One way to assess supply chain performance could be through measurement of its logistical performance. The focus on the time and cost is understandable as implementing SCM aims to reduce lead times, satisfy the customer, reduce costs, and to reduce inventory (Houlihan 1985, Lambert and Cooper 2000, Stevens 1986). 
SCM and logistics measurement literature distinguishes between financial and non-financial metrics. One of the proponents of the former is Christopher (2011). He proposes that logistic performance among others should be measured based on the return on investment. A problem is that many soft parameters like a good relationship with the customer cannot be quantified easily. These parameters can however still impact the success of a supply chain and need to be monitored (Brewer and Speh 2000).

In order to effectively control the processes in a supply chain it is necessary to develop and maintain a system for keeping track of the measurement information (Gunasekaran et al. 2004). Despite the necessity of a measurement system, Fawcett and Cooper (1998) report on a lack of a proper systematic procedure for gathering the necessary measurement information. In the Performance Measurement System (PMS) proposed by Gunasekaran et al. (2004) different metrics are allocated based on whether they belong to plan, source, make, or deliver processes. They also allocate the metrics based on which managers they are suited for namely strategic, tactical, or operational managers.

Another perspective highlighted by Bai and Sarkis (2012) is that even though there are a large number of performance measurement systems, very few of them take the logistic and SCM aspects into consideration. They develop a framework for assessing the results of current measurements based on the outcome of logistics. According to Bai and Sarkis (2012) this framework can be used to analyse which metrics are most critical, depending on the logistics outcomes desired. Thakkar (2012) is coherent in the view that supply chain performance is overlooked in many PMS. He also argues that much focus is put on measuring internal process performance. The supply chain operations reference model (the SCOR model) is one PMS that focuses on the whole supply chain. One of the key components of a successful supply chain PMS is to align processes among the members and find metrics that measures the whole chain and not a single member.

\section{The SCOR model}

One PMS that is available for use by all industries is the SCOR model previously endorsed by the scupply chain council (SCC) but is now endorsed by APICS (APICS 2015). The SCOR model consists of three parts: business process re-engineering, benchmarking, and best practice analysis. The business process re-engineering part consists of predefined process specifications in a hierarchical structure in three different levels. These processes can be used to map the current state of the supply chain to identify problematic areas and to map the future state of the supply chain.

Moreover, the benchmarking part is standardised and consists of predefined metrics (see Table 1) also hierarchically structured. These can be used to measure the supply chain in terms of how well the supply chain performs in terms of reliability, responsiveness, agility, cost, and assets. An industry benchmark can be created by submitting anonymous measurement results to APICS. The SCOR model also incorporates a number of best practices that can be used in order to identify ideas for how to resolve common supply chain issues. 
There is in total 11 KPIs in the SCOR model used to measure e.g. a supply chain's reliability. The supply chain reliability attribute is customer oriented and describes how reliable the supply chain is in fulfilling the customer's requirements. It can be assessed by measuring the level 1 metric perfect order fulfilment. This KPI consists of level 2 metrics for measuring how many orders are delivered on time, at the right location, with the right quantity of products, the right documents, and in the right quality. What is 'right' is mutually defined by the customer and the supplier.

Table 1. The SCOR model's KPIs.

\begin{tabular}{|c|c|c|}
\hline & Attribute & Strategic metric (level 1, KPI) \\
\hline 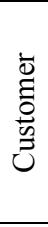 & $\begin{array}{l}\text { Reliability } \\
\text { Responsiveness } \\
\text { Agility }\end{array}$ & $\begin{array}{l}\text { RL.1.1 Perfect order fulfilment } \\
\text { RS.1.1 Order fulfilment cycle time } \\
\text { AG.1.1 Upside supply chain flexibility } \\
\text { AG.1.2 Upside supply chain adaptability } \\
\text { AG.1.3 Downside supply chain adaptability } \\
\text { AG.1.4 Overall value at risk (VaR) }\end{array}$ \\
\hline 를 & $\begin{array}{l}\text { Cost } \\
\text { Assets }\end{array}$ & $\begin{array}{l}\text { CO.1.1 Total supply chain management cost } \\
\text { CO.1.2 Cost of goods sold } \\
\text { AM.1.1 Cash-to-cash cycle time } \\
\text { AM.1.2 Return on supply chain fixed assets } \\
\text { AM.1.3 Return on working capital }\end{array}$ \\
\hline
\end{tabular}

There are several benefits of using the SCOR model. Cohen and Roussel (2005) point out the SCOR model's ability to generate benefits in the three modelling levels. In level 1, where the outline of the whole supply chain can be modelled, benefits are usually found as synergies between business units and in an agreement on performance priorities. Benefits in the form of supply chain simplification and a shared vision of supply chain processes are found in the second level. The third level with the processes well defined, holds benefits in the form of best practices and predefined metrics. Bolstroff and Rosenbaum (2007) report the financial benefits of using the SCOR model in more than 60 real projects. They claim the results to be consistent across all projects and in summary, the projects improved the operating income by $3 \%$, reduced information technology operating expenses, and showed an ongoing profit improvement of $0.5-1 \%$ per year. Xia (2006) points out better communication and planning collaboration with suppliers as two other benefits of using the SCOR model. However, it has been identified that the SCOR model needs to be adapted to different environmental settings in order to reap the benefit. Examples exist where the model has been adapted to after-sales industries (Legnani 2011) and healthcare industries (di Martinelly et al. 2009).

\subsubsection{Performance measurement in construction}

As for many other industries the ultimate task for a construction company is to produce products according to a customer's specific requirements regarding cost, time, and quality. This is what some authors call the 'iron triangle' (Toor and Ogunlana 2010). Frödell et al. (2008) identified that construction clients regarded a project as successful if it is kept within the budget, finished on time, and is delivered with a high quality. However, it is difficult to be excellent in high quality and to perform well in terms of both cost and time (Atkinson 1999). Many papers focus on the quality aspect of the iron triangle (Kagioglou et al. 2001, 
Wong and Fung 1999). Logistics can be a facilitator for improving both cost and time in the iron triangle but also quality. There is a major interest in developing measurements for cost and time in construction and in defining why delays and cost overruns occur (Fang and $\mathrm{Ng}$ 2011, González et al. 2014, Hwang et al. 2009).

It is often claimed that the temporary nature and other uncertainties in the industry has a negative impact on the cost and time (Son and Rojas 2011). A considerable portion of the outset-phase is devoted to building up the organisation and the supply chain and to build up trust. If the supply chain and the organisational structure already exist from the beginning, less time has to be spent on this phase. Plus, the risk of conflicts due to lack of trust will probably decline (Chua and Kog 1999). This can have a positive effect on cost and time but also on safety.

As illustrated in Figure 1, a construction project can be subdivided into a supply process and a construction process. According to Kagioglou et al. (2001), much focus and attention from academia on performance measurement is laid on the construction process. However, in order to reduce e.g. lead times and costs it is important to also measure the supply process.

When it comes to the supply process it is important to measure supplier performance, material quality, lead times, inventory levels, etc. Voordijk (2010) analyses what trade-offs exist in the distribution costs of construction materials. Among many things, he analyses how different order quantities affect the total cost and suggests a model for measuring the physical distribution cost. Vrijhoef and Koskela (2000) argued that the total cost could increase if material is purchased solely based on low cost parameters. This is also true for the time and quality aspects in the 'iron triangle'. If deficiencies in the material quality are not discovered in time, extensive reworks could be a necessity if the materials are assembled (Vrijhoef and Koskela 2000). It is also important to measure soft parameters in the supply process such as how well a relationship between suppliers and contractors works (Amornsawadwatana 2011, Dubois and Gadde 2000).

Regarding the construction process, many measurements often concern waste levels, subcontractor performance, safety, assembly times, etc. Subcontractors accomplish a great deal of the work performed on the construction site. Karim et al. (2006) report that about $90 \%$ of the work performed on-site is allocated to subcontractors. Evaluating subcontractors work and the relationship with the subcontractors thus becomes important (Yeung et al. 2008). Karim et al. (2006) also highlight that a non-functioning relationship with the subcontractors can have a negative impact on reworks as communication and information sharing is hampered and can lead to non-updated wrong drawings being distributed. Keeping track on the amount of reworks is important as cost and time overruns can otherwise become a reality. Ling and Peh (2005) identified a total of 55 different performance metrics for the construction process ranging from customer satisfaction to waste management. Even if reworks and waste are two important elements, they concluded that the waste levels were the most infrequent performance element after employee turnovers to be measured among contractors. 
Other important aspects of the construction process are the planning process and how satisfied the customer is. From the client perspective it is important to measure the level of satisfaction (Chan and Chan 2004, Yeung et al. 2008) and how many defects the building object is tainted with. Other aspects are if the project is ended within the agreed time, budget, and quality frames (Radujković et al. 2010). Gidado (2004) highlighted the fact that proper planning procedures have a positive impact on time aspects. It could be argued that even the client should be interested in planning abilities for better information about the project progress. Aspects to be borne in mind when developing construction measurements include how often, to what extent, and where in the planning process the subcontractors and suppliers enter as this affects their possibilities to contribute in the planning process (Kelsey et al. 2001).

\subsection{Synthesis and re-visiting the scope}

This section aims at synthesising the frame of references. The purpose of the thesis is to develop a SCP framework for construction. As described in section 2.3.2, Tavares Thomé et al. (2012) can be used as a basis for developing the SCP framework for construction. This includes identifying context, input, structure and processes, and the outcome. The context is given in this thesis and includes design-build, on-site production, new construction, Sweden, house-building. The structure and process includes organisation, process, and KPI. Hence the formulation of the last three research objectives of this thesis:

\section{Objective 2. Develop a SCP process}

Objective 3. Develop a SCP organisation

\section{Objective 4. Identify performance measurements}

The SCP process will include the outcome of SCP, the necessary input, and a process structure describing important activities in producing the SCP outcome. The focus in this thesis is on the supply-related aspects of SCP and construction planning, as little attention has been given to this earlier. One of the outcomes of the pre-construction planning is a purchase plan and a material delivery schedule for the whole project, as illustrated in Figure 2. This is in line with the task of developing a material requirement plan in mid-term SCP. Both concerns identifying what materials are needed and when. The SCOR process in Figure 6 can thus be used as a basis for developing the SCP process as the focus in the SCOR process is on establishing a material sourcing plan.

The suggested SCP organisation includes the necessary meetings, participants, and IT tools and acts as a means to integrate the main contractor, subcontractors, and suppliers. It is often discussed how important it is to involve subcontractors in the planning process. As much of the work is outsourced it also means that subcontractors and suppliers should be involved in developing the material delivery schedule because and thus improve coordination. However, subcontractors and suppliers are seldom involved in planning the project. If they are not involved in project planning and construction planning it also means that they are not 
involved in the material delivery scheduling. It is therefore important to identify how they should be involved in SCP in construction.

The last objective suggests a number of important SCP-related KPIs to keep track of. The KPIs presented in Table 1 are used as a basis. The literature on performance measurement in construction has an overweight of client-related measurements. Supply chain related performance measurement is scarce. It is however important to also measure the supply chain performance as it can also affect the customer. A low material delivery reliability can delay the construction project resulting in consequences for the client.

It is not common to talk about SCP in construction. Tserng et al. (2006) is one of the few papers on SCP in construction, focusing on the supply process from a supplier perspective. The perspective in this thesis is on the integration of the construction process and the supply process as depicted in Figure 1. The focus is thus on a project level in both the preconstruction phase and the on-site phase. Figure 8 illustrates the different phases in planning in construction and how they are related to the different levels of SCP.

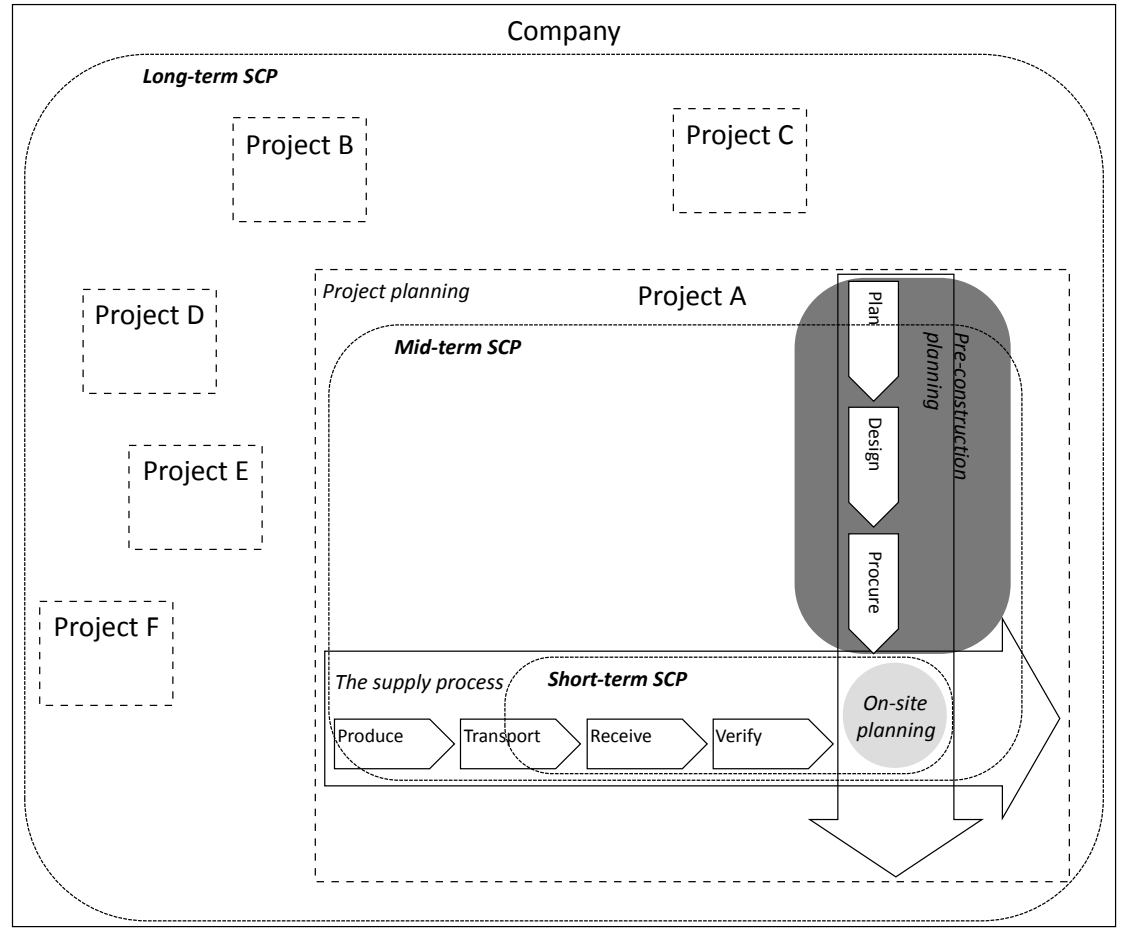

Figure 8. Illustrating the connection between SCP, construction planning, and projects.

The long-term perspective of SCP including supplier selection, production location, and product program is not something that is planned at the project level. These should be planned on a company-wide strategic level, but as described in section 2.1, supplier selection is carried out in different phases in construction today. On a strategic level, long-term agreements are entered into with suppliers and subcontractors, but these are not always used 
by project purchasers on a project level. The site manager also has the option to select some suppliers and subcontractors on his or her requests.

Mid-term SCP is connected to the pre-construction phase. It includes selecting suppliers and subcontractors that are to be included in a certain project. This means that with reference to the production time schedule the required material and the time which it is needed, are identified. Once this has been identified, suppliers and subcontractors can be sourced. Midterm SCP thus includes developing a material delivery schedule.

Looking at the on-site planning in construction, it can be realised that it concerns both a midterm perspective and a short-term perspective. An important part of material requirement plans is that they should be updated regularly. The update should be done with a planning horizon until the accumulated production lead time for the end-product is over. In construction, the accumulated production lead time for the end-product is equal to the planned construction project time. This means that material delivery schedules should be updated regularly but for the whole project. The short-term focus in on-site planning resembles the ordering of materials in SCP. This is about calling of materials on-site before the planned delivery date for the materials.

To summarise, the purpose of this thesis is to develop a SCP framework for construction that integrates the main contractor, subcontractors, and suppliers. The SCP framework will aid in developing the supply related plans on a pre-construction level and update them on-site. This framework is a means for integrating the supply process and construction process in Figure 1. 


\section{Research design}

The content presented in this section aims to describe the overall research design and explain why the chosen research methods were selected. It also aims to describe how each study included in the thesis was conducted. Finally, the author's statement is given.

\subsection{Research motivation}

The thesis is written at a department where the positivistic view is predominant. Guba and Lincoln (1994) describe positivism as: "position of naive realism, assuming an objective external reality upon which inquiry can converge to". This means that the truth is out there and can be determined via experimental methods (Popper 2005). However, even though a positivistic perspective serves well in gathering and testing objective data it falls short in describing why it happens. Knowledge is also seldom free of bias and subjective meanings. It can therefore make sense to even take an interpretive approach in understanding why things happen. Yin (2009) calls this perspective for a post-positivistic approach. With a positivistic standpoint the thesis strives to develop a normative framework for planning the supply chain but admits that interpretive input in developing the model is necessary.

Regarding research strategy, Meredith (1998) claims that developing theory and understanding about a "phenomenon" is best done through an explorative study. This is supported by Eisenhardt (1989), Sousa and Voss (2001), and Voss et al. (2002) who all argue for an explorative approach towards constructing a theory and developing an understanding when the "phenomenon" is relatively under-investigated. It can be argued that SCP in construction is "relatively under-investigated" (Tserng et al. 2006). Most papers are about supply chain management in construction without considering the planning part in terms of planning the supply chain. Either this means that the topic is of no interest for the construction community or that the topic is relatively under-investigated. The vast number of articles and reports (Agapiou et al. 1998, Akintoye et al. 2000, BIS 2013, Dainty et al. 2001b, Egan 1998, Vrijhoef and Koskela 2000) that stipulate SCM as the remedy to all problems in construction speaks for rejection of the first explanation. If SCM is important for construction, then it is time to also look at the planning part of SCM. This suggests that SCP in construction is an under-investigated topic. The thesis therefore provides knowledge about how important planning of the supply chain is and how it can be done in construction. This is done through a descriptive process of describing the current state of the industry and a normative process of developing the framework.

The word framework is a difficult word to define. As Soni and Kodali (2013) elaborate on, there is no coherence in the literature on what a framework is and what separates it from a 
model. In this thesis, framework is used for identifying what actions can be undertaken for a certain purpose (Soni and Kodali 2013). However, the meaning of a model is to guide entities (such as companies) to a better practice (like best practice). A model is therefore of a normative nature. A framework, on the other-hand, is more descriptive in nature as it contains 'tools' for seeking solutions to existing problems. The 'tools' in the SCP framework developed in this thesis include the process for describing planning procedures, suggested organisation of whom to include in planning, and KPIs to measure supply chain performance and guide the decision making.

\subsection{The research process}

The research process in this thesis is depicted in Figure 9. The initial idea with the project was to adapt the whole SCOR model to the characteristics of the construction industry. Two previous case studies called Inwall, see Nordqvist (2008), and Tornet, see Bengtsson and Gustad (2008), indicated that the model had to be adapted to the construction industry. Main reasons were that the SCOR model is developed for industries with long production runs and with no consideration of project production. Other reasons include the three different types of flows (material, labour, and equipment) identified in Figure 3, which SCOR does not consider. When it was time to adapt the 'Plan' process in the SCOR model, it was realised that further investigation than just adapting the process was necessary. Many of the problems such as low delivery reliability are effects of not including SCP in the overall project planning. It was necessary to investigate what problems exist and how SCP should be designed to address the problems. This gave input to look at SCP and how it should be designed in a construction context.

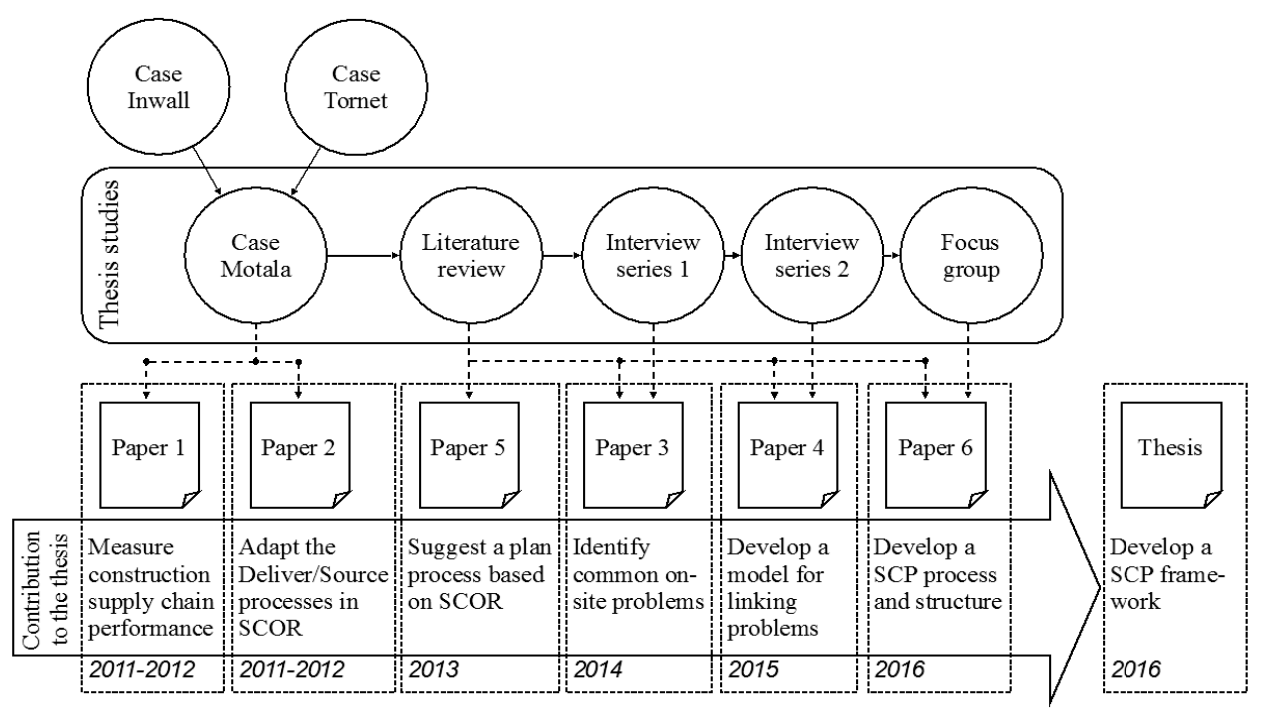

Figure 9. The research process with outputs.

The first case (Motala) started in 2010 focussed on measuring and studying the 'Deliver' process from the suppliers and the 'Source' process at the construction site. These two 
processes describe the material delivery activities at the suppliers' end and the sourcing process for construction materials on-site. The results indicated what needed to be adapted in these two processes. The author of this thesis was involved in the data gathering process during this stage but enrolled as a $\mathrm{PhD}$ student only during in the analysis phase in this stage. During the Motala case study measurements of the construction logistics were also made. This was done in order to get an understanding of the current situation of how the logistics works in the industry today. The measurement concerned supply chain reliability and responsiveness. The case study resulted in Papers 1 and 2.

The next step in the process was to adapt the planning process in the SCOR model. However, early on in the process, it was realised that the planning process would not be easy to adapt. First of all, what should the planning process contain? Secondly, who should be included in the planning process? In a first attempt, a literature study was performed to identify common on-site problems and a general conceptual analysis to investigate how a SCP process could be designed to cope with these problems. The results suggested a SCP process for the construction industry and this was presented in Paper 5. This process does not describe how it should be used. An organisational structure is therefore necessary and an in-depth study was initiated to develop a SCP framework containing both the processes and an organisational structure for developing the plan. It started with interview series 1 to identify new on-site problems, validate previously found problems, and see how SCP can facilitate in addressing the problems. This is presented in Paper 3. The next step was then to identify how the problems are inter-linked and how the on-site problems are dealt with today. This was done in interview series 2 which also included a validation of the results from interview series 1 . This resulted in a model for developing both inter-linkages between on-site problems and linkages to SCP levels. The model is presented in Paper 4. The identified on-site problems together with the model to inter-link them, gave input to the final study. This study included a series of focus groups to develop a SCP process and suggest an organisation for SCP to meet the characteristics of the construction industry. This is presented in Paper 6.

The thesis as such aims at developing the SCP framework by combining the measurements from the case study and the process and organisation from the focus group to form the SCP framework. The final stage of the study is to use logical reasoning to find out how the logistical problems identified in the literature review study and interview study can be addressed by the SCP framework. The conclusion drawn in this thesis, the SCP framework and the explanation on how the problems can be addressed, resembles a conceptual model as described by Meredith (1993). The description part comprises description of SCP in the construction context and the logistical problems, which are the two main concepts discussed in the thesis. The explanation part includes description of how the SCP framework can address the logistical problems. This is where the thesis ends, and it does not provide further refinement and testing to check whether the SCP framework aids in eliminating the problems. The result does not fulfil the level of being a conceptual framework or a theory. But following Meredith's research cycle, a theory cannot be developed without first developing a conceptual model for further refinement into a theory. This thesis thus contributes as a starting point in the research cycle by suggesting a conceptual model that demonstrates how 
the SCP framework can be a facilitator for improving the construction industry by addressing common problems in logistics.

The studies presented above have resulted in six papers. Figure 10 illustrates how these papers are connected to each other and the objectives. The first objective can be described as a means of mapping the current state in construction when it comes to supply chain performance and the logistical problems that exist. This step is a descriptive process and Papers 1 to 4 illustrate the current situation when it comes to logistics in construction. Papers 1 and 2 take on the work with illustrating logistics in terms of measuring them (Paper 1 and 2 ) and how the logistic activities in a supply chain could be mapped (Paper 2). However, the main purpose of Papers 1 and 2 is not to describe the problems, as indicated by the dashed boxes in Figure 10. Instead, the objective of these two papers is to describe what KPIs are important measure for aiding in SCP. Measuring the logistics in a supply chain also reveals problems with the logistics (Paper 1).

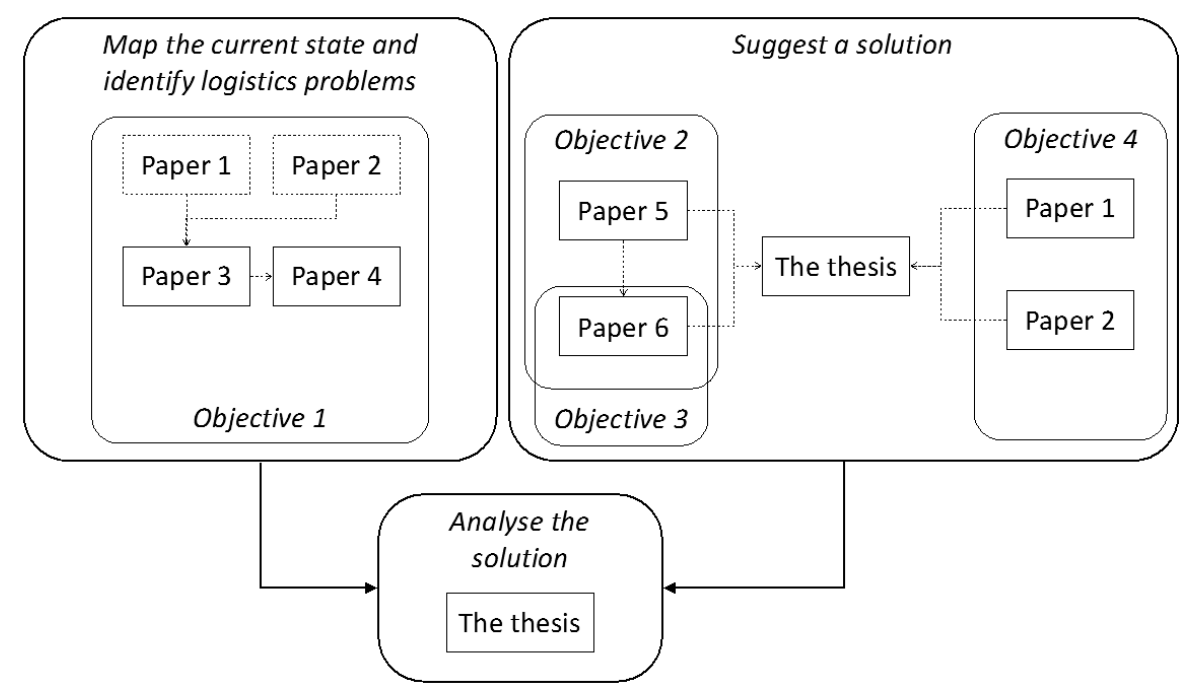

Figure 10. How each paper is connected to each objective.

Objectives 2 to 4 can be summarised as a means to find a solution to the identified problems. This is a normative process and concerns suggesting a solution to the identified problems in Papers 3 and 4. Papers 3 and 4 provide knowledge and understanding of how SCP could be a facilitator for addressing the problems in construction. This is of importance for developing the SCP framework. The actual framework development takes place in Papers 1, 2, 5, 6 and in this thesis. Papers 1 and 2 focus on the KPI component. Paper 5 suggests the overall normative planning process based on the SCOR model, while Paper 6 focuses on the structure of the planning procedure. However, Paper 6 also refines the overall process suggested in Paper 5 to better reflect the characteristics of the construction industry. The thesis as such analyses how the solution can address the identified problems by using the SCP framework. 


\subsection{Methodological approach}

The following sub-sections describe how each study was conducted. They describe why the method was chosen, how the data was gathered, analysed, and validated. The studies produced a total of six written papers, of which one has been published in a peer-reviewed academic journal (Paper 1), two are conference presentation (Paper 2 and 6), two are submitted to journals (Papers 3 and 4), while one paper is a working paper (Paper 5).

\subsubsection{The case study}

Theory has traditionally been developed by combining literature research findings with common sense and experiments (Eisenhardt 1989). However, the depth of understanding is then limited to what others have already written and what experimentally can be controlled. Many aspects within an organisational theory and a behavioural science cannot be experimented accurately. Glaser and Strauss (2006) therefore argued for developing theory based on understanding gained from observing the 'phenomenon' without being blinded by previous anticipations. This is however difficult and Eisenhardt (1989) and Yin (2009) suggest an approach where the phenomenon is observed in its natural setting but with an initial hypothesis to avoid what they call a 'fishing trip'. This approach is called case study research. Case study research is one of the most commonly used research methods in operations management (Voss et al. 2002) probably because of the richness in data and the depth of understanding.

Case study research has been used in the thesis as one of two methods to fulfil research objective 1 to map the current state. Getting an understanding in logistical problems on-site and measuring the logistic performance on-site can be translated into what and why questions. These are questions that suit a case study approach (Yin 2009) as they focus more on understanding what and why things occur. The performance part is a what question and the logistics problem is a what and why question. A case study research can therefore be a valid method for fulfilling parts of objective 1 .

\section{Selecting a case}

Flick (2009) and Yin (2009) both argue that single case studies serve an important role in shaping hypothesis to test and build an understanding that can be tested in other cases later on. This is often called theoretical generalisation, where each case helps in either broadening or narrowing a theory domain. A single case study has been conducted in this thesis and presented in Paper 1 and Paper 2. A single case was chosen as logistical problems would also be identified via a literature review and an interview series. It is thus not necessary with multiple cases for generalisation reasons. A single case study was therefore seen as a sufficient approach.

Collaboration with a Swedish construction company was already established and a suitable case was identified by considering three criteria. (1) The case should be in the framework supplement phase as this is the phase where the most materials are delivered to the site. This is also the phase where most subcontractors enter the project leading to a large number of craftsmen and organisations sharing the same site. (2) The budgeted cost should be in the range of $€ 1-10$ million, which is considered to be a medium-sized project. According to the 
contact person at the case company larger projects seldom experience the logistical problems as the medium sized projects do. (3) Finally, the case should be within geographical proximity for the researcher. This enables the researcher to visit the site when something of interest for the researcher happens. Another aspect considered when selecting the case was that the site manager and the construction supervisors should be open-minded in assisting the researcher. This facilitates the work of gathering necessary data as the openness in attitude is propagated to the craftsmen.

\section{Data gathering}

To gather the necessary data two methods were used, site observations and a smaller survey. The direct observations were done in order to measure the supply chain reliability. After discussion with the case company representatives it was decided that all kinds of material should be studied. For each incoming delivery, a form was used to note the date, time, item delivered, quantity (number of pallets), received documents, delivery place, and condition. After analysing the actual delivery with the order documents it could be determined if the items were perfectly delivered. In order to verify the findings and also to extend the set of data with more observations, the responsible craftsmen for managing incoming deliveries were asked to fill out a form after each delivery. The form consisted of the same observation points as for the researcher. However, some samples were taken to check that the craftsmen performed the tracking in the same manner as the researcher. Except from this quantitative research, notable qualitative insights were also gathered on how a late delivery, for instance, affects the construction site.

The measurement of responsiveness of the supply chain started with developing an as-is map in order to analyse the activities conducted by the craftsmen. This was also the basis for the adaptations suggested. A regular stopwatch was used to measure the time spent on each activity. Measurements were also verified by interviewing the site manager and the craftsmen. In this way they could verify if the times were considered representative or not.

\section{Analysis}

The measurements were stored in an Excel file for future analysis. In this file, the measurements could be displayed on different aggregation levels. The measurements could be presented at the project level, supplier level, and a transporter level. In this way it could be analysed if a certain supplier outperformed other suppliers. It could also be analysed if a certain transporter was to blame for any delivery failures. Finally, the measurements were compared with information from the SCC to see how the construction suppliers performed in comparison with other types of suppliers.

A case study diary with notes about activities and problems was developed. These notes contained information about what activities were performed and why, together with the time and date, etc. This information was then classified into 'activities'. In this manner, a conceptual map of what the craftsmen do in a certain process could be drawn. This map was then compared with the activities and the structure emphasised in the SCOR model. This brought forth similarities and differences between how processes were performed on the construction site and how the SCOR model expects the processes to be performed. In order to 
verify the findings, results were shown to the site manager. If the activities were 'abnormal', revisions had to be done according to the information from the site manager. The similarities and differences observed between the SCOR model and the activities on-site were suggested as necessary adaptions.

\section{Validity}

Yin (2009) describes three different types of validities to consider when doing a case study: construct, internal, and external. Stuart et al. (2002) also mentioned the importance of reliability through case protocols and case databases. The case study has been protocoled and all information like notes, measurements data, etc. are stored in databases.

It is difficult to verify if construct validity and confirmability has been achieved. Supply chain performance could mean many things. Were the right measurement and the right level of aggregation chosen? This cannot easily be answered as another performance metric could be chosen for measuring other aspects of supply chain performance. A 'perfect' delivery is in this case considered to be on-time, in correct amount, with the right documents, at the right place, and in the right condition. Construct validity can then be considered to be achieved if these elements are measured and are well-documented in the SCOR model.

The observations and measurements have been conducted by two researchers and the results have always been discussed with the site manager to increase internal validity. External validity is not the main priority here as it is a single case study and the focus is on identifying KPIs and logistical problems. However, the findings from this study have been tested in subsequent studies to increase validity. Both papers from this study have been authored by more than one researcher. This has led to constant discussion about the research process and the findings, which in turn has encouraged the author to embrace new perspectives and ideas when discussing the process. These are all means of improving the reliability.

\subsubsection{The literature review}

A literature review is an important part in research in order to shape the scope of the research and find gaps (Croom 2009). However, the literature review can also be used as a data gathering method. The first perspective is often called a traditional review while the latter one is called a systematic review (Cronin et al. 2008, Jesson et al. 2011). The structured systematic literature review tries to identify all relevant literature based on predefined search criteria. It is therefore not an ad hoc scoping method. Jesson et al. (2011) presented a procedure for a structured review that started with identifying the scope and planning the review. The planning contains identifying the search keywords and sources to search within. It is important to develop well-defined research questions both concerning the planning and the scope. There is a risk that the literature review becomes a 'fishing trip' without a clear purpose and research questions. However, a traditional review can aid in shaping the research questions (Croom 2009).

The literature review approach in this thesis study resembles the systematic approach. The method was utilised in order to identify common logistics problems and planning problems. 
Initial understanding for the research area already existed as the case study had already been conducted.

\section{Search criteria}

As previous knowledge already existed, it was quite clear which search terms should be used. They are presented in Table 2 together with the approach undertaken. Search criteria used is also presented in Table 2. Main sources were the papers listed in the Academic Search Premier, Business Source Premier, Scopus, and Web of Knowledge databases. The four different search terms yield several different type of papers concerning SCM, planning, and problems. The time span was set to 1980-2015 in order to reduce the number of papers. Year 1980 was a suitable lower limit as most of the construction papers concerning SCM are published in the 1990's and later.

Before starting the review certain journals and research subjects were selected to avoid papers from non-relevant journals and fields like medicine. All relevant papers were stored by title in an Excel spreadsheet. These 1000 titles were scanned to identify duplicates and 'non-interesting' papers that did not suit the purpose of the study. This yielded 100 potentially interesting papers. The second step was to read through the abstract of these papers to eliminate papers that did not fulfil the purpose. In total 29 papers were selected for further reading.

Table 2. Search data for the literature review.

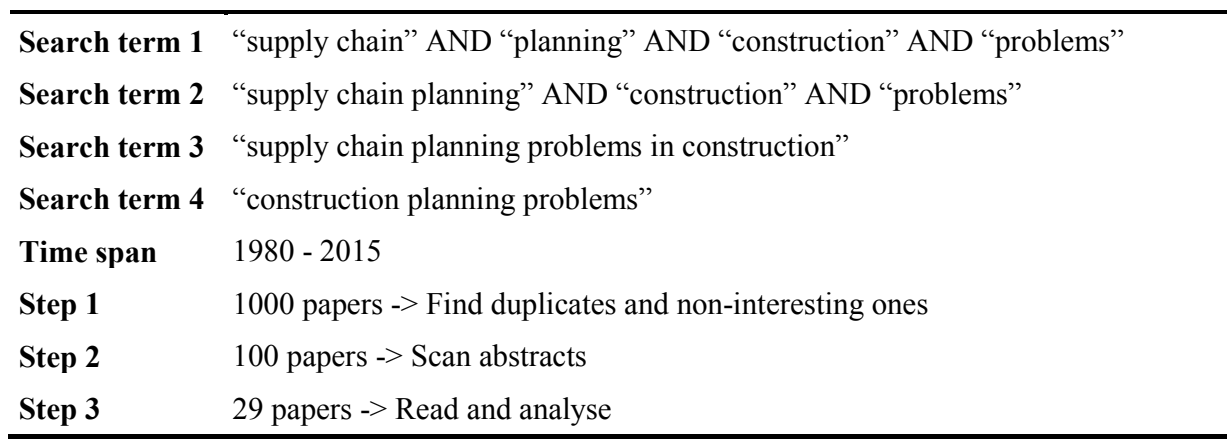

\section{Analysis and validity}

The analytical process used in the literature review is thematic analysis (Flick 2009). This is the same analytical method as the one used in the first interview series and is further discussed in the interview series section. Concerning validity, the literature review was used to get a broader understanding for SCM, planning, and logistical problems in construction. The grouping of problems from the literature review were later validated via the interview series but also the focus group study. This is often called a methodological triangulation (Yin 2009).

\subsubsection{The interview series}

There are several types of interviews and ways of conducting interviews. Flick (2009) describes the problem-centred interview as a useful method for building theory by probing a 
topic centred around a certain problem. It is easier for respondents to come forward with input if the discussion is based on common problems that they experience. Problem centric interviews are suitable when the respondent is an 'expert' (Flick 2009). Interviews in general are a useful method for both broadening and deepening the knowledge about a topic (Bryman and Bell 2015). Broadening because the respondent might give new input and deepening because he or she can describe why certain things are the way they are. Yin (2009) suggest a semi-structured approach for conducting an interview because a risk with structured interviews is that the interviewer gets too dependent on the interview guide and forgets to listen to alternative ideas.

The interview series conducted in this thesis study was two-fold. Both interview series consisted of semi-structured problem oriented interviews with experts. While the first series focused on identifying logistical problems on-site and planning problems, the second one focused on validating the problems and trying to find linkages between the problems. Semistructured problem oriented interviews with experts are a suitable method as problems were already found through observations and the literature review, but not by interviewing experts that have to deal with the problems.

\section{Selecting respondents}

Site managers from different construction projects were considered as experts in this series. Site managers have to deal with logistical problems and planning on a daily basis. Problems arising from earlier planning or from activities in the supply chain affect the construction site. The site manager then sees the effect of these problems. However, project managers and purchasers were also seen as important experts to interview based on their role in the supply chain. Respondents to the interview series were gathered by contacting construction companies that were collaborating with the research group. By describing the reason for the interview and what kind of skills the respondent should have, a total of eleven respondents could be identified. Skills required include at least five years of experience, working experience with design-build projects, and experience with small to large projects.

During the second interview series it emerged that more purchasers and suppliers had to be interviewed about the issue. Three site managers, three supplier representatives, three project purchasers, and three central purchasers were interviewed. They were selected by contacting construction companies collaborating with the research group. The site managers were first selected by identifying projects that experience the common problems. Purchasers and suppliers were selected through the site managers.

\section{Data gathering}

An interview guide based on the previous knowledge about the construction industry, logistics, and planning was developed for the first interview series. The guide included themes like how planning is conducted and the problems that commonly occur, how the logistics are working and common problems, how important planning is for logistics to work smoothly, etc. This guide was sent to the respondents one week before the scheduled interview. The interviews lasted about 1 to 2 hours and were recorded and later transcribed. The interviews and the literature discussed in the literature review were then coded in a 
qualitative research software. This was done two times as new topics were discovered as the coding process proceeded.

The second interview series was conducted by developing an interview guide based on the findings from Paper 3. The interviews focused on the identified problem areas and why the problems in these areas arise and what the effects are. The length of the interviews varied from two to three hours. A second interview was scheduled if the first one approached two hours in length. Some interviews were held via telephone. No recordings were taken but extensive notes were recorded.

\section{Analysis}

The general analytic method applied for the first interview series and the literature review was thematic analysis (Braun and Clarke, 2006, Flick, 2009). First, the transcribed interviews and literature were carefully read in order to get the overall understanding for the data and the topic. Second, an initial code structure was developed based on the understanding gathered during the interviews and literature search. Notes during these steps helped in developing the initial code structure. The initial code structure was then used on the data. Third, the nature of the different codes made it possible to group them into different themes. The final step consisted of naming the different identified themes.

A content analysis was performed for the second interview series. Interviews for the same projects were sorted under the same spreadsheet in Excel. The interviews were then coded based on type of problem and the level of the SCP hierarchy they exist. The connections between problems were also drawn on a printed A2 version of the spreadsheets. The links were then summarised in three pictures for each project. These link-charts were then compared in order to find differences and similarities.

\section{Validity}

A means to achieve internal validity and credibility (Guba and Lincoln 1994) is via a summary feedback process, where the participants could comment the output of the study. Construct validity is ensured in the second interview series by designing the interview guide based on the previous findings from the case study, the literature review, and the first interview series. The findings from the interview series have been tested in the focus group study to ensure external validity. Recordings, transcriptions, and respondent database have been developed to ensure reliability.

\subsubsection{The focus group}

The advantage of a focus group interview compared to individual interviews is the opportunity to gather richer data (Flick 2009, Wibeck 2010). If one respondent describes a phenomenon in a focus group, the other has the potential to give opposing descriptions. This in turn can lead to a greater understanding among the respondents and provide new perspectives that would not have been possible in individual interviews. Focus groups can be used in the initial phase of a research project to gather input to shaping the hypothesis but also to verify findings from previous studies (Rodrigues et al. 2010). Bryman and Bell (2015: 525) discussed a number of disadvantages of utilising focus group studies. The main 
drawback is the lack of control. The moderator should not interfere much with the respondents and this lack of control can affect the quality of the data.

Focus group study was used in the thesis for two reasons: (1) to validate the problems identified via the case study, literature review, and the interview series. Wibeck (2010) argue that one of the reasons for choosing a focus group study is to validate previous findings. (2) to develop the structure of the SCP framework. All the respondents expressed their opinions on what is important for them when it comes to planning the logistics and material deliveries.

\section{Selecting respondents}

There are two different approaches when it comes to designing a focus group. The first one utilises several homogenous groups (Wibeck 2010), while the other one utilises one or several heterogeneous groups (Flick 2009). The type of research question should determine which approach to use. A homogenous approach can be valid if the goal of the focus group is to gather input from similar people and compare them with other groups. However, identifying what is 'homogenous' is difficult as depending on what perspective you study all groups can also be seen as heterogeneous groups (Flick 2009). Heterogeneous groups can increase the dynamics of the discussion with greater chance for opposing meanings.

In this study it was identified that a heterogeneous focus group best served the purpose. Supplier representatives, purchasers, and site managers were all invited to discuss why logistics problems occur and how the planning should be done to avoid problems. It was important that different perspectives on the problems and planning was introduced. Invitees were found by contacting companies that were collaborating with the research group and describing the purpose of the focus group. It was then possible to identify suitable respondents. Some invitees were selected based on the fact that they had been participating in other parts of the research project. Six invitees in total agreed to participate. This is in line with the recommendation by Wibeck (2010).

\section{Data gathering}

Two seminars were held with the same focus group, except from some replacements. A stimulus material (Flick 2009, Wibeck 2010) was sent to the participant before the first seminar that summarised the research project so far and the meaning of the focus group. Before the scheduled seminar a couple of discussion themes were developed with some clarifying questions. Each seminar had three discussion themes. Theme 1.1 concerned identifying logistical problems on-site and theme 1.2 was related to linking the problems. This was done by discussion but also by letting the respondents write down problems and place them in different figures depicting the problem areas. Theme 1.3 initiated the idea about how to design the structure. The respondents were asked to perform a home work where they tried to identify important input, output, and meetings to be included. Theme 2.1 focused on identifying important input and output in SCP in construction, while theme 2.2 discussed the structure of organisation and meetings, and theme 2.3 concerned the barriers with an integrating SCP framework. The seminars lasted five hours and were recorded and photos of pictures were taken. Two persons from the research group took notes while the third moderated the seminars. 


\section{Analysis}

Themes 1.1, 1.3, 2.1-2.3 were analysed by studying the content of the pictures and notes together with the recordings. This is what Wibeck (2010) referred to as content analysis rather than interaction analysis. It was not of interest to analyse why they differ in opinions, instead the focus was to identify what they discuss about. The topics that arose during the discussion were all written down in an analysis diary. The identified problems were compared with those identified previously to see if new problems were just old problems but with new names. The links in theme 1.2 were identified via an interaction analysis. It was not easy for the respondents to identify these links. Instead the interaction became more important. If one problem was mentioned and the discussion shifted over to another problem, then links exist between these problems. Theme 2.2 was also analysed by following the literature about SCP in conjunction with the characteristics of the structure identified in order to develop the structure. Summaries of the seminars were sent to the participants and they were asked to comment on the content.

\section{Validity}

There are a number of research quality aspects to consider when doing interviews and focus group studies according to Flick (2009), Rodrigues et al. (2010), and Yin (2009). When it comes to credibility, theoretical saturation is an important factor. However, in this study focus group was used for validation and for designing a conceptual model. Theoretical saturation is therefore not applicable. It would however be important with saturation when testing the model in future studies. Credibility was however achieved via the summary feedback process, where the participants can comment on the output of the study. Confirmability (or internal validity) was achieved via data gathering triangulation. The problems were identified both via a literature review and a series of interviews and also validated via a focus group study. This ensures confirmability. Transferability (or external validity/generalization) was not the main priority in theory building. However, multiple companies participated in the study and a heterogeneous focus group was utilised which improves the transferability. Finally, dependability (or reliability) was achieved by a rigorous documentation process from the literature review to the focus group study. All interviews are available in recorded format and all planning and data gathering activities were documented.

With regard to the issue of bias, (Hallowell and Gamatese 2010) suggested a number of bias aspects to be considered when carrying out a Delphi study. Even though their method is different from the ones presented in this paper, the discussion on bias is still valid. Collective unconscious is minimized as the participants are all able to discuss why they think a certain thing is important. Adherence to trends is therefore minimized. Neglect of probability and the von Restorff effect are a difficult aspect to cope with as worst case problems give a proportionally larger consideration and attention. It is therefore important to let everyone scrutinize the identified problems and discuss them together. The same goes with 'my side' bias and the 'recency effect' as a problem raised by one side can be questioned by the others even if it is quite a recent problem. When it comes to dominance, the moderator constantly asks for all participants' input to the discussed theme, including those participants who were more silent during the discussion. 


\subsection{Author's statement}

The main stakeholders in this project are the Development Fund of the Swedish Construction Industry (SBUF) and the research centre Brains and Bricks $\left(\mathrm{B}^{2}\right)$ with the Swedish construction company PEAB in the forefront. $\mathrm{B}^{2}$ is a research centre endorsed by Linköping University with participants representing the contractors and the clients. All studies in this thesis are conducted with the construction companies PEAB, JM, NCC, Skanska, and Arcona.

The first study (the Motala case) was undertaken by the author of this thesis, together with Glenn Gyllin when working towards a thesis for the Master's degree, and Maria Johansson and Fredrik Persson were the supervisors (Gyllin and Thunberg 2010). An earlier version of the findings was presented at Plan's forskning och tillämpningskonferens 2011 (Thunberg 2011) and has been revised into two separate papers (Paper 1 and 2) with the author's cosupervisor as the main author in one of them (Persson and Thunberg 2012, Thunberg and Persson 2014). In the Master's thesis work and in Paper 2, work was shared equally (conceptualising ideas and writing) between the authors. In Paper 1 most of the writing was done by the author of this thesis. In Paper 3 the author of the thesis was responsible for writing, data collection, and analysis. The two co-authors (Martin Rudberg and Tina Karrbom-Gustavsson) took part in conceptualising ideas and commenting on the written text. A new co-supervisor (Anna Fredriksson) was introduced to Paper 4 and she took part in conceptualising ideas, though the main writing, data gathering, and analysis was done by the thesis author. In Paper 5, the main supervisor (Martin Rudberg) took part in compiling the deemed changes to the Planning process and writing, although the author of the thesis was accountable for the entire compilation process and the literature review. For the final Paper 6 the author of the thesis was responsible for designing the focus group and moderating it, while the co-authors (Anna Fredriksson and Martin Rudberg) participated in the focus group by taking notes. Conceptualising ideas was undertaken by all authors but the author of the thesis was responsible for writing the main parts of the paper. 


\section{Research Findings}

This chapter starts with discussing the four objectives and how the different papers contribute towards fulfilling the four objectives. How the papers are connected to each objective is illustrated in Figure 10. The chapter ends with developing the SCP framework, i.e. fulfilling the purpose of the thesis.

\subsection{Identify common logistical problems and how they are linked}

It is mainly the literature review and the interview series that form the ground for fulfilling the identification part of objective 1. The results from these studies are presented in Paper 3. Paper 4 does provide important findings on how the problems are inter-linked and how SCP can be a facilitator for addressing the problems. Besides, Papers 1 and 2 provide important information about logistical problems such as low supply chain reliability and responsiveness. These issues of performance measurements are not treated here, but they will be discussed in section 4.4 .

It was identified in Paper 3 that the problems experienced on-site can be categorised as either material flow issues, internal company communication, project communication, or complexity. The material flow issues concern problems with low delivery reliability and other problems with the supply of materials. Internal company communication includes problems with sharing information and lack of familiarity with the project. This lack of familiarity and sharing information is also common among other project members and could together with a lack of trust also be seen as a project communication issue. The complexity issue includes different uncertainties that the construction project has to cope with and these include changing site layouts and client changes.

The identified problems are illustrated in Figure 11. The focus group study, which mainly focused on developing the process and suggesting an organisation, also included a session for validating the identified problems and grouping. The focus group study concluded that the identified problems and the description of the groups well describe the construction industry when it comes to logistics. They also promoted hidden costs, legal issues, and entrepreneurship as complexity issues to cope with. Hidden costs include the benefits of solutions to logistical problems and are hard to quantify in monetary terms. It is easier to see the costs of implementing the solution but not the benefits. Legal issues include problems like how different contract forms and laws affect the logistics. Different contract forms affect communication channels and the relationship between supplier and contractor. The entrepreneurship includes issues related to the nature of the project in construction industry 
with focus on one project at a time, fire-fighting mentality, and lack of standardised processes.

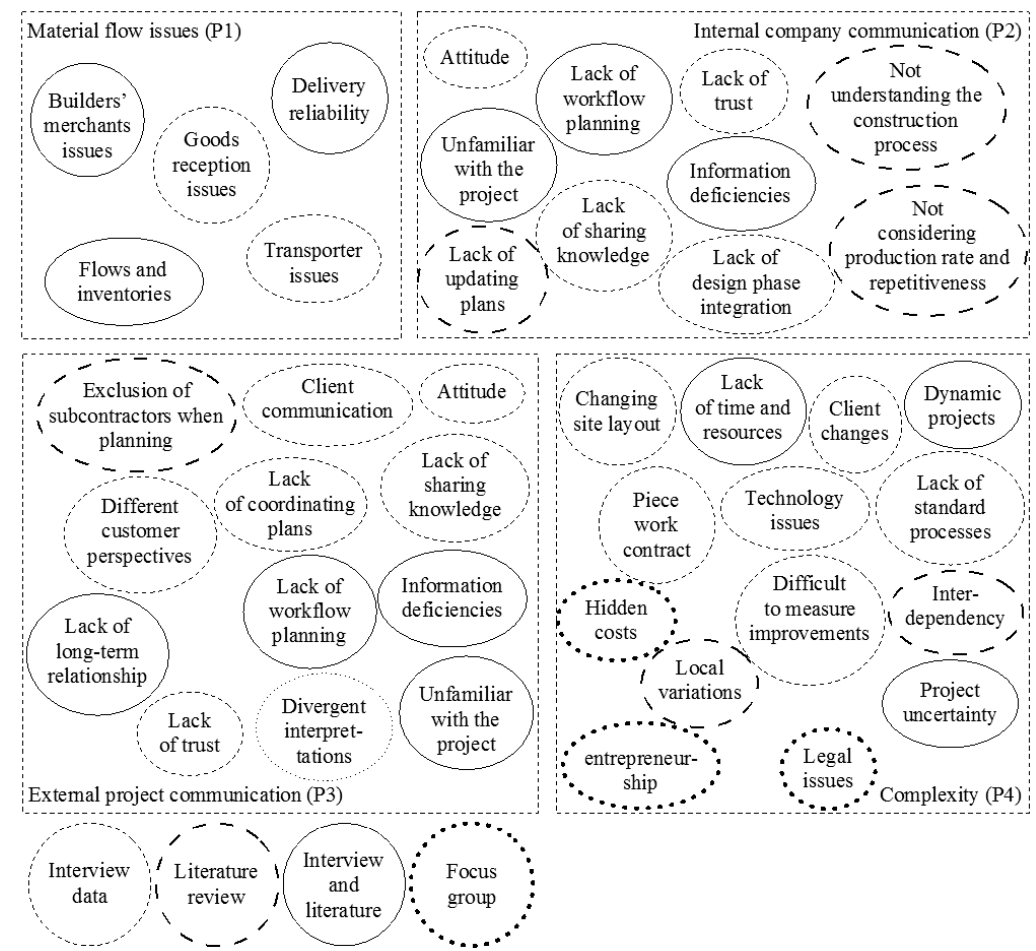

Figure 11. Grouping identified problems into problem categories.

The nature of the identified problem categories reflects different parts of a project. As illustrated in Figure 1, a construction project consists of a supply and a construction process. This means that the problem categories in Figure 11 can be associated with the construction process, or the supply process, or the intersection between them. It can be argued that material flow issues (P1) originate from the supply chain (illustrated in Figure 12), while internal company communication (P2) originates from the construction process. As the project includes both contractors and suppliers it can be argued that project communication (P3) issues originate from the lack of integrating the construction process and the supply process. The complexity (P4) issues are however present all the time and are coupled neither with the supply process nor with the construction process. 


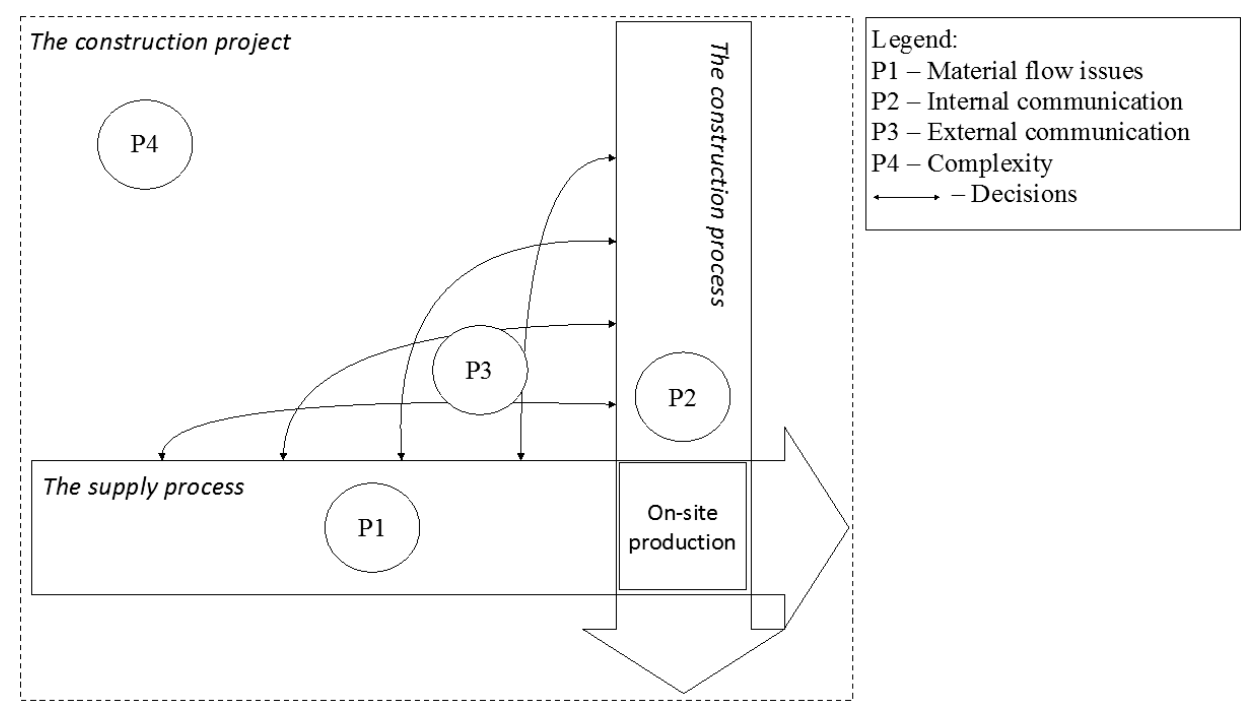

Figure 12. Positioning the identified problem categories in the construction project.

It was realised during the study in Paper 3 that there exists inter-linkages among many of the problems. Some of the problems in Figure 11 are of executional character while others are of plan development character. Executional problems concern, for instance, late deliveries (part of Delivery reliability) and the plan development problems concern issues such as developing the material delivery schedule or lack of coordinating plans. Paper 4 therefore focused on creating linkages among the problems and link the problems to either a mid-term company/pre-construction SCP level or the short-term on-site SCP level (discussed in section 2.5 ) or the executional level. This was done via a series of semi-structured interviews.

The result of the study in Paper 4 is a model for linking the problems and is presented in Figure 13. The model categorizes the problem as either material flow issue, company communication, project communication, or complexity. With this model it is possible to identify how problems are linked and at what level in the project or company they exist. Thus, it is possible to identify what problems would be dealt with at the company level and what problems should be dealt with at the project level. Linking the problems also illustrates how dealing with the company's strategic problems can have a positive effect on executional problems due to the linkages. Examples of developing linkages among the problems are also illustrated in Figure 13. It can be seen that a lack of standardised processes for logistics and temporary organisations are connected and can result in difficulties in sharing information. The lack of correct and updated information will affect the reliability of the material delivery schedule. If this plan is unreliable it will negatively affect the flow of materials resulting in several express deliveries and a lack of space on-site. 


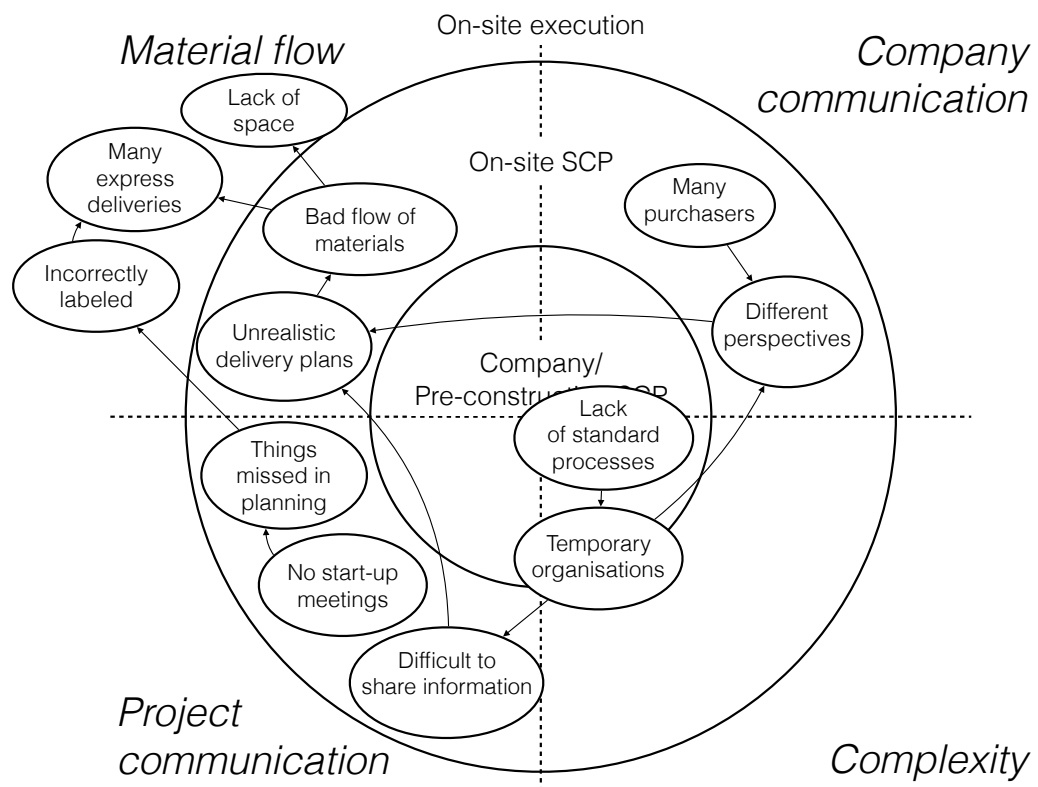

Figure 13. A model for linking the identified problems.

The planning levels illustrated in Figure 13 are results of the discussion in section 2.5 on what SCP is in construction. The model contributes to the thesis by explaining how SCP can be a facilitator for overcoming many of the identified problems. This is done by including different planning levels in the discussion on SCP in construction. The three different types of problems need to be addressed differently. This means that in construction, SCP is more than on-site planning. It includes parts of all three levels: (long-term) company, (mid-term) pre-construction, and (short-term) on-site. The focus in this thesis is on the mid-term and short-term. This indicates that the process and organisation needs to be separated into a preconstruction and an on-site process and organisation.

\subsection{Develop a supply chain planning process}

The process suggested for SCP in this thesis is based on the planning process in the SCOR model and is presented in Figure 6. This process is generic and summarises the planning of sourcing materials (i.e. finding the source of materials and acquisition) as balancing requirements with resources. This process suits discrete manufacturing industries with continuous material flows and pre-established supply chains. But in project industries, such as the construction industries, the supply chain has to be established at the same time as the material delivery schedule. A construction project also includes several subcontractors with their own material delivery schedules that have to be synchronised with the main contractor's material delivery schedule. The first step of developing a SCP process for construction focused on the sourcing part and was presented in Paper 5.

It was suggested in Paper 5 that the subcontractors' and the main contractor's sourcing of materials be distinguished. This separation is shown in Figure 14. The separation is suggested for better illustrating the myriad of contractors that have to establish a sourcing plan. Paper 5 
could also conclude that the balancing of the sourcing plans is missing. This means that each contractor makes their own material delivery schedule without balancing it with the other contractors. This is problematic as the project site is often limited in space for receiving and storing materials. If large deliveries are scheduled for the same date and time, it will affect the accessibility on-site. It also means that if changes are made to the production time schedule, it is difficult to update the different contractors' sourcing plans.

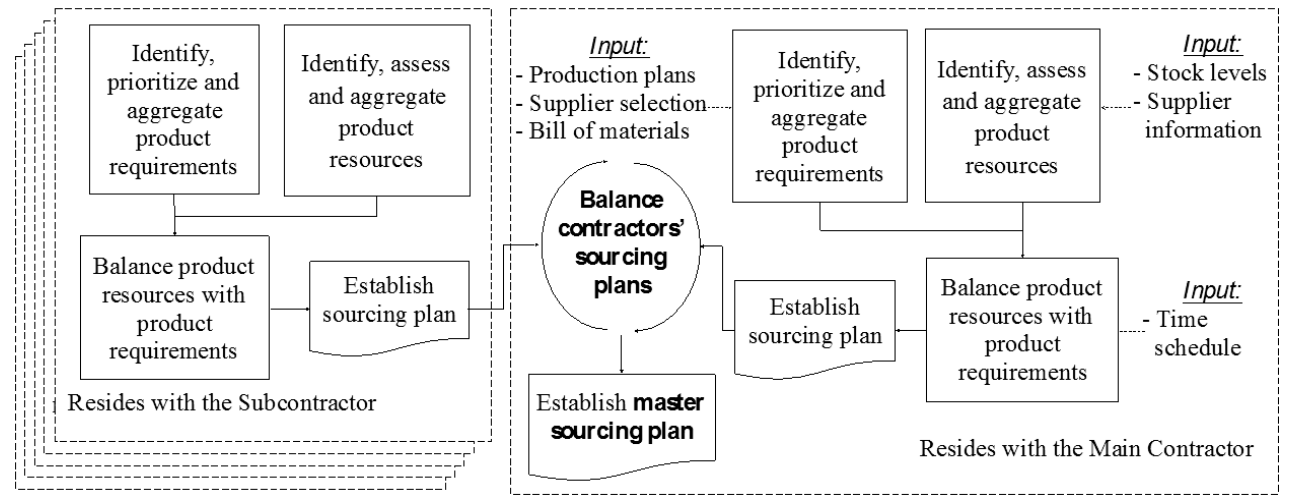

Figure 14. The SCP process for construction for the sourcing part.

The process illustrated in Figure 14 is broad in its description and lacks in details. It was identified during the focus group study presented in Paper 6 that this process was too general and needed to be further adapted to the construction industry. Figure 14 does not distinguish between planning in the pre-construction process or in the on-site process. Paper 6 suggested that a material delivery schedule should be established in the pre-construction process and be regularly updated on-site. Paper 6 also suggested the inclusion of inputs and outcomes other than those presented in Figure 14. The outcomes of SCP mentioned by the participants can be summarised as a material delivery schedule that is regularly updated, a plan of pre-conditions and prerequisites, what-if analyses, and a site layout plan including a material flow plan adapted to the different phases of the construction project and the construction site. The input to SCP mentioned by the participants can be summarised as: supplier lead times, supplier selections, room divisions, the production time schedule, standard activity times, bill of quantities, material selection, subcontractors' delivery schedules, time fences, and responsibilities.

This resulted in separating the SCP process in Figure 14 into one pre-construction process illustrated in Figure 15 and one on-site process illustrated in Figure 16. The pre-construction process focuses on developing the material delivery schedule and the other outcomes while the on-site process focuses on keeping them regularly updated. Figure 15 and Figure 16 are the two SCP processes suggested for inclusion in the SCP framework and will be discussed further in the subsequent sections below.

\subsubsection{The pre-construction planning process}

The pre-construction planning process starts in the pre-construction phase and is illustrated in Figure 15. It starts at the main contractor with identifying the bill of quantities and available 
resources. Drawings, trade selections, principal documents, and standard activity times are important inputs for identifying necessary resources. If no resources are available, it is necessary to outsource the production to subcontractors. The bill of quantity is developed on the basis of the drawings and principal documents. The bill of quantity is also an important input in developing the material forecast for the whole construction project. The bill of quantity, available resources, drawings, principal documents, and standard activity times are important inputs for developing the time-shifted production time schedule. The production time schedule presents what activities should be performed and when. Associated with these activities are the necessary materials. The production time schedule thus allows for an understanding of which materials are needed and when. Material requirements are identified based on this information. This represents the main contractor's material forecast for the project.

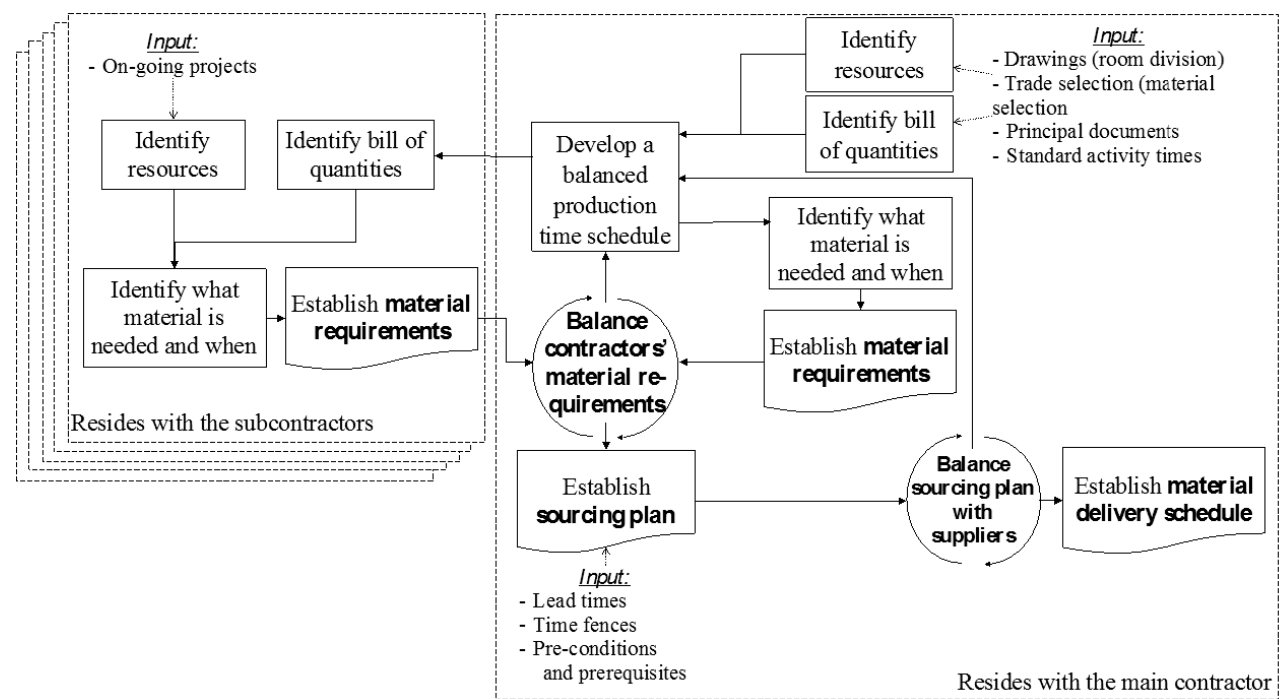

Figure 15. The pre-construction planning process.

The production time schedule is an important input to the subcontractors. Based on the production time schedule they could identify what materials they need and establish their own sourcing plan. It is important that the subcontractors also verify that they have the necessary resources available. Important input is therefore information about on-going projects. The material requirements from the different contractors represent each companies' material forecast for the project. The importance is to coordinate these needs and develop one sourcing plan for the whole project. This is done in the balancing activity with the contractors. This activity allows for a coordination with subcontractors, often discussed in the literature as lacking today.

The balancing activity will result in an overall sourcing plan. This includes from where the material will be sourced, when material orders need to be placed, and when the material will arrive. Hence the essential inputs include supplier lead times, time fences, pre-conditions and prerequisites. The pre-conditions and prerequisites also need to be identified and shared with 
the suppliers as part of the supplier balancing activity. This activity lets the key suppliers react to the sourcing plan and the production time schedule and acts as a way of coordinating the plans with the suppliers. If any problems are identified, the production time schedule could be updated. If no problems exist it will lead to a material delivery schedule stating when materials will arrive on-site.

The pre-construction process focus on developing the material delivery schedule and not the production time schedule. However, this schedule is important for the material delivery schedule and the subcontractors should be involved in developing the time schedule. How this balancing and involvement should be designed, has however not been discussed in this thesis. The process does however illustrate how the subcontractors' and the main contractor's material requirements should be balanced. This balancing activity aids in identifying activities scheduled at the same place, and update the production time schedule accordingly. Many of the activities reside with the main contractors for the sake of coordination. Splitting the process of balancing of the sourcing plan between contractors does not provide for a holistic perspective and coordination of the project.

\subsubsection{The on-site planning process}

The pre-construction process focuses on developing a material delivery schedule for the whole project. However, this material delivery schedule needs to be updated regularly. The closer to the execution of the plan the better the knowledge is about what can be executed and what needs to be postponed. It is thus necessary to have an on-site process where the material delivery schedule is updated regularly. This on-site planning process is illustrated in Figure 16.

The first thing to do is to identify what should be done and what can be done. The production time schedule, the material delivery schedule, and available resources are important inputs for these activities. Based on the production time schedule a list of activities to perform at a certain time can be developed. This constitutes the should be done part. The production time schedule is regularly checked against available resources and what other activities have been performed. This results in an understanding of what can be done. Comparing the should with can leads to the conclusion of what will be done and what materials are needed.

The subcontractors need the information of what will be done and what materials are needed for balancing with other on-going projects and updating their material requirements. The material requirements should then be balanced among the contractors for identifying problems with the schedule. An updated sourcing plan can be developed when no problems exist. The sourcing plan should also include pre-conditions and prerequisites and when orders should be placed. The main contractor should balance this sourcing plan with the key suppliers for finding collisions and update the material delivery schedule. 


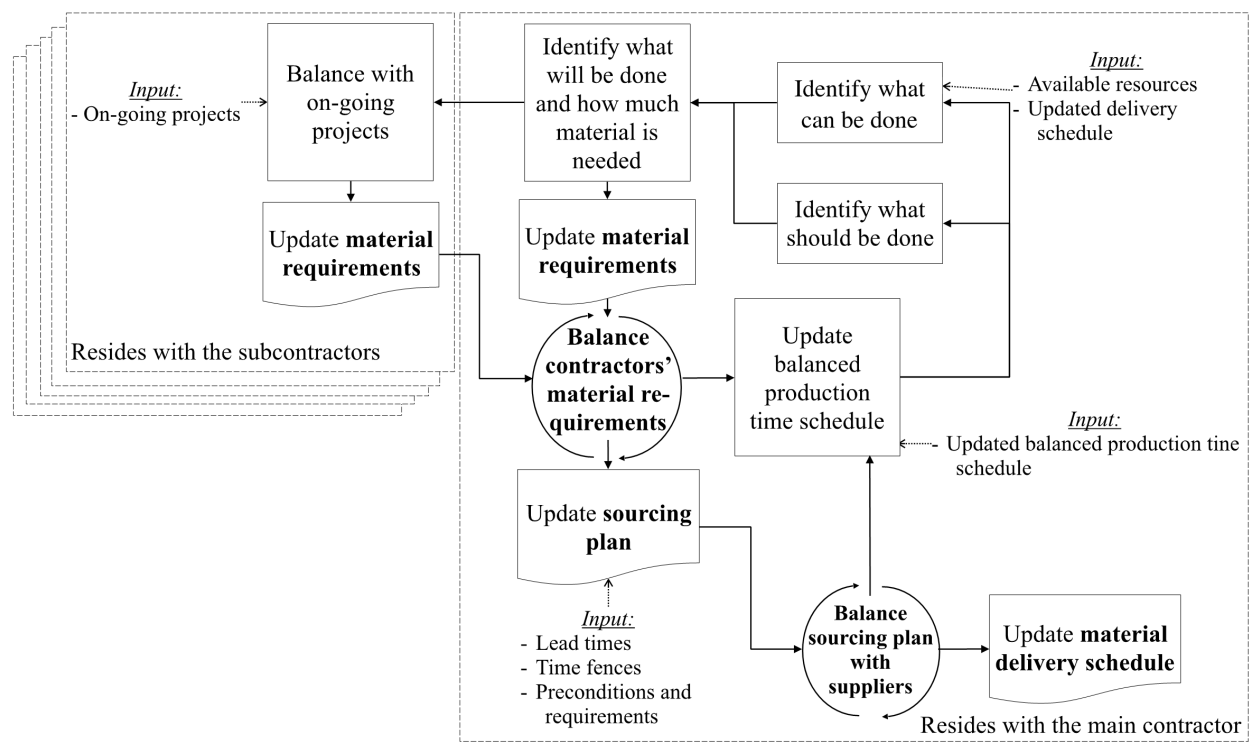

Figure 16. The on-site planning process.

\subsection{Developing a supply chain planning organisation}

The illustration of how planning in construction is conducted in a design-build contract presented in Figure 2 indicates that the material delivery schedule is developed in the preconstruction planning phase. This is also elaborated in the SCP process described in section 4.2. The material delivery schedule is often developed by the purchaser as part of the purchasing plan. However, as the schedule should be regularly updated on-site by on-site personnel it means that only including the purchaser in the development does not provide for an efficient process. This is also supported by e.g. Dainty et al. (2001b), and Gidado (2004) who claim that other project members such as suppliers and subcontractors should be involved in the planning process. The focus group study presented in Paper 6 aimed at developing an organisation to produce the outcomes of the process.

Four types of meetings were identified as being necessary to facilitate the process of developing a material delivery schedule in the pre-construction phase and updating it on-site. These are pre-construction subcontractor meetings, purchase meetings, weekly update meetings, and supplier start-up meetings. These meetings are summarised in Table 3. The first two meetings are held during the pre-construction SCP process illustrated in Figure 17, while the other two meetings are conducted during the on-site SCP process illustrated in Figure 18. The meetings are discussed below and describe what the agenda should include, who should participate, and what IT tools are necessary.

\subsubsection{Pre-construction subcontractor meeting}

This meeting should focus on balancing the material requirements among the contractors to develop the sourcing plan as illustrated in Figure 17. This includes identifying issues of production time schedule, supplier selection, lead times, time fences, pre-conditions and 
prerequisites. The meeting is a way to coordinate plans among contractors in the preconstruction phase itself. It is thus necessary that all subcontractors are selected and that the production time schedule is developed and distributed among the contractors. It is important that the subcontractors select all their suppliers and can share this supplier selection with the main contractor. The subcontractors should also share information about supplier lead times, time fences, pre-conditions and prerequisites that the main contractor needs during the meetings with the suppliers.

Table 3. The SCP organisation.

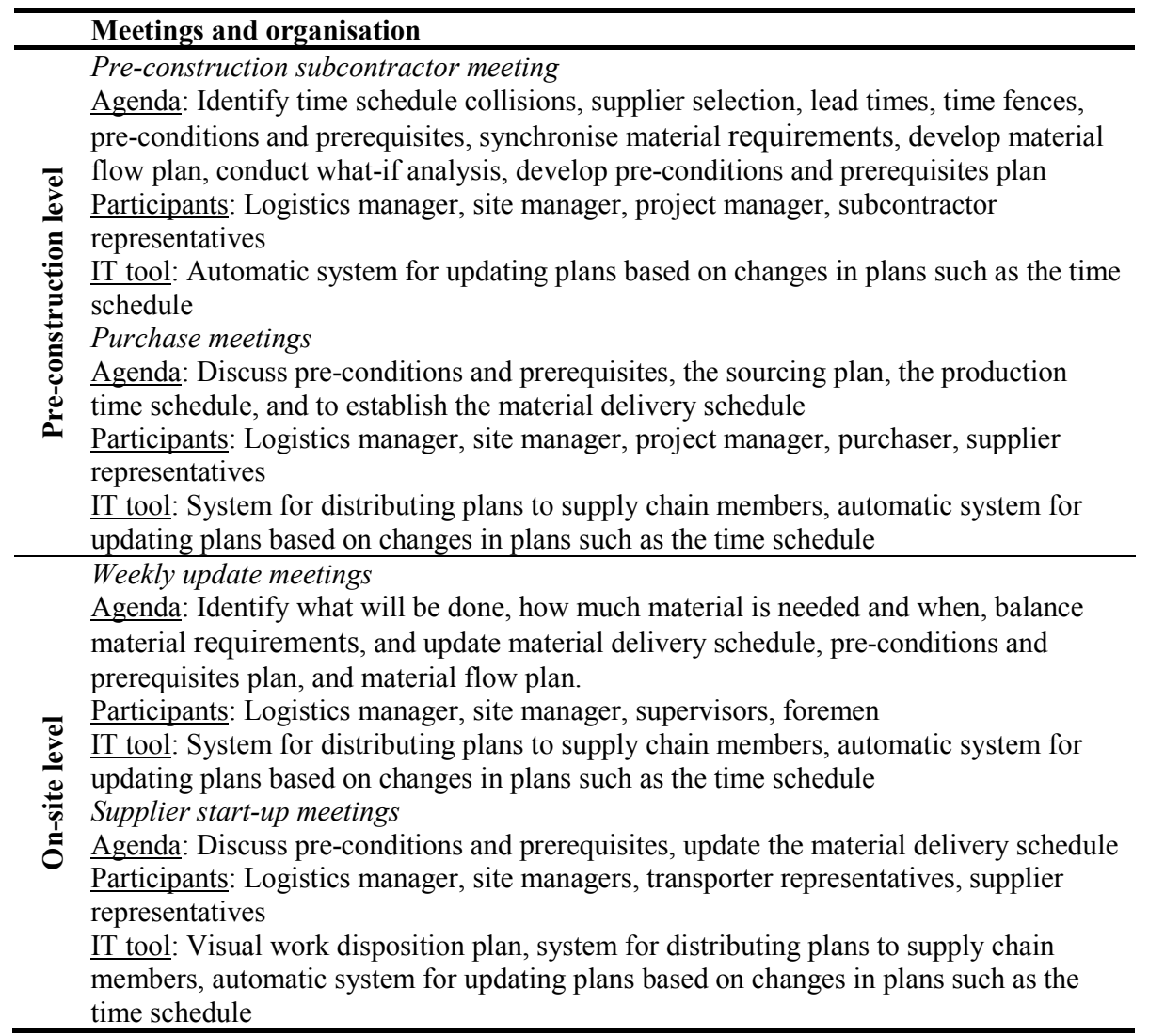

Prior to the pre-construction subcontractor meeting, the contractors need to identify what materials they need and when, based on the bill of quantity and the production time schedule. The material requirements should also be distributed to the other contractors together with the production time schedule. These material requirements are balanced in the pre-construction meeting for developing the sourcing plan. If issues in the plans and schedules are identified, then the production time schedule and finally the material requirements must be updated. An IT tool for automatically updating all plans is necessary to facilitate this updating process. This IT tool should integrate drawing software, time scheduling software and delivery 
planning software. If something is changed in the drawing or the time schedule, it should automatically update the material requirements that can be balanced among the contractors.

The participants should include the logistics manager, the site manager, project manager, and subcontractor representatives. The site manager has important information about constructability, while the project manager has knowledge in the overall project in the preconstruction phase. Who can act as subcontractor representatives is something that needs further investigation. It should be someone with experience about the project and who will work on-site. A logistics manager should be involved in the meeting for discussing resolution of logistics issues.

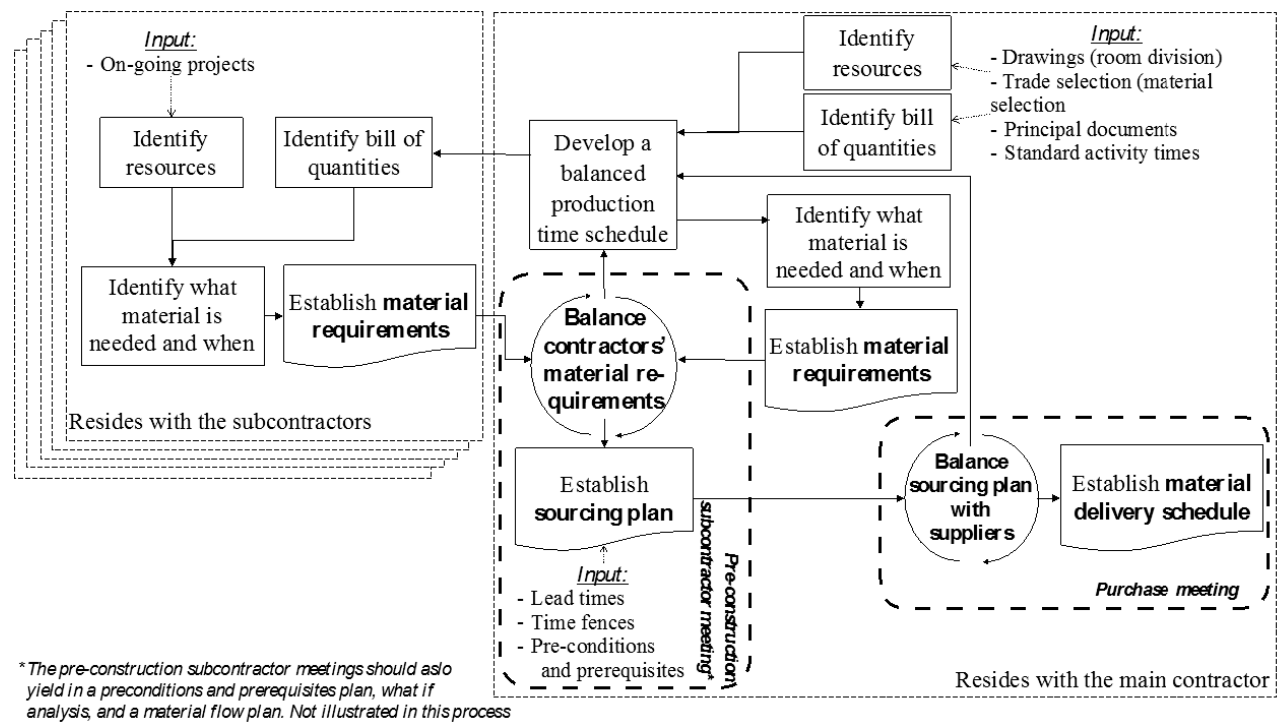

Figure 17. Pre-construction SCP planning process activities treated during the meetings.

\subsubsection{Purchase meetings}

The result of the pre-construction subcontractor meeting is a balanced sourcing plan that includes what material will be ordered from where and when, lead times, time fences, preconditions and prerequisites. However, this sourcing plan needs to be coordinated with key suppliers. This is done with each key supplier during the purchase meetings. The focus during this meeting should be on discussing pre-conditions and prerequisites, the sourcing plan, the production time schedule, and to establish the material delivery schedule. Figure 17 illustrates the meetings' focus on establishing the material delivery schedule. The reason for only involving the key suppliers is to reduce the workload of the main contractor. It is often critical materials like framework materials and kitchen materials that affect the project performance if they are delayed. It is thus necessary to involve these suppliers in the planning process.

The meeting should focus on discussing pre-conditions and prerequisites in order to identify how materials should be packed etc. and how the construction site infrastructure will look like. If problems are identified, it could lead to an update of the production time schedule and 
of the drawings as well. This should be facilitated by the IT tool discussed earlier. It could therefore be important to include key suppliers in the process of developing the production time schedule. This is not covered in this thesis. After all meetings have been held, the balancing activity should result in a material delivery schedule including all delivery dates for all materials required for the project. The meetings should also result in a list of all preconditions and prerequisites and that list should be distributed to all suppliers together with the material delivery schedule. This allows for all suppliers to familiarise themselves with the project. It could therefore be important with an IT tool for distributing delivery schedules, lead times, time fences, etc. automatically like an enterprise resource planning system.

Participants should include the logistics manager, the site manager, project manager, purchaser, and supplier representatives. The purpose for including the site managers and project managers in these meetings is the same as that of the pre-construction subcontractor meeting. Additional members from the main contractor include the purchaser who has critical knowledge in legal purchasing issues and a logistics manager for discussing logistics issues. It is important that representatives from the supplier include both persons who will manage the regular contact on-site and the sales-personnel. Including only sales-personnel and purchasers might result in too little discussion on practical issues that have to be resolved.

\subsubsection{Weekly update meetings}

Weekly update meetings cover activities in the on-site SCP process, which is illustrated in Figure 18. This on-site process aims at regularly updating the material delivery schedule according to current situations on-site. This can be done during the regular meetings already existing on-site. These meetings are often held once a week and should focus on controlling the progress of the project and compare the progress with the production time schedule. The should do activities in the time schedule should be compared with the can do activities and the result should be a set of will do activities. This also includes controlling material levels on-site. Knowing what will be done and what materials are needed, can help to update the material requirements plan and the sourcing plan. The weekly meeting therefore includes the first activities in the on-site SCP process with the focus on balancing material requirements for updating the sourcing plan. As far as IT tools are concerned, a system for distributing plans to supply chain members and an automatic system for updating these plans based on changes in other plans such as the time schedule, is considered necessary for distributing information and updating plans.

As the weekly update meetings are already planned, it is important to realise that the meetings should not merely focus on sharing information about construction aspects and updating the production time schedule, but also include the updating of the material delivery schedule. The agenda should include: identifying what will be done, how much material is needed and when, balancing material requirements, and updating the sourcing plan and material delivery schedule. On-site production personnel such as site managers and supervisors from all contractors must be among the participants. These participants have important information about current production activities, what can be done, and how much material is needed. 


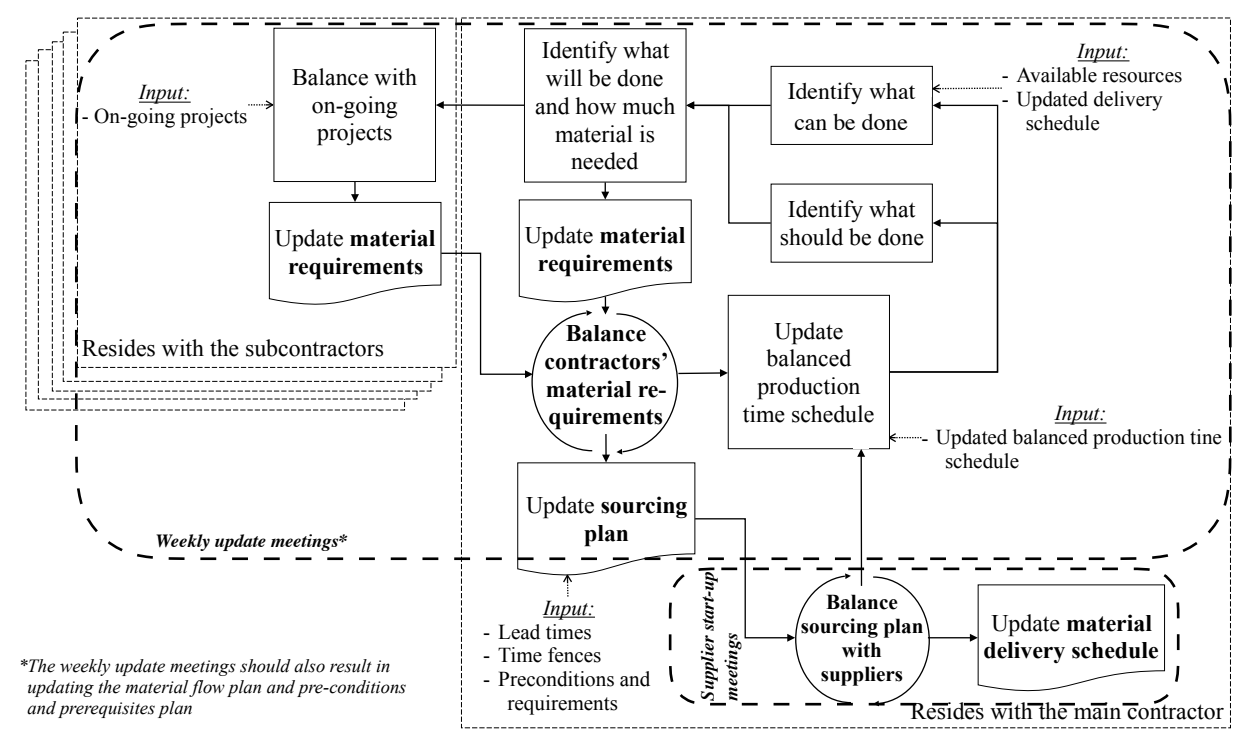

Figure 18. On-site SCP process activities treated during the meetings.

\subsubsection{Supplier start-up meetings}

After updating the sourcing plan, it should be balanced with the suppliers. Figure 18 also illustrates how the supplier start-up meetings are connected to the on-site SCP process. Small changes in the sourcing plan should be distributed to all suppliers. Major changes could however result in involving the key suppliers in a second purchase meeting on-site. The supplier start-up meeting focuses on planning the physical deliveries of materials to the site. For this it is essential that a material delivery schedule has been established and balanced among the suppliers and contractors. A supplier start-up meeting should be held a couple of weeks before the first delivery of key supplier materials. This meeting is held with each key supplier.

The meeting includes discussing pre-conditions and prerequisites and, if necessary, making minor changes in the material delivery schedule for each key supplier. Major changes should be avoided as resources have been allocated both on-site and at the supplier's end. Changing the material delivery schedule too much at this point could result in major delays on-site and planning nervousness in the system. The pre-conditions and prerequisites identified in the purchase meeting should be updated in the supplier start-up meeting. The closer the execution the better is the knowledge about conditions on-site.

The site manager and the supplier's representatives are key participants at these meetings. However, the transporter is also an important participant as they are the party that will physically transport materials to the site. It is important that the transporter is involved in determining the pre-conditions and prerequisites that they need to consider. Further investigation is needed in order to identify who should participate from the transporter's side. Necessary IT tools include visual work disposition plans, a system for distributing plans to 
supply chain members, and an automatic system for updating plans based on changes in other plans such as the time schedule.

\subsection{Identify performance measurements}

Papers 1 and 2 suggested that supply chain reliability, supply chain responsiveness, and supply chain costs should be assessed. Supply chain reliability can be assessed by measuring the perfect order fulfilment (POF). Supply chain responsiveness can be assessed using the order fulfilment cycle time. Supply chain costs can be assessed by measuring the total supply chain management cost. Paper 1 presented results on the perfect order fulfilment metric, source cycle time metric (SCT), and costs to source metric (CTS). The latter two metrics are part of the order fulfilment cycle time and the total supply chain management cost respectively.

The POF metric focuses on identifying how many deliveries are 'perfect'. That means they are delivered at the right time with the right materials and the right quantities along with the right documents, and with no damages. This value is important for assessing suppliers' logistic service. The metric is therefore important in the developed pre-construction SCP process for decision making. A low value should initiate improvement work or new supplier selection. The value is thus important when developing the production time schedule. Materials with low perfect order fulfilment could mean that activities where the materials are needed should be extended or further investigated. The value is also important in the purchase meeting as the prerequisites should state what a perfect delivery is. Paper 2 also suggests that notification on time should be part of the perfect order fulfilment as most transporters do not notify before deliveries. This is something that has to be discussed during the supplier start-up meeting with transporters for identifying when a delivery has to be notified.

The order fulfilment cycle time is an important metric for identifying how long it takes for an order to be processed and delivered. Paper 1 focused on the source cycle time on-site as many of the materials are difficult to handle and require a lot of work and time on-site. A high value should lead to changes in how materials are packed and labelled. These things should aid the craftsmen in unloading materials on-site. A high value also means that the productivity is low. The value should be monitored during the weekly update meetings.

Finally, the total cost of supply chain management can be assessed for keeping track of costs associated with the management of the supply chain. Paper 1 focused on the cost to source metric. This was done by multiplying the source cycle time with associated costs for sourcing materials. This included salaries and costs for other resources used. The metric is a monetary visualisation of the source cycle time and could be used alongside.

It is suggested that these three metrics be included in the SCP framework. However, Table 1 also depicted other KPIs offered by the SCOR model for measuring supply chain performance. These KPIs can also be of importance to measure in order to track supply chain performance. Flexibility is important in construction and the metrics suggested by the SCOR 
model define flexibility such as number of days required to achieve an unplanned sustainable $20 \%$ increase in the quantities delivered. Measuring this could prove important in order to identify how long it takes to respond to changes in the material delivery schedule on-site. Further investigation is needed as with the other KPIs suggested by the SCOR model.

Several measurements often used in construction were presented in section 2.4.2. These can be summarised as: quality, reworks, defects, waste levels, client satisfaction, subcontractor performance, safety, budget, assembly times, time plan adherence, and project completion time. Many of these metrics are connected to each other. As an example quality, reworks, and defects are inter-dependent. These metrics are also important to keep track of, from a SCP perspective. It needs to be identified during the weekly-meetings whether the production is running on time or not. If not, it means that the production time schedule and the material delivery schedule need to be updated. A supplier also needs to be aware of low material quality levels in order to improve the production and material quality. The performance measurements to be included are listed in Table 4.

Table 4. The identified performance measurements.

\begin{tabular}{ll}
\hline Performance measurement & Description \\
\hline Perfect order fulfilment & If materials are correctly delivered \\
Order fulfilment cycle time & Project completion time \\
Upside supply chain flexibility & How quick the supply chain responds to changes \\
Overall value at risk (VaR) & What if analysis for how supply chain risks affect costs \\
Total supply chain management cost & The total cost for supply materials \\
Cost of goods sold & Total construction costs \\
Cash-to-cash cycle time & How fast an investment flows back into the company \\
Quality & Can be measured e.g. via number of defects or as part of POF \\
Reworks & A high level means many changes or defects \\
Waste levels & The level of packaging etc. stored on-site \\
Client satisfaction & Can be measured via quality \\
Subcontractor performance & Number of errors committed by the subcontractor \\
Assembly times & To update standard activity times and time schedules \\
Production time schedule adherence & For updating the material delivery schedule \\
Notifying on time & The transporter should notify before delivery \\
\hline
\end{tabular}

\subsection{A construction supply chain planning framework}

The purpose of this thesis is to develop a SCP framework for construction that integrates the main contractor, subcontractors, and suppliers. This includes two steps, (1) to develop a framework and (2) to investigate if this aids in integrating the main contractor, subcontractors, and suppliers. The second step is discussed in section 5. Concerning the first step, it was discussed in section 2.3.2 that the framework of Tavares Thomé et al. (2012) for S\&OP can be used as a basis for developing the SCP framework for construction. The planning framework developed by Tavares Thomé et al. (2012) presented in Figure 7 consisted of seven parts: context, input, business plan, strategic plan, structure and process, outcome, and operations. The position and linkages between the business plan, the strategic plan and the S\&OP describes how the S\&OP is affected by the decisions made in these plans. The strategic plan and the business plan are also important inputs to the SCP but are out of 
scope of this thesis. The operations describe how the S\&OP will use manageable activities to perform the planned activities in the S\&OP. These three should not be included in the SCP framework as such, as they rather illustrate the previous and subsequent activities of the SCP.

The framework in Figure 19 is based on the framework developed by Tavares Thomé et al. (2012) with some adaptions. The process is separated from the organisation to distinguish between activities and organisation. KPI is also separated from the organisation and is seen as an input to the process part, as the KPIs are not treated exclusively during the meetings. Meetings and collaboration, Organisation, and Information technology are named Meetings, Participants, and IT tools to better illustrate the content of the organisation.

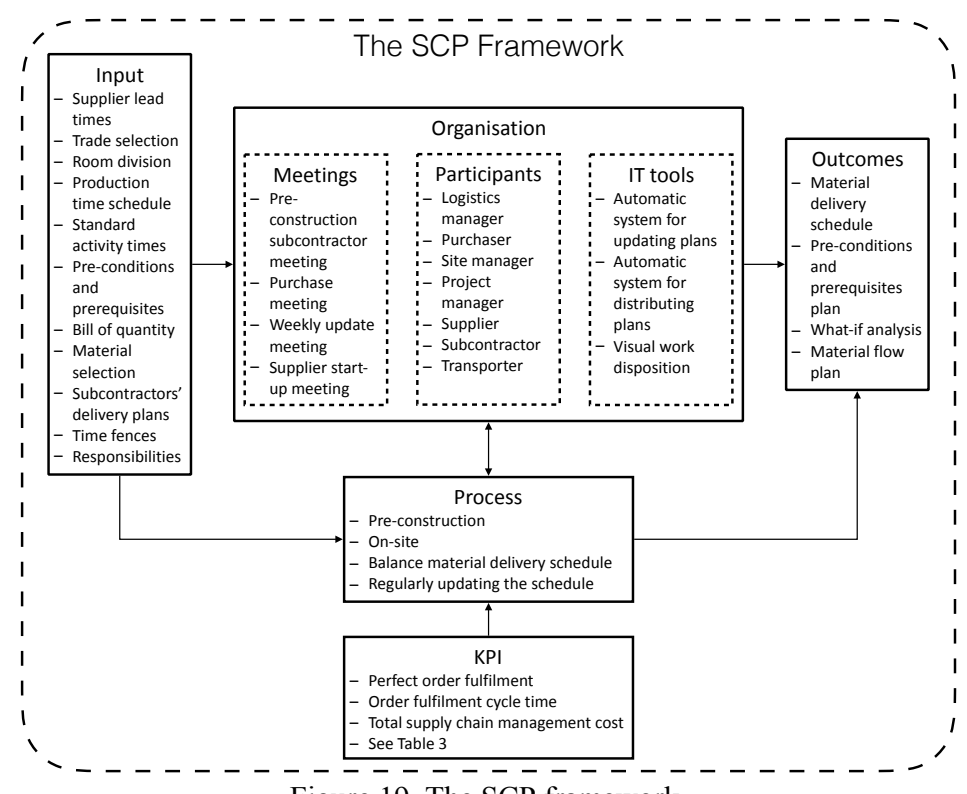

Figure 19. The SCP framework.

The inputs, outcomes, and process are the results of fulfilling objective 2 in section 4.2. It was discussed that the process should be subdivided into pre-construction process and on-site process, focusing on establishing and updating balanced material delivery schedules. Input to the process and organisation include important information like bill of quantity, material selection, trade selection, standard activity times, and time fences. This information is important for establishing delivery dates, dates when changes are allowed, and whom to balance the plans with. It was also discussed that the main outcome of the SCP process should be a material delivery schedule.

As far as the organisation part is concerned, the content of the Meetings, Participants, and ITtools comes from the results of fulfilling objective 3 in section 4.3. Four meetings, two in the pre-construction phase and two on-site, were identified as necessary. These are preconstruction subcontractor meetings, purchase meetings, weekly update meetings, and supplier start-up meetings. The first one must involve the subcontractors in the planning process, balancing sourcing plans, and establish a sourcing plan for the whole construction 
project with delivery dates, order dates, and pre-conditions and prerequisites. Purchase meetings should focus on involving the suppliers in the planning process and establishing a material delivery schedule. Weekly update meetings focus on updating the material delivery schedule on-site. Finally, the supplier start-up meetings should involve the suppliers in the on-site process and prepare for the material delivery. The logistics manager, project manager, purchaser, site manager, supplier representatives, subcontractor representatives, and transporter representatives must participate in the SCP organisation. The necessary IT tools include systems for updating plans, distributing them, and visualise the site layout.

Section 4.4 provided a number of relevant KPIs to keep track of in the SCP process. These are all listed in Table 4, which is a consequence of fulfilling objective 4. Some of the suggested KPIs are perfect order fulfilment, order fulfilment cycle time, and total supply chain management cost. A low perfect order fulfilment from the supplier should result in improving the communication with the supplier. The low level can be a result of faulty information when developing the material delivery schedule. Input like time fences and lead times might be set too opportunistically. The order fulfilment cycle time is important for keeping track of how much time the sourcing material, for instance is taking. Long sourcing times might indicate that further investigation of pre-conditions and prerequisites is needed.

It was stipulated that the purpose of the thesis involved two steps: develop the framework and integrate the main contractors, subcontractors, and suppliers. The first part is fulfilled by suggesting the SCP framework in Figure 19. The latter part is fulfilled by involving the main contractor, the subcontractors, and the suppliers as participants in the SCP organisation. It is also fulfilled by depicting important subcontractor activities in the SCP process in Figure 15 and Figure 16. The discussion about the implications of integrating them plus how the developed SCP framework can address the identified issues in objective 1, can be found in the next chapter. 


\section{Discussion}

The aim of this chapter is two-fold. First is a discussion held on the research findings in terms of how the developed SCP framework can address the identified problems in logistics, the theoretical implications, and managerial implications. The second aim of this chapter is to provide a discussion on the research process focussing on research quality.

\subsection{The SCP framework and the identified problems}

Papers 3 and 4 identified different logistics problems common to the construction industry. They are reproduced in Table 5 together with a description on how the developed SCP framework addresses each problem.

Table 5. Addressing the identified problems.

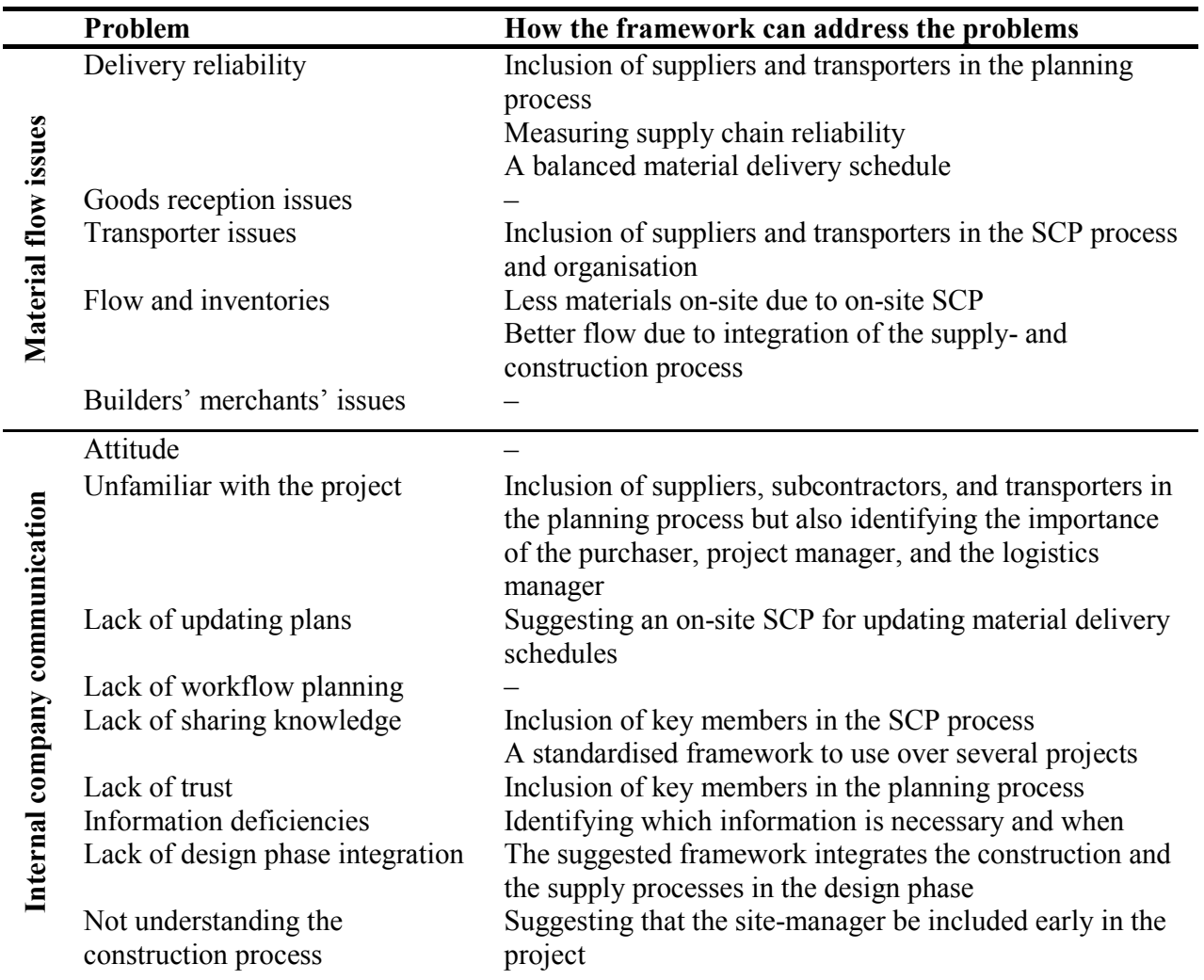




\begin{tabular}{|c|c|c|}
\hline & Problem & How the framework can address the problems \\
\hline & $\begin{array}{l}\text { Not considering production rate } \\
\text { and repetitiveness }\end{array}$ & - \\
\hline 葛 & $\begin{array}{l}\text { Exclusion of subcontractors } \\
\text { when planning } \\
\text { Client communication } \\
\text { Different customer perspectives } \\
\text { Lack of long-term relationship } \\
\text { Divergent interpretations } \\
\text { Lack of coordinating plans }\end{array}$ & $\begin{array}{l}\text { Suggesting a SCP organisation where the subcontractors } \\
\text { are included } \\
- \\
\text { Inclusion of key members in the SCP process for } \\
\text { developing mutual goals } \\
\text { Arguing for developing long-term relationships with } \\
\text { suppliers to make the framework successful } \\
\text { Inclusion of key members in the SCP organisation } \\
\text { Balancing different contractors' plans }\end{array}$ \\
\hline \multirow{5}{*}{ 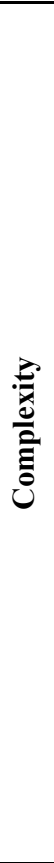 } & $\begin{array}{l}\text { Lack of time and resources } \\
\text { Project uncertainty }\end{array}$ & $\begin{array}{l}\text { A pre-conditions and prerequisites plan prior to } \\
\text { construction and a material flow plan makes it easier to } \\
\text { cope with uncertainties such as changing site layout } \\
- \\
\text { A pre-conditions and prerequisites plan prior to } \\
\text { construction and a material flow plan makes it easier to } \\
\text { cope with uncertainties } \\
\text { Inclusion of key members in the SCP process }\end{array}$ \\
\hline & Piece work contract & - \\
\hline & $\begin{array}{l}\text { Technology issues } \\
\text { Lack of standardised processes }\end{array}$ & $\begin{array}{l}\text { Suggesting IT tools to ease the planning } \\
\text { Suggesting a standardised SCP process for coping with } \\
\text { logistics issues }\end{array}$ \\
\hline & $\begin{array}{l}\text { Difficult to measure } \\
\text { improvements } \\
\text { Interdependency } \\
\text { Client changes } \\
\text { Local variations }\end{array}$ & $\begin{array}{l}\text { Suggests different KPIs to keep track of } \\
\text { Suggests the importance of identifying suitable KPIs } \\
- \\
\text { Introduces time fences for when changes are ok } \\
\text { A pre-conditions and prerequisites plan prior to } \\
\text { construction and a material flow plan makes it easier to } \\
\text { cope with uncertainties such as local variations }\end{array}$ \\
\hline & Dynamic projects & $\begin{array}{l}\text { A pre-conditions and prerequisites plan prior to } \\
\text { construction and a material flow plan makes it easier to } \\
\text { cope with uncertainties such as dynamic projects } \\
\text { Suggesting a standardised SCP process to cope with } \\
\text { logistics issues }\end{array}$ \\
\hline
\end{tabular}

\subsubsection{Addressed problems}

It should be mentioned that the framework has not been tested. The discussion here is therefore of a tentative nature. As Paper 4 suggests, there is a connection between the problem areas. The complexity inherited in the construction industry with dynamic projects and lack of standards will affect the ability to communicate both internally within the company and externally within the project. The lack of communication in turn will affect the physical flow of materials. The dynamic nature affects communication that can lead to faulty information about deliveries that finally can cause delays in the material flow.

The developed SCP framework addresses problems in all problem areas. The framework as such improves the supply planning in construction by introducing a balanced material delivery schedule. The work of developing this schedule addresses the complexity issues. KPIs are suggested, which have to be measured for identifying improvements. The process can facilitate addressing the dynamic nature, changing site layouts, and local variations as 
pre-conditions and prerequisites are incorporated in the planning process and this should be shared with the participants. A better planning of the material flow and regularly updating the plan can also reduce the uncertainties. Plans should be seen as tentative documents developed prior to construction and must be updated on-site. They should be updated on a regular basis to cope with uncertainties.

The key aspect of the framework is to involve the subcontractors and the suppliers more actively in the planning process. Involving them early in the project improves coordination and trust as they are able to express their views on the time schedule and material deliveries. If the main contractor develops the plans without firmly establishing the plans with the subcontractors and suppliers it can result in diminished trust within the project. All of these are important problems in the project communication area. The framework facilitates in coordinating plans, including suppliers and subcontractors in the planning process, and sharing goals. All of these are important for developing trust among members.

Involving both project members and internal staff members in the planning process can also result in better understanding of the project and less information deficiencies. Ideas about the project can be shared among members within the balancing activities and any uncertainties in information can be sorted out. These are important problems in both the internal company communication area and in the project communication area. Involving the suppliers and the subcontractors in the planning process is a means to integrate the supply process and the construction process. It should also be noted that architects should be involved in the planning process, but this is subject to further research.

Tools for coping with complexity and improving communication through better planning processes could result in a better material flow. More realistic material delivery schedules firmly established among contractors and suppliers provide for a better delivery reliability. This can be verified by measuring the suggested KPIs. Better identification of what material is needed and when, together with better supply chain reliability can reduce the inventory levels on-site. It is not needed to order extra materials, to store on-site for coping with uncertainties in the time schedule.

\subsubsection{Unaddressed problems}

Some of the problems are not addressed by the developed framework. These are: builders' merchants' issues, lack of work flow planning, not considering production rate and repetitiveness, client communication, lack of time and resources, piece work contracts, and interdependencies. The focus group suggested that the work flow plan should include logistic aspects like inventories etc. and should be updated. This is important but not covered by this framework. As discussed earlier, the contract types used, defines to what extent the client should be involved. The client is more involved in general construction contracts. The suggested framework is developed based on a design-build context with less involvement of the client. However, more studies are necessary for identifying how the client should be involved. Lack of time and resources for planning is a common issue. The framework requires more time spent in the planning phase. However, if more time is spent on developing plans in the early phase, less time will have to be spent on re-work and changes on-site. 


\subsection{Theoretical implications}

It was stated in the beginning of the thesis that it aims at extending the body of knowledge within the construction management field of research. It was stated that this research field is rather a scientific discipline that uses theories from other scientific disciplines than a theory in itself (Voordijk and Adriaanse 2016). With knowledge from the SCM scientific discipline/research field, this thesis contributes by suggesting SCP as a means to address problems in logistics. What the thesis also contributes with is:

- A framework for SCP in construction containing:

$\circ$ A process for planning the material deliveries

- An organisation that involves subcontractors and suppliers in the planning process

- Performance measurements for assessing the supply chain and construction project

The effect of this is:

- Means to integrate the supply process and the construction process

- An understanding in how SCP can address common problems

- Means to address the trust issue within the industry

- Suggesting how to cope with the decoupled nature of the construction industry

- Means to develop propositions based on the identified logistics problems and SCP

The thesis contributes with a SCP framework (Figure 19) consisting of two SCP processes (Figure 15 and Figure 16) for developing e.g. a material delivery schedule and updating it onsite. The processes can act as a way of involving the suppliers and subcontractors in the planning process. This is done through the balancing activity and the developed SCP organisation. The balancing activity suggests sharing the sourcing plans and developing a material delivery schedule based on experiences among subcontractors. The SCP organisation includes both subcontractors and suppliers as participants in meetings where the plans are developed. As the pre-construction process is commenced in the pre-construction planning phase it can be considered that the suppliers and subcontractors are involved early in the project. Dainty et al. (2001b), Gidado (2004), and Laufer and Tucker (1987) among others argue that subcontractors are often involved too late in the planning process. This discussion can also be extended to include the suppliers. It is however seldom discussed how the suppliers and subcontractors should be involved.

An integration of the construction process and the supply process is necessary for reducing non-value adding activities (Friblick 2000). This includes sharing information about the construction process and giving input to the production time schedules. If this is not comprehended it can cause delays and extensive reworks discussed by Love and Edwards (2004), and Vrijhoef and Koskela (2000). The SCP process developed together with the organisational structure suggest how the suppliers and subcontractors could be involved in the planning process. It is discussed in section 4.3 that subcontractors should be involved early in a pre-construction subcontractor meeting and share their information about the production time schedule, and material requirements. They are also involved in weekly 
update meetings where they can share information about how the plans should be updated. Suppliers should also be involved in a purchase meeting where important information such as pre-conditions and prerequisites are discussed. This is further discussed on-site prior to delivery, where the transporter is also involved in the meeting. This offers an opportunity to share information from a supply process perspective and thus is a means for integrating the supply process and the construction process.

It is common in the literature that issues in the supply chain are discussed based on how the supply chain can be improved (cf. Vidalakis et al. 2011, Voordijk 2010). It is seldom discussed how the construction process and the supply process interact, as discussed by Friblick (2000) and Vrijhoef and Koskela (2000). This thesis utilises a SCM perspective when analysing problems in construction. Some problems in Table 5 such as a lack of trust and lack of sharing information are often discussed in the literature based on a construction perspective (cf. Doloi 2009). However, these problems are also often discussed in SCM and logistic literature (Laureano Paiva et al. 2014). SCM and logistical problems are not just material flow problems like late deliveries. Looking at common problems in construction with a SCM perspective has a potential for adopting new concepts for addressing the problems. As discussed in Paper 4, many of the problems in the construction industry can be seen with a SCM perspective. A lack of trust can affect information sharing, which affects the plans and finally the delivery reliability. This thesis offers a new perspective on the problems by addressing the problems with a SCP framework. Table 5 and the discussion in section 5.1 describes how the developed SCP framework can address the problems and Paper 4 discusses how the problems are inter-linked. Thus the thesis contributes by elucidating how SCM and SCP can be part of the construction industry's repertoire for addressing problems such as trust and communication and thus improve the material flow as well.

A topic that is often discussed in construction literature is the lack of trust among project members. This lack of trust can have a negative effect on the overall performance (Doloi 2009). Addressing this problem will thus have a significant effect on project success and productivity. The balancing activity in the SCP processes improves coordination of plans and involving the subcontractors and the suppliers in the planning process. This facilitates sharing of information and knowledge and integrating the suppliers, which is important for fostering a trustful climate (Laureano Paiva et al. 2014). The process and structure together with the KPI will aid in improving the trust issue. The process will help the participants to strive for the same goal such as a balanced material delivery schedule that will reduce time and cost overruns. Including the subcontractors in the planning process can also improve knowledge sharing and develop an open climate for improving trust. The KPI part helps the participants to identify improvement areas and work together for improving. This alone will not per se make the construction industry more trustful but will facilitate the development of a trustful atmosphere.

In order to reap the benefit of the framework and cope with the trust issues, is it necessary to first cope with the decoupled nature of the construction industry (Dubois and Gadde 2002). This decoupled nature results in issues with coordinating work between project members and participating companies, causing problems with communication, trust, commitment, etc. The 
SCP framework developed in this thesis does not offer a solution on how to come to terms with the decoupled nature. However, as discussed earlier, the SCP framework does offer a means for coping with coordination and integration issues by means of the balancing activities as subcontractors and suppliers are involved in the planning process. Coordination and integration are both two requirements for coping with the decoupled nature. SCP can thus be a means for coping with the decoupled nature.

A final theoretical contribution is the possibility to develop propositions which need to be tested in the future. Table 5 presents how the framework can aid in addressing the problems. However, these are tentative and have not been tested for verification or falsification. It is possible to form propositions to test, like "including the main contractor, subcontractors, and suppliers in developing a balanced material delivery schedule will improve trust in the project". It is possible to formulate propositions for each of the statements given in Table 5 .

\subsection{Managerial implications}

Except for contributing to the research field, the thesis also contributes with some important managerial implications. The developed SCP framework, as described in section 4.5, consists of processes for developing a material delivery schedule, an organisational structure for facilitating the implementation of the processes, and KPIs for measuring supply chain performance. It has also been discussed that this framework can have a positive effect on coordination, trust, and integration. These will be discussed here from a managerial point of view.

Measuring supply chain performance is important for understanding how well the supply chain performs in comparison to competitors for identifying areas for improvement, and for understanding how the supply chain is designed. Papers 1 and 2 suggest three metrics to measure. However, before measuring the supply chain performance it is necessary to map the supply chain for identifying which activities to measure. Paper 2 suggests a model for mapping the supply chain. Using this model and the suggested KPIs in the SCP framework, construction companies can identify an as-is state of the supply chain but also develop a future to-be state of the supply chain. The as-is state can result in identification of problem areas that need improvement. The mapping tool and the measurements suggested, offer a possibility for the supply chain and project members to speak the same language. The mapping tool also contributes with understanding the supply chain and how it can be designed to cope with the identified problems and excel in supply chain improvements. What gets measured gets done, and a first step is to map and measure the supply chain. A performance measurement system needs to be designed in order to measure the supply chain. As performances of supply chains are seldom measured, new systems for measurements and later follow-up measurements need to be established.

The thesis also identifies common logistical problems (Table 5) and a model in Paper 4 for showing how the problems are inter-linked. The model in Paper 4 helps construction companies to identify how common problems are inter-linked and where in the managerial hierarchy they are located. Some of the problems like lack of long-term relationships with 
suppliers and subcontractors are situated on a strategic long-term level. This indicates that addressing these problems should be dealt with by managers at a company-wide strategic level and not by managers at the project level. Logistics and SCM in construction is often seen as a project endeavour that should be managed by project managers and site managers. However, the thesis suggests through the model in Paper 4 that a holistic perspective on logistics and SCM should be implemented where strategic managers cope with strategic SCM issues and site managers with on-site logistic issues. The project nature of the construction industry with temporary organisations and "lonely islands" needs to be questioned. A centralised view of SCM and SCP needs to be adopted where SCM and logistics are seen as being more strategic, which is lacking today.

The processes and the organisation in the SCP framework has three main implications: improving coordination, updating plans, and identification of key participants. Improving coordination is achieved through involving the suppliers and subcontractors in the planning process for developing a material delivery schedule. This however implies that more longterm agreements and relationships are established with suppliers and subcontractors. Coordination is lacking in construction today (Fellows 2009) and planning is about coordinating resources and activities (Gupta and Maranas 2003). Improving the planning processes can thus improve coordination. Involving subcontractors and suppliers in the planning of material deliveries as offered in the suggested organisational structure is a means to improve coordination. This can have a positive effect on the success of projects as deficiencies are discovered early in construction project. This also implies that goals and information can be shared more easily among supply chain members. It can also improve relationships with suppliers and subcontractors as knowledge is shared and issues are discussed. Involving the subcontractors and suppliers in the balancing activity can thus improve coordination.

The regular updating of plans as suggested in the on-site SCP process will also have a positive effect on the success of the project and on knowledge sharing. Developing a plan that is never updated is a problematic perspective on planning. The extent of uncertainties in the beginning of the project is greater than towards the end. This means that the first plan will be more rough and should be continuously updated on-site as uncertainties get resolved. Replanning is also part of planning. Updating the material delivery schedule can have a positive effect as production time schedule issues are avoided. Postponing a delivery does not necessarily mean that the whole project will be delayed. On the contrary, it can be used for overcoming other problems that might have ended up in project delays.

\subsection{Reflection on research quality}

Table 6 below summarises how each study has addressed validity, reliability, and bias. A plus sign indicates means to achieve research quality and a minus sign indicate flaws in achieving research quality. The overall idea with the studies in the thesis was to include different methods for achieving methodological triangulation. Case studies, literature review, interview series, and focus group studies have all helped in developing the SCP framework. The results from preceding studies have aided in shaping successive studies. To give one 
example, the code structure in the first interview series helped in shaping the interview guide for the second interview series. This provides a means for achieving construct validity.

Table 6. The research quality of each study.

\begin{tabular}{|c|c|c|c|}
\hline Construct validity & Internal validity & External validity & $\begin{array}{l}\text { Reliability and } \\
\text { avoiding Bias }\end{array}$ \\
\hline 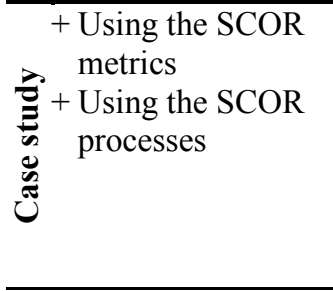 & $\begin{array}{l}\text { Clearly defined } \\
\text { activities to measure } \\
+ \text { Defining unit of } \\
\text { analysis } \\
\text { - Difficult to define } \\
\text { activities and unit of } \\
\text { analysis } \\
\end{array}$ & - Just one case & $\begin{array}{l}+ \text { Several researches } \\
+ \text { Several } \\
\text { measurements } \\
+ \text { Case diary for } \\
\text { documenting each } \\
\text { research step }\end{array}$ \\
\hline $\begin{array}{l}\text { Using the SCOR } \\
\text { processes } \\
\text { - Difficult to define } \\
\text { 'problem' } \\
\end{array}$ & $\begin{array}{l}\text { + Several papers on the } \\
\text { same topic } \\
\text { - Only one method }\end{array}$ & $\begin{array}{l}\text { - Process not } \\
\text { empirically tested } \\
\text { - Only literature } \\
\text { problems }\end{array}$ & $\begin{array}{l}+ \text { Structured review } \\
+ \text { Review database } \\
\text { for documenting } \\
\text { the process }\end{array}$ \\
\hline $\begin{array}{l}+ \text { Using the input } \\
\text { from Paper } 5 \\
\text { - Difficult to define } \\
\text { 'problem' } \\
\end{array}$ & $\begin{array}{l}\text { Respondent } \\
\text { verification of the } \\
\text { problems }\end{array}$ & $\begin{array}{l}\text { Heterogeneous } \\
\text { respondents } \\
\text { - No project } \\
\text { managers and } \\
\text { consultants were } \\
\text { interviewed }\end{array}$ & $\begin{array}{l}\text { Two rounds of } \\
\text { coding } \\
+ \text { Recorded and } \\
\text { transcribed } \\
\text { interviews } \\
\text { - Only one } \\
\text { researcher } \\
\text { analysing } \\
\end{array}$ \\
\hline $\begin{array}{l}\text { Using input from } \\
\text { Paper } 3 \text { in } \\
\text { developing } \\
\text { in interview guide } \\
\text { - Difficult to define } \\
\text { 'problem' }\end{array}$ & $\begin{array}{l}\text { + Respondent } \\
\text { verification of the } \\
\text { problems } \\
\text { - Lack of feedback loop } \\
\text { to respondents }\end{array}$ & $\begin{array}{l}\text { Heterogeneous } \\
\text { respondents } \\
\text { - No project } \\
\text { managers and } \\
\text { consultants were } \\
\text { interviewed } \\
\text { - The model need to } \\
\text { be tested on more } \\
\text { projects }\end{array}$ & $\begin{array}{l}+ \text { Printed charts of } \\
\text { links } \\
+ \text { Documenting the } \\
\text { process } \\
\text { - Only one } \\
\text { researcher } \\
\text { analysing }\end{array}$ \\
\hline
\end{tabular}




\begin{tabular}{|c|c|c|c|}
\hline Construct validity & Internal validity & External validity & $\begin{array}{l}\text { Reliability and } \\
\text { avoiding Bias }\end{array}$ \\
\hline $\begin{array}{l}\text { + Using input from } \\
\text { Paper } 5 \text { to } 5 \text { in } \\
\text { developing the } \\
\text { interview guide } \\
\text { - No mutual } \\
\text { perspective } \\
\text { - Not a suitable } \\
\text { method for } \\
\text { development of the } \\
\text { SCP structure }\end{array}$ & $\begin{array}{l}\text { + Respondent's } \\
\text { verification of the } \\
\text { problems } \\
+ \text { Feedback loop to } \\
\text { respondents }\end{array}$ & $\begin{array}{l}\text { + Heterogeneous } \\
\text { respondents } \\
\text { - No project } \\
\text { managers and } \\
\text { consultants were } \\
\text { interviewed } \\
\text { - Processes and } \\
\text { structure not } \\
\text { empirically tested }\end{array}$ & $\begin{array}{l}+ \text { Recorded } \\
\text { interviews } \\
+ \text { Feedback loop to } \\
\text { respondents } \\
\text { - One strong } \\
\text { participant }\end{array}$ \\
\hline
\end{tabular}

In order to facilitate high research validity in the case study, several tactics were used. Construct validity was achieved by using the SCOR model's metrics and processes for measuring and mapping the delivery and sourcing of materials. After years of use in other industries, the SCOR model has been revised into clear processes and metrics that are used for measuring performance and for mapping. Internal validity was achieved by clearly identifying the start and the end of activities together with the site manager. However, this was a difficult task, overlaps of activities exist, which affect the sourcing times among other things. A problem with single case study is the lack of generalisation. Several cases would have improved the external validity, which makes it difficult to draw general conclusions about the supply chain performance in construction. However, the results from the study have been discussed during the course of the other studies and during different industry seminars. General comments from the industry indicate that the results are representative for the industry. Regarding reliability, a case database was developed and notes and pictures were taken during observations and measurements. Two researchers were used for improving the reliability of observations.

The literature review resulted in a first suggestion of how the SCP process could be designed. This process was based on the SCOR model, ensuring construct validity as discussed above. However, defining 'problem' was difficult. It was an iterative process on defining what type of problems should be identified. This relates to construct validity. Firstly, problems about planning were searched for, but were later changed to logistical problems as it was subsequently identified that the interview series actually concerned logistical problems. Internal validity was achieved by identifying several different papers that addressed problems, planning, and logistics. However, as only one method was used, internal validity was hampered. The negative effect was subsequently reduced with the use of interview series. Regarding external validity, the proposed process from the literature review was not tested at the time. However, the process has continuously been revised during the focus group study. Reliability was achieved by documenting keywords used, number of results, relevant papers, and date of search.

The interview series has been designed based on previous studies. The output from the first interview series resulted in an understanding of problems and how they can be categorised. 
This helped in forming the interview guide in the second interview series and enhanced construct validity. However, defining 'problem' was difficult here too. Internal validity was achieved by letting the respondents verify earlier results and also with the inclusion of several respondents of the same category (e.g. site manager). However, the respondents in the second interview series were not provided with any feedback of the interviews. This reduces the possibility of identifying misunderstandings. Heterogeneous respondents were used for improving external validity, even though several respondents of each category were used. It was realised in the focus group study that project managers and consultants should have been involved to improve generalisation. The model developed in the interview series 2 has not been tested, which affects the external validity. Reliability was achieved by documenting the coding process, recording and transcribing interviews, and drawing pictures of inter-linkages of problems. Even if the result of the analysis has been discussed among researchers, it was mainly done by the author of this thesis, which can affect bias negatively due to lack of different perspectives.

The use of focus groups has been useful for developing the framework. The participants have all contributed by validating previous findings. This provides a means for achieving external validity. The problem here is that the process is developed based on logical reasoning without testing the process on an actual project to see how the problems are addressed. The conclusion of the testing should also exemplify how different contexts affect the design of the framework. The lack of external validity can hamper the usability and the generalisation. However, the focus group participants were able to provide feedback on the suggested framework. The use of a heterogeneous group makes generalisation better, but can also result in a situation where they were talking about different things as they had different perspectives. It is difficult to say whether this was the case in this study. However, one of the members in the group was "stronger" in his opinions than others. This resulted in the discussion often taking his perspective. It was important to have this in mind when developing the framework. 


\section{Conclusions}

This chapter aims to present a general summary to show how each objective and the purpose have been fulfilled. The chapter and the thesis are summed-up with a reflection on future research.

\subsection{Objectives and purpose reflection}

The conclusion is that SCP can be a facilitator for addressing the identified problems through integration of the supply and construction processes, via the integration of the main contractor, the subcontractors, and the suppliers. The construction industry has had problems with productivity and with the flow of information and materials. It has for a long time been discussed among academics and practitioners how SCM can be a facilitator for addressing these problems. However, it has not been discussed how SCP as part of SCM can facilitate addressing the many logistical problems. The purpose of this study was to develop a SCP framework for construction that integrates the main contractor, subcontractors, and suppliers. Four research objectives were developed to fulfil:

\section{Objective 1. Identify common logistical problems and linkages between them}

Objective 2. Develop a SCP process

Objective 3. Develop a SCP organisation

\section{Objective 4. Identify performance measurements}

Table 7 describes how the thesis and the six included papers contribute in fulfilling the objectives. Some of the means to fulfil a certain objective are presented in italics. This means that the purpose of the paper was not to fulfil the objective but to contribute with important inputs towards the fulfilment of the objective.

Objective 1 is mainly fulfilled by the result of Papers 1 to 4 . By measuring the supply chain reliability, supply chain responsiveness, and total supply chain management cost, it was identified in Paper 1 that the supply chains in one case project experienced a low supply chain reliability. This was measured using the POF metric. A continuous low supplier POF can mean that changes need to be implemented at a strategic level. This can involve initiating a supplier improvement program or redesigning the supply chain for improving the supply chain reliability. Paper 2 contributes by mapping the supply chain processes 'Deliver' and 'Source' based on the SCOR model and identifying differences in the construction industry that need to be considered in the development of the SCP framework. One of the characteristics is the low integration between the main contractor, subcontractors, and suppliers in the planning process. This is an important input to developing the SCP process. 
Paper 3 contributes by extending the identification of logistical problems by introducing an empirical study. Some of the key problems are a lack of trust, relationship, and communication. Trust, relationship, and communication are all important parts of SCM and are absolutely essential to have a competitive supply chain. Even if the main purpose of Paper 5 was to suggest a SCP process it does also present a literature review on logistical problems in construction.

Paper 4 developed a model for linking the logistical problems and to identify encountered in developing a SCP and what problems are of an executional character. Problems such as late deliveries are execution related problems and can be a result of the problems with developing a material delivery schedule in SCP. The latter can be a result of not including suppliers and subcontractors in the SCP process. The model provides an understanding of how problems are related. This is often missed in the literature today. Dealing with communication and trust issues in the project environment can thus have a positive effect on the issues related to the supply process such as late deliveries.

Table 7. How each research objective was fulfilled

\begin{tabular}{|c|c|c|c|c|}
\hline & Objective 1 & Objective 2 & Objective 3 & Objective 4 \\
\hline 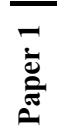 & $\begin{array}{l}\text { Map the current logistics } \\
\text { performance }\end{array}$ & & & $\begin{array}{l}\text { Suggest important } \\
\text { KPIs to keep track of } \\
\text { in the SCP framework }\end{array}$ \\
\hline 离 & $\begin{array}{l}\text { Identify logistical } \\
\text { problems via mapping } \\
\text { the 'Deliver'/'Source' } \\
\text { processes }\end{array}$ & & & $\begin{array}{l}\text { Suggest important } \\
\text { KPIs to keep track of } \\
\text { in the SCP framework }\end{array}$ \\
\hline 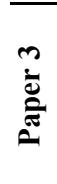 & $\begin{array}{l}\text { Identify common } \\
\text { logistical problems on- } \\
\text { site and discuss how SCP } \\
\text { can be a facilitator for } \\
\text { mitigating the problems }\end{array}$ & & & \\
\hline ¿্ঠ் & $\begin{array}{l}\text { Identify how problems } \\
\text { are linked and how SCP } \\
\text { can be a facilitator for } \\
\text { improving the industry }\end{array}$ & & & \\
\hline ñ & $\begin{array}{l}\text { Identify common } \\
\text { logistical problems in } \\
\text { the literature }\end{array}$ & $\begin{array}{l}\text { Suggest a SCP process } \\
\text { that balances contractors' } \\
\text { sourcing plans }\end{array}$ & & \\
\hline $\begin{array}{l}b \\
\grave{\Xi} \\
\stackrel{\Xi}{\sigma}\end{array}$ & & $\begin{array}{l}\text { Develop a pre- } \\
\text { construction SCP process } \\
\text { and an on-site SCP } \\
\text { process. }\end{array}$ & $\begin{array}{l}\text { Develop an } \\
\text { organisational } \\
\text { structure for the } \\
\text { processes. }\end{array}$ & \\
\hline
\end{tabular}

Objective 2 is mainly fulfilled by the results from Papers 5 and 6 . The focus in Paper 5 is to suggest a process for SCP in construction. It was identified how important it is to involve the subcontractors in the planning process. Not doing so will affect the reliability of the plan as important information and knowledge are not shared. It was therefore realised that the SCP 
process should contain an activity where the subcontractors are involved. This activity includes sharing of information in the form of balancing material requirements. The process in Paper 5 is generic and needed to be adapted to better reflect the characteristics of the construction industry. Paper 6 refines this process and develops both a pre-construction process and an operational process where the former focuses on establishing a material delivery schedule, while the latter on updating it on-site. Paper 6 also develops an SCP organisation for facilitating implementation of the processes (objective 3). The SCP organisation is also divided into one pre-construction part and one on-site part. Paper 6 stresses the importance of involving subcontractors and suppliers in the SCP process.

The final objective 4 is fulfilled in Papers 1 and 2 but also by the thesis as such. The KPIs are suggested in Paper 1 and 2 and concern measuring supply chain reliability, supply chain responsiveness, and total supply chain management costs. The papers also argued that notification is an important part in measuring supply chain reliability. The other metrics that could be of importance in the SCP framework (see Table 4) have also been suggested in the thesis.

The SCP framework with processes, organisation, and KPIs, has been developed in the thesis. As part of SCM, SCP can facilitate the addressing of problems by involving supply chain members in both the planning process through the coordination mechanism as well as in the organisational structure. The implication of the developed framework could be better integration of the supply and construction processes and integration of the main contractor, subcontractors, and suppliers in the planning process. The thesis also focuses on identifying how the logistical problems can be addressed by the SCP framework. This is further discussed in Table 5 and in section 5.1. It was discussed that the framework with the involvement of subcontractors and suppliers can be a facilitator for improving trust and communication. These are two problems that often cause other problems such as late deliveries. The thesis also addresses the other three objectives by summarising all papers. The result of the thesis is the SCP framework presented in Figure 19 in section 4.5.

The SCP framework presented in Figure 19, the discussion about how the framework can facilitate in addressing the problems presented in Table 5, and the discussion in section 5.2 about how the supply chain members are integrated are all means to fulfil the purpose: to develop a SCP framework for construction that integrates the main contractor, subcontractors, and suppliers. Another result of this study shows how research propositions can be developed and tested through the discussion about the addressing of the problems in Table 5 .

\subsection{Future research}

The thesis offers opportunities for future studies. These are described below:

- What KPIs are needed and how to measure them

- Identify who should be involved during the meetings 
- Test the framework to see how the problems are addressed and how productivity is affected

- How contextual differences affect the framework

- Identify how architects and consultants should be involved

- Identify how resources should be balanced over several projects

- Integrating suppliers and subcontractors at the strategic level

Focusing on these parts and to investigate if the anticipated benefits of the framework in Table 5 are realistic will also make it possible to refine this planning framework into a scientific conceptual framework. That is, to step into the next stage of building theory.

The KPIs suggested in this thesis are presented in Table 4. In Papers 1 and 2 it was argued that these KPIs can have an important effect on how well the supply chain performs. However, the measurement of these KPIs included only three sub-metrics. It should be studied which other metrics in these KPIs are needed and whether any other KPIs are required. The construction industry is also characterised by a high level of customisation. It could therefore be of importance to measure the supply chain flexibility to see how quick the supply chain is in adapting to new environments. It should be identified how this KPI should be measured. The thesis has not touched upon how the measurement systems should be designed. The measurements in Paper 1 were done manually. This is not a proper method if the metric is going to be used on a daily basis. Further investigation is needed to identify how the KPIs could be measured automatically.

The developed SCP organisation also needs to be studied further. This includes identifying who should participate in the meetings and whether any other meetings are necessary for implementing the two SCP processes. It has been discussed in general terms in this thesis who the participants should be, such as supplier representatives. Future studies should elaborate more clearly as to who these representatives are.

The work presented in this thesis is on a conceptual level. The framework has thus not been tested in real-case environment. Hence the discussion in section 5.1.1 about how the problems can be addressed is quite generalised. Future studies need to test the framework in several cases for identifying if the framework does offer the anticipated outcomes or not. These outcomes include overcoming the problems and improving the productivity.

The framework developed in this thesis has been based on a design-build context. However, as described by Tavares Thomé et al. (2012), the context where planning is done, plays an important role in the design of the process and structure. It should therefore be investigated how different contract types, building objects, project forms, etc. affect the design of the SCP framework. Does it affect inputs, outcomes, the process design, the organisational structure, and the KPIs? A pre-fabricated house project might need certain KPIs, while complex oneof-a-kind projects need other KPIs. The context therefore needs further investigation.

The work in this thesis has been focusing on how to integrate the supply process with the construction process. However, it is often discussed that parties within the construction process also need to be integrated. This includes how architects and consultants should be 
involved in the planning process. These project members are omitted in the developed SCP framework. However, the architects have important roles in the material delivery schedule and logistics. The decisions the architects make about the design, affects the materials that can be used and consequently the suppliers to be selected. It is therefore important to also include them in the planning process and thus integrate the design and construction processes.

The two final aspects for future studies concern lifting the focus from a mid-term/short-term project focus to a long-term company focus. The framework developed in this thesis focuses on the mid-term/short-term project level. However, studies are also needed on how planning on a long-term level affects the SCP on a mid-term/short-term level. One thing to study is resource allocation at the project portfolio level. Materials and resources need to be shared among several projects. This requires extensive planning and information sharing among members in the supply chain. However, if resources cannot be efficiently allocated it will have a negative effect on the SCP on a mid-term/short-term level with lack of resources etc. The long-term level and the mid-term/short-term level need to be integrated. This also includes involving suppliers and subcontractors at this long-term level. If suppliers can get information about the expected material levels for several projects over a longer period, it can have a positive effect on their operational planning and performance. 


\section{References}

Agapiou, A., Clausen, L. E., Flanagan, R., Norman, G., and Notman, D. (1998), "The Role of Logistics in the Materials Flow Control Process", Construction Management \& Economics, 16, 2, 131-137.

Akintoye, A., McIntosh, G., and Fitzgerald, E. (2000), "A Survey of Supply Chain Collaboration and Management in the Uk Construction Industry", European Journal of Purchasing \& Supply Management, 6, 3-4, 159-168.

Amornsawadwatana, S. (2011), "Effective Design of the Construction Supply Chain: A Case of Small Buildings in Thailand", IEEE International Conference on Industrial Engineering and Engineering Management, Singapore.

APICS. (2015), American Production and Inventory Conrol Society's Homepage [Online], American Production and Inventory Conrol Society (APICS) Available: http://bit.ly/1LUcsHC [Accessed 5th of March 2015].

Atkinson, R. (1999), "Project Management: Cost, Time and Quality, Two Best Guesses and a Phenomenon, Its Time to Accept Other Success Criteria", International Journal of Project Management, 17, 6, 337-342.

Bai, C., and Sarkis, J. (2012), "Supply-Chain Performance-Measurement System Management Using Neighbourhood Rough Sets", International Journal of Production Research, 50, 9, 2484-2500.

Ballard, G. (2000), The Last Planner System of Production Control, Doctor of Philosophy, Thesis, Type, University of Birmingham.

Bankvall, L., Bygballe, L. E., Dubois, A., and Jahre, M. (2010), "Interdependence in Supply Chains and Projects in Construction", Supply Chain Management: An International Journal, 15, 5, 385-393.

Bengtsson, J., and Gustad, Ö. (2008), Kartläggning Av Materialflödet I Peabs Försörjningskedja Till Byggarbetsplatsen, Med Scor, Master, Thesis, Type, Linköpings universitet.

BIS (2013), Supply Chain Analysis into the Construction Industry - a Report for the Construction Industrial Strategy, Department for Business Innovation \& Skills (BIS), London.

Bolstroff, P., and Rosenbaum, R. (2007), Supply Chain Excellence - a Handbook for Dramatic Improvement Using the Scor Model, Amacom, New York. 
Brewer, P. C., and Speh, T. W. (2000), "Using the Balanced Scorecard to Measure Supply Chain Performance", Journal of Business Logistics, 21, 1, 75-93.

Bryman, A., and Bell, E. (2015), Business Research Methods, Oxford university press, Oxford, Uk.

Bryson, J. M. (2011), Strategic Plannig for Public and Nonprofit Organizations, John Wiley \& Sons, Ipswich, MA.

Bygballe, L. E., Jahre, M., and Swärd, A. (2010), "Partnering Relationships in Construction: A Literature Review", Journal of Purchasing \& Supply Management, 16, 4, 239-253.

Byggkommissionen (2002), Skärpning Gubbar!: Om Konkurrensen, Kvaliteten, Kostnaderna Och Kompetensen I Byggsektorn : Betänkande, Näringsdepartementet, Stockholm.

Chan, A. P. C., and Chan, A. P. L. (2004), "Key Performance Indicators for Measuring Construction Success", Benchmarking: An International Journal, 11, 2, 203-221.

Christopher, M. (2011), Logistics and Supply Chain Management, Prentice Hall - Financial Times, Edinburgh Gate.

Chua, D. K. H., and Kog, Y. C. (1999), "Critical Success Factors for Different Project Objectives", Journal of Construction Engineering \& Management, 125, 3, 142.

Cohen, S., and Roussel, J. (2005), Strategic Supply Chain Management, McGraw-Hill, New York.

Cox, A., and Ireland, P. (2002), "Managing Construction Supply Chains: The Common Sense Approach", Engineering Construction \& Architectural Management, 9, 5/6, 409-418.

Cronin, P., Ryan, F., and Coughlan, M. (2008), "Undertaking a Literature Review - a Stepby-Step Approach", British Journal of Nursing, 17, 1, 38-43.

Croom, S. (2009), "Introduction to Research Methodology in Operations Management", In Karlsson, C. (Ed.) Researching Operations Management, Routledge, Abingdon, Uk.

CSCMP. (2013), Supply Chain Management Terms and Glossary [Online], Council of Supply Chain Management Professionals (CSCMP), Available: http://bit.ly/1sYBIlP [Accessed 29th of May 2013].

Dainty, A., Moore, D., and Murray, M. (2006), Communication in Construction - Theory and Practice, Taylor and Francis, Abingdon, Oxon.

Dainty, A. R. J., Briscoe, G. H., and Millett, S. J. (2001a), "Subcontractor Perspectives on Supply Chain Alliances", Construction Management \& Economics, 19, 8, 841-848.

Dainty, A. R. J., Millett, S. J., and Briscoe, G. H. (2001b), "New Perspectives on Construction Supply Chain Integration", Supply Chain Management: An International Journal, 6, 4, 163-173. 
di Martinelly, C., Riane, F., and Guinet, A. (2009), "A Porter-Scor Modelling Approach for the Hospital Supply Chain", International Journal of Logistics Systems and Management, $5,3,436-456$.

Doloi, H. (2009), "Relational Partnerships: The Importance of Communication, Trust and Confidence and Joint Risk Management in Achieving Project Success", Construction Management and Economics, 27, 11, 1099-1109.

Dubois, A., and Gadde, L.-E. (2000), "Supply Strategy and Network Effects — Purchasing Behaviour in the Construction Industry", European Journal of Purchasing \& Supply Management, 6, 3-4, 207-215.

Dubois, A., and Gadde, L.-E. (2002), "The Construction Industry as a Loosely Coupled System: Implications for Productivity and Innovation", Construction Management \& Economics, 20, 7, 621.

Egan, J. (1998), Rethinking Construction, Department of the Environment, Transport and the Regions, London.

Eisenhardt, K. M. (1989), "Building Theories from Case Study Research", Academy of Management Review, 14, 4, 532-550.

Engwall, M. (2003), "No Project Is an Island: Linking Projects to History and Context", Research Policy, 32, 5, 789-808.

Fahimnia, B., Davarzani, H., and Eshragh, A. (2015), "Planning of Complex Supply Chains: A Performance Comparison of Three Meta-Heuristic Algorithms", Computers \& Operations Research.

Fang, Y., and Ng, S. T. (2011), "Applying Activity-Based Costing Approach for Construction Logistics Cost Analysis", Construction Innovation: Information, Process, Management, 11, 3, 259-281.

Faniran, O. O., Oluwoye, J. O., and Lenard, D. J. (1998), "Interactions between Construction Planning and Influence Factors", Journal of Construction Engineering and Management, $124,4,245-256$.

Fawcett, S. E., and Cooper, M. B. (1998), "Logistics Performance Measurement and Customer Success", Industrial Marketing Management, 27, 4, 341-357.

Fearne, A., and Fowler, N. (2006), "Efficiency Versus Effectiveness in Construction Supply Chains: The Dangers of "Lean" Thinking in Isolation", Supply Chain Management: An International Journal, 11, 4, 283-287.

Fellows, R. (2009), "Culture in Suplly Chains", In Pryke, S. (Ed.) Construction Supply Chain Management, Wiley-Blackwell, Hong Kong.

Fleischmann, B., Meyr, H., and Wagner, M. (2008), "Advanced Planning", In Stadtler, H. \& Kilger, C. (Eds.), Supply Chain Management and Advanced Planning - Concepts, Models, Software, and Case Studies, 4th ed, Springer, Berlin.

Flick, U. (2009), An Introduction to Qualitative Research, SAGE Publication, London, UK. 
Friblick, F. (2000), Supply Chain Management in the Construction Industry - Opportunity or Utopia?, Degree Licentiate in Engineering, Thesis, Type, Lund University.

Frödell, M. (2014), Organisation of Purchasing and Buyer-Supplier Relationships in Large Construction Companies, Doctoral, Thesis, Type, Chalmers.

Frödell, M., Josephson, P. E., and Lindahl, G. (2008), "Swedish Construction Clients' Views on Project Success and Measuring Performance", Journal of Engineering, Design and Technology, 6, 1, 21-32.

Gidado, K. (2004), "Enhancing the Prime Contractor's Pre-Construction Planning", Journal of Construction Research, 5, 1, 87-106.

Gidado, K. I. (1996), "Project Complexity: The Focal Point of Construction Production Planning", Construction Management \& Economics, 14, 3, 213-225.

Glaser, B., and Strauss, A. (2006), The Discovery of Grounded Theory : Strategies for Qualitative Research, Aldine Transaction, New Brunswick.

González, P., González, V., Molenaar, K., and Orozco, F. (2014), "Analysis of Causes of Delay and Time Performance in Construction Projects", Journal of Construction Engineering and Management, 140, 1, 04013027.

Guba, E. G., and Lincoln, Y. S. (1994), "Competing Paradigms in Qualitative Research", In Denzin, N. K. \& Lincoln, Y. S. (Eds.), Handbook of Qualitative Research, Sage, Thousand oaks, CA.

Gunasekaran, A., Patel, C., and McGaughey, R. E. (2004), "A Framework for Supply Chain Performance Measurement", International Journal of Production Economics, 87, 3, 333.

Gunasekaran, A., Patel, C., and Tirtiroglu, E. (2001), "Performance Measures and Metrics in a Supply Chain Environment", International Journal of Operations \& Production Management, 21, 1/2, 71-87.

Gupta, A., and Maranas, C. D. (2003), "Managing Demand Uncertainty in Supply Chain Planning", Computers \& Chemical Engineering, 27, 8-9, 1219-1227.

Gyllin, G., and Thunberg, M. (2010), Analysis of Scor Implementation at Peab, Masters, Thesis, Type, Linköping University.

Hallowell, M. R., and Gamatese, J. A. (2010), "Qualitative Research: Application of the Delphi Method to Cem Research", Journal of Construction Engineering \& Management, 136, 1, 99-107.

Houlihan, J. B. (1985), "International Supply Chain Management", International Journal of Physical Distribution and Materials Management, 15, 1, 22-38.

Hwang, B.-G., Thomas, S. R., Haas, C. T., and Caldas, C. H. (2009), "Measuring the Impact of Rework on Construction Cost Performance", Journal of Construction Engineering \& Management, 135, 3, 187-198. 
Jesson, J. K., Matheson, L., and Lacey, F. M. (2011), Doing Your Literature Review Traditional and Systematic Techniques, Sage, London, Uk.

Johansen, E., and Wilson, B. (2006), "Investigating First Planning in Construction", Construction Management \& Economics, 24, 12, 1305-1314.

Jonsson, P., and Holmström, J. (2016), "Future of Supply Chain Planning: Closing the Gaps between Practice and Promise", International Journal of Physical Distribution \& Logistics Management, 46, 1, 62-81.

Jonsson, P., Rudberg, M., and Holmberg, S. (2013), "Centralised Supply Chain Planning at Ikea", Supply Chain Management: An International Journal, 18, 3, 337-350.

Josephson, P.-E., and Saukkoriipi, L. (2005), Slöseri I Byggprojekt, Behov Av Förändrat Synsätt, FoU-Väst,

Josephson, P. E., and Hammarlund, Y. (1999), "The Causes and Costs of Defects in Construction: A Study of Seven Building Projects", Auto. in Const., 8, 6, 681-687.

Kagioglou, M., Cooper, R., and Aouad, G. (2001), "Performance Management in Construction: A Conceptual Framework", Construction Management \& Economics, 19, 1, 85-95.

Karim, K., Marosszeky, M., and Davis, S. (2006), "Managing Subcontractor Supply Chain for Quality in Construction", Engineering, Construction \& Architectural Management, 13, $1,27-42$.

Kelsey, J., Winch, G. M., and Penn, A. (2001), Understanding the Project Planning Process: Requirements Capture for the Virtual Construction Site, University College London, London.

La Londe, B. J., and Masters, J. M. (1994), "Emerging Logistics Strategies: Blueprints for the Next Century", International Journal of Physical Distribution \& Logistics Management, 24, 7, 35-47.

Lambert, D. M., and Cooper, M. C. (2000), "Issues in Supply Chain Management", Industrial Marketing Management, 29, 1, 65-83.

Larson, P. D., and Halldorsson, A. (2004), "Logistics Versus Supply Chain Management: An International Survey", International Journal of Logistics: Research \& Applications, 7, 1, 17-31.

Latham, M. (1994), Constructing the Team, HMSO, London.

Laufer, A., and Tucker, R. L. (1987), "Is Construction Project Planning Really Doing Its Job? A Critical Examination of Focus, Role and Process", Constructiom Managementt \& Economics, 5, 3, 243-266.

Laureano Paiva, E., Teixeira, R., Marques Vieira, L., and Beheregaray Finger, A. (2014), "Supply Chain Planning and Trust: Two Sides of the Same Coin", Industrial Management \& Data Systems, 114, 3, 405-420. 
Legnani, E. (2011), Controlling and Improving the Provision of after-Sales Services, Doctor of Philosophy, Thesis, Type, Universtà Degli Studi di Bergamo.

Ling, F. Y. Y., and Peh, S. (2005), "Key Performance Indicators for Measuring Contractors' Performance", Architectural Science Review, 48, 4, 357-365.

Love, P., and Edwards, D. (2004), "Forensic Project Management: The Underlying Causes of Rework in Construction Projects", Civil Engineering \& Environmental Systems, 21, 3, 207-228.

Love, P. E. D., Irani, Z., and Edwards, D. J. (2004), "A Seamless Supply Chain Management Model for Construction", Supply Chain Management, 9, 1, 43-56.

Love, P. E. D., and Li, H. (2000), "Quantifying the Causes and Costs of Rework in Construction", Construction Management \& Economics, 18, 4, 479-490.

Lummus, R. R., and Vokurka, R. J. (1998), "Strategic Supply Chain Planning", Production and Ineventory Management Journal, 39, 3, 49-58.

Lundin, R. A. A., and Söderholm, A. A. (1995), "A Theory of the Temporary Organization", Scandinavian Journal of Management, 437.

Menches, C. L., Hanna, A. S., Nordheim, E. V., and Russell, J. S. (2008), "Impact of PreConstruction Planning and Project Characteristics on Performance in the Us Electrical Construction Industry", Construction Management \& Economics, 26, 8, 855-869.

Meng, X. (2012), "The Effect of Relationship Management on Project Performance in Construction", International Journal of Project Management, 30, 2, 188-198.

Mentzer, J. T., DeWitt, W., Keebler, J. S., Soonhoong, M., Nix, N. W., Smith, C. D., and Zacharia, Z. G. (2001), "Defining Supply Chain Management", Journal of Business Logistics, 22, 2, 1-25.

Mentzer, J. T., Stank, T. P., and Esper, T. L. (2008), "Supply Chain Management and Its Relationship to Logistics, Marketing, Production, and Operations Management", Journal of Business Logistics, 29, 1, 31-46.

Meredith, J. (1993), "Theory Building through Conceptual Methods", International Journal of Operations \& Production Management, 13, 5, 3-11.

Meredith, J. (1998), "Building Operations Management Theory through Case and Field Research", Journal of Operations Management, 16, 4, 441-454.

Modig, N. (2007), Material Flows Incurred by Activities at Project Sites, Doctor of Philosophy, Thesis, Type, Chalmers University of Technology.

Montana, P., and Charnov, B. (2008), Barron's Management, Business Review Books, New York.

Nordqvist, S. (2008), Analys Av Logistikflöden Hos Inwall, Katrineholm, Thesis, Type, Linköpings universitet. 
Nordstrand, U. (2008), Byggprocessen, Liber, Stockholm, Sweden.

O’Brien, W. J., London, K., and Vrijhoef, R. (2002), "Construction Supply Chain Modeling: A Research Review and Interdisciplinary Research Agenda", IGLC10, Gramado, Brazil.

Olhager, J. (2013), "Evolution of Operations Planning and Control: From Production to Supply Chains", International Journal of Production Research, 51, 23/24, 6836.

Pan, N. H., Lin, Y. Y., and Pan, N. F. (2010), "Enhancing Construction Project Supply Chains and Performance Evaluation Methods: A Case Study of a Bridge Construction Project", Canadian Journal of Civil Engineering, 37, 8, 1094-1106.

Persson, F., and Thunberg, M. (2012), "Adapting the Scor Model to the Construction Industry Settings", NOFOMA 2012 - The 24th Annual Nordic Logistics Research Network Conference, 7-8th of June, Turku, Finland.

Pibernik, R., and Sucky, E. (2007), "An Approach to Inter-Domain Master Planning in Supply Chains", International Journal of Production Economics, 108, 1-2, 200-212.

PMI (2004), Pmbok, PMI.

PMI. (2013), Project Definition [Online], (PMI) Project Management Institute, Available: http://www.pmi.org/ [Accessed 09 Sep 2013].

Popper, K. (2005), Popper - the Logic of Scientific Discovery, Taylor \& Francis, New York.

Radujković, M., Vukomanović, M., and Dunović, I. B. (2010), "Application of Key Performance Indicators in South-Eastern European Construction", Journal of Civil Engineering and Management, 16, 4, 521-530.

Rodrigues, V. S., Piecyk, M., Potter, A., McKinnon, A., Naim, M., and Edwards, J. (2010), "Assessing the Application of Focus Groups as a Method for Collecting Data in Logistics", International Journal of Logistics Research and Applications, 13, 1, 75-94.

Rudberg, M., Klingenberg, N., and Kronhamn, K. (2002), "Collaborative Supply Chain Planning Using Electronic Marketplaces", Integrated Manufacturing Systems, 13, 8, 596610.

Saad, M., Jones, M., and James, P. (2002), "A Review of the Progress Towards the Adoption of Supply Chain Management (Scm) Relationships in Construction", European Journal of Purchasing \& Supply Management, 8, 3, 173-183.

SCB. (2013), (SCB) Statistics Sweden, Available: http://www.scb.se/ [Accessed 9th of May 2013].

SCOR (2010), Scor - Supply Chain Operations Reference Model Version 10.0, SCC,

Sodhi, M. S. (2003), "How to Do Strategic Supply-Chain Planning", MIT SLOAN MANAGEMENT REVIEW, 45, 1, 69-75. 
Son, J., and Rojas, E. M. (2011), "Evolution of Collaboration in Temporary Project Teams: An Agent-Based Modeling and Simulation Approach", Journal of Construction Engineering \& Management, 137, 8, 619-628.

Soni, G., and Kodali, R. (2013), "A Critical Review of Supply Chain Management Frameworks: Proposed Framework", Benchmarking: An International Journal, 20, 2, 263 298.

Sousa, R., and Voss, C. (2001), "Quality Management: Universal or Context Dependent?", Production and Operations Management, 10, 4, 383-404.

Statskontoret (2009), Sega Gubbar - En Uppföljning Av Byggkommissionens Betänkande "Skärpning Gubbar". Statskontoret, Stockholm.

Stevens, G. (1986), "Integrating the Supply Chain", International Journal of Physical Distribution and Materials Management, 19, 8, 3-8.

Stuart, I., McCutcheon, D., Handfield, R., McLachlin, R., and Samson, D. (2002), "Effective Case Research in Operations Management: A Process Perspective", Journal of Operations Management, 20, 5, 419-433.

Tavares Thomé, A. M., Scavarda, L. F., Fernandez, N. S., and Scavarda, A. J. (2012), "Sales and Operations Planning: A Research Synthesis", International Journal of Production Economics, 138, 1, 1-13.

Tennant, S., and Fernie, S. (2013), "Organizational Learning in Construction Supply Chains", Engineering, Construction \& Architectural Management, 20, 1, 83-98.

Thakkar, J. J. (2012), "Scm Based Performance Measurement System: A Preliminary Conceptualization", Decision (0304-0941), 39, 3, 5-43.

Thunberg, M. (2011), "Performance Measurements for Improving Construction Logistics - a Case Study", PLANs FoT-konferens, Norrköping.

Thunberg, M., and Persson, F. (2014), "Using the Scor Model's Performance Measurements to Improve Construction Logistics", Production Planning and Control, 25, 13, 1065-1078.

Toor, S.-u.-R., and Ogunlana, S. O. (2010), "Beyond the 'Iron Triangle': Stakeholder Perception of Key Performance Indicators (Kpis) for Large-Scale Public Sector Development Projects", International Journal of Project Management, 28, 3, 228-236.

Tserng, H. P., Yin, S. Y. L., and Li, S. (2006), "Developing a Resource Supply Chain Planning System for Construction Projects", Journal of Construction Engineering and Management, 132, 4, 393-407.

Van Landeghem, H., and Vanmaele, H. (2002), "Robust Planning: A New Paradigm for Demand Chain Planning", Journal of Operations Management, 20, 6, 769-783.

Vidalakis, C., Tookey, J. E., and Sommerville, J. (2011), "The Logistics of Construction Supply Chains: The Builders' Merchant Perspective", Engineering Construction \& Architectural Management, 18, 1, 66-81. 
Vollmann, T., Berry, W., Whybark, C., and Jacobs, R. (2005), Manufacturing Planning and Control for Supply Chain Management, Mc graw hill, New york.

Voordijk, H. (2010), "Physical Distribution Costs in Construction Supply Chains: A Systems Approach", International Journal of Logistics Systems and Management, 7, 4, 456-471.

Voordijk, H., and Adriaanse, A. (2016), "Engaged Scholarship in Construction Management Research: The Adoption of Information and Communications Technology in Construction Projects", Construction Management and Economics, 1-16.

Voss, C., Tsikriktsis, N., and Frohlich, M. (2002), "Case Research in Operations Management", International Journal of Operations \& Production Management, 22, 2, 195-219.

Vrijhoef, R. (1998), Co-Makership in Construction: Towards Construction Supply Chain Management, $\mathrm{PhD}$, Thesis, Type, Delft University of Technology.

Vrijhoef, R., and Koskela, L. (2000), "The Four Roles of Supply Chain Management in Construction", European Journal of Purchasing \& Supply Management, 6, 169-178.

Vrijhoef, R., and Ridder, H. d. (2007), "A Systems Approach for Developing a Model of Construction Supply Chain Integration", 4th Nordic Conference on Construction Economics and Organisation, Luleå, Sweden.

Walker, A. (2015), Project Management in Construction, John Wiley \& Sons, Chichester, Uk.

Wegelius-Lehtonen, T. (2001), "Performance Measurement in Construction Logistics", International Journal of Production Economics, 69, 107-116.

Wibeck, V. (2010), Fokusgrupper - Om Fokuserade Gruppintervjuer Som Undersökningsmetod, Studentlitteratur, Lund.

Winch, G. M. (2010), Managing Construction Projects, Wiley-Blackwell.

Winch, G. M., and Kelsey, J. (2005), "What Do Construction Project Planners Do?", International Journal of Project Management, 23, 2, 141-149.

Wong, A., and Fung, P. (1999), "Total Quality Management in the Construction Industry in Hong Kong: A Supply Chain Management Perspective", Total Quality Management, 10, 2, 199-208.

Wysocki, R. K. (2012), Effective Project Management, John Wiley \& Sons, Indianapolis.

Xia, L. X. X. (2006), "Supply Chain Modelling and Improvement in Telecom Industry: A Case Study", Industrial Informatics, 2006 IEEE International Conference on.

Yates, J. K., and Eskander, A. (2002), "Construction Total Project Management Planning Issues", Project Management Journal, 33, 1, 37. 
Yeung, J. F. Y., Chan, A. P. C., and Chan, D. W. M. (2008), "Establishing Quantitative Indicators for Measuring the Partnering Performance of Construction Projects in Hong Kong", Construction Management \& Economics, 26, 3, 277-301.

Yin, K. R. (2009), Case Study Research: Design and Methods, Sage, London.

Zwikael, O. (2009), "Critical Planning Processes in Construction Projects", Construction Innovation: Information, Process, Management, 9, 4, 372-387. 


\section{Papers}

The articles associated with this thesis have been removed for copyright reasons. For more details about these see:

http://urn.kb.se/resolve?urn=urn:nbn:se:liu:diva-131617 